University of Louisville

ThinkIR: The University of Louisville's Institutional Repository

8-2018

\title{
A novel fibroblast growth factor 1 variant reverses nonalcoholic fatty liver disease in type 2 diabetes.
}

Qian Lin

University of Louisville

Follow this and additional works at: https://ir.library.louisville.edu/etd

Part of the Endocrine System Diseases Commons, and the Pharmacology Commons

\section{Recommended Citation}

Lin, Qian, "A novel fibroblast growth factor 1 variant reverses nonalcoholic fatty liver disease in type 2 diabetes." (2018). Electronic Theses and Dissertations. Paper 3016.

https://doi.org/10.18297/etd/3016

This Doctoral Dissertation is brought to you for free and open access by ThinkIR: The University of Louisville's Institutional Repository. It has been accepted for inclusion in Electronic Theses and Dissertations by an authorized administrator of ThinkIR: The University of Louisville's Institutional Repository. This title appears here courtesy of the author, who has retained all other copyrights. For more information, please contact thinkir@louisville.edu. 


\title{
A NOVEL FIBROBLAST GROWTH FACTOR 1 VARIANT REVERSES NONALCOHOLIC FATTY LIVER DISEASE IN TYPE 2 DIABETES
}

BY

Qian Lin

M.S. at Wenzhou Medical University, 2016

\author{
A Dissertation \\ Submitted to the Faculty of the \\ School of Medicine of the University of Louisville \\ for the Degree of \\ Doctor of Philosophy in Pharmacology and Toxicology \\ Department of Pharmacology and Toxicology \\ University of Louisville \\ Louisville, Kentucky
}

August 2018 

A NOVEL FIBROBLAST GROWTH FACTOR 1 VARIANT REVERSES NONALCOHOLIC FATTY LIVER DISEASE IN TYPE 2 DIABETES

\author{
BY \\ Qian Lin \\ Dissertation Approved on
}

August 2, 2018

Dissertation Committee:

\begin{tabular}{c}
\hline Dr. Yi Tan \\
\hline Dr. Paul Epstein \\
\hline Dr. Lu Cai \\
\hline Dr. Wenke Feng \\
\hline Dr. Leah Siskind
\end{tabular}




\section{ACKNOWLEDGEMENTS}

The entire PhD study is a challenge and wonderful journey. I not only learn the knowledge in the research and promote personal ability in academic field, but also know the different cultures and make new friends from different countries. Sincerely, I could never finish it without the support of lots of people. First, I would like to appreciate my mentor, Dr. Yi Tan, for his guidance and support in the entire periods of research, as well as his concerns to my health and safety. I also would like to thank my dissertation committee members, Dr. Lu Cai for his expertise in diabetes and encouragement to my personal development. Thanks to Dr. Feng for his expertise in fatty liver disease, and Dr. Leah Siskind and Dr. Paul Epstein, for their expertise in diabetic complications and metabolic disorders. They have provided tremendous help on my graduate research and thesis writing.

I am also to show my gratefully thank to all the present and former members in our lab. They give me lots of help and kindness in my work and livings. Especially, I want to thank Dr. Hein and Dr. Cai in our department, and Dr. Li in Wenzhou Medical University, for their efforts to build the partnership between Department of Pharmacology \& Toxicology and Wenzhou Medical University, providing me an opportunity to study here. I am also grateful to the present and former faculty and staff in our department for their help in doing research and in daily life.

Finally, I want to thank my parents, my sister and my brother and my family for

their selfless love and support during my life. I can't wait to invite and meet them at my graduation ceremony. 


\begin{abstract}
A NOVEL FIBROBLAST GROWTH FACTOR 1 VARIANT REVERSES NONALCOHOLIC FATTY LIVER DISEASE IN TYPE 2 DIABETES
\end{abstract}

Qian Lin

August 2, 2018

Nonalcoholic fatty liver disease (NAFLD) is the most common chronic liver disorder and is strongly associated with type 2 diabetes (T2D). Our recently engineered FGF1 partial agonist, carrying triple mutations $\left(\mathrm{FGF} 1 \triangle^{\mathrm{HBS}}\right.$ ) exhibits greatly reduced proliferative potential, while preserving the full metabolic activity of wild-type FGF1. This study tests the preventive and therapeutic effects of FGF1 $\triangle \mathrm{HBS}$ on NAFLD in $\mathrm{db} / \mathrm{db}$ T2D and explores potential mechanisms. The results showed that administration of FGF1 $\triangle$ HBS to 2-monthold $\mathrm{db} / \mathrm{db}$ mice for 2 months constantly lowered blood glucose levels, improved insulin sensitivity, and lowered liver weight, lipid deposition, and inflammation, along with improvement of liver function. Simultaneously, FGF1 $\triangle \mathrm{HBS}$ treatment prevented diabetesinduced hepatic oxidative stress along with promoting nuclear translocation of the antioxidant transcription factor Nrf2 and elevating its downstream antioxidant genes. In addition, FGF1 $\triangle \mathrm{HBS}$ administration inhibited the activity and/or expression of hepatic lipogenic genes including SREBP-1, FAS and SCD-1. Furthermore, FGF1 $\triangle^{\mathrm{HBS}}$ treatment rescued hepatic fatty acid oxidation signaling, including elevated expressions of CPT-1a, PPAR $\alpha$ and PGC-1 $\alpha$. Moreover, FGF1 $\triangle{ }^{\mathrm{HBS}}$ treatment greatly increased hepatic 
phosphorylation of the key energy sensor AMPK, along with upregulating its downstream genes $A C C$ and SREBP-1 phosphorylation, indicating that FGF1 ${ }^{\mathrm{HBS}}$ regulation of hepatic lipid metabolism is associated with AMPK signaling pathway. Mechanistically, hepatic cells treated with palmitate (Pal) mimicked the diabetic phenotype of hepatic oxidative damage and lipid disorder seen in $\mathrm{db} / \mathrm{db}$ mice, all of which could be reversed by supplementing with FGF1 $\triangle^{\mathrm{HBS}}$. Knockdown of Nrf2 by SiRNA completely abolished the anti-oxidative capacity of FGF1 ${ }^{\mathrm{HBS}}$ but did not affect the beneficial effects of FGF1 $\triangle^{\mathrm{HBS}}$ on Pal-induced lipid metabolic disorder. Whereas, AMPK knockdown by SiRNA completely abolished FGF1 $\triangle \mathrm{HBS}$ ability to prevent Pal-induced hepatic lipotoxicity and SREBP-1-mediated lipid metabolic disorder, along with inhibiting Nrf2-mediated antioxidative signaling pathway. Most importantly, administration of FGF1 $\triangle^{\mathrm{HBS}}$ to 9-monthold $\mathrm{db} / \mathrm{db}$ mice for 3 months completely reversed the phenotype of NAFLD along with activation on Nrf2 and AMPK signaling pathways.

Our findings demonstrate that, in addition to its potent glucose-lowering and insulinsensitizing effects, FGF $1^{\triangle \mathrm{HBS}}$ can reverse NAFLD in T2D, by its ability to upregulate AMPK to activate Nrf2-mediated antioxidative pathway and inhibit SREBP-1-mediated lipid metabolic pathway.

Keywords: Fibroblast growth factor 1, nonalcoholic fatty liver disease, oxidative stress, AMP-activated protein kinase, nuclear factor erythroid 2-related factor 2, sterol regulatory element-binding protein 


\section{TABLE OF CONTENTS}

PAGE

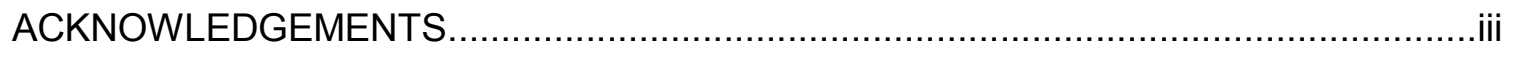

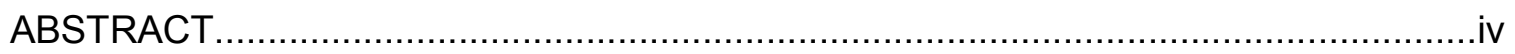

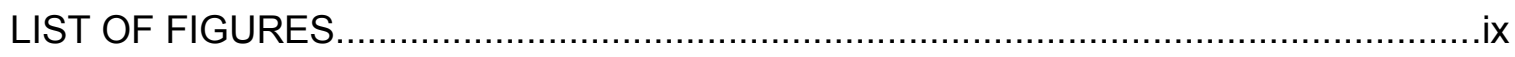

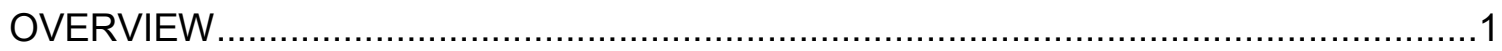

\section{CHAPTER I}

1. Title: The preventive effects of a novel fibroblast growth factor 1 variant on nonalcoholic fatty liver disease in type 2 diabetes

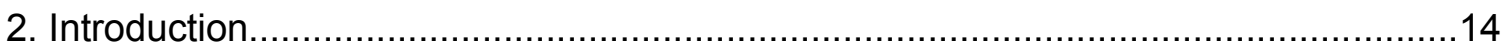

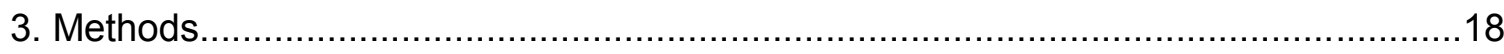

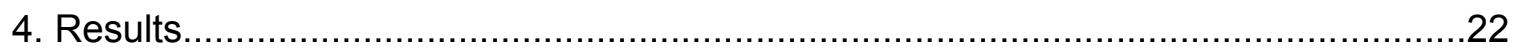

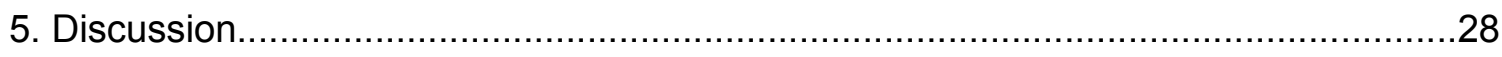

\section{CHAPTER II}

1. Title: The role of nuclear factor erythroid 2-related factor 2 in fibroblast growth factor 1 protection against non-alcoholic fatty liver disease

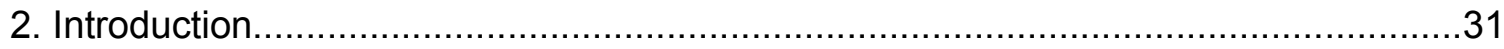

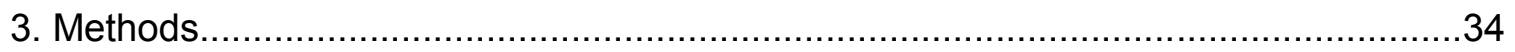

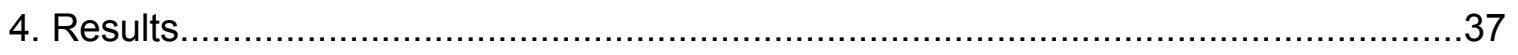

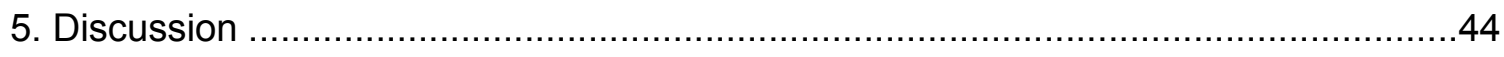




\section{CHAPTER III}

1. Title: The role of AMP-activated protein kinase $\alpha$ in fibroblast growth factor 1 protection against non-alcoholic fatty liver disease

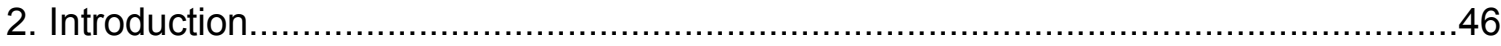

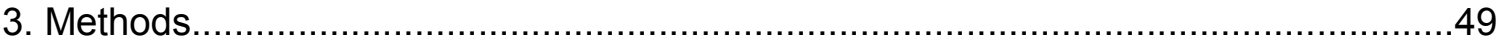

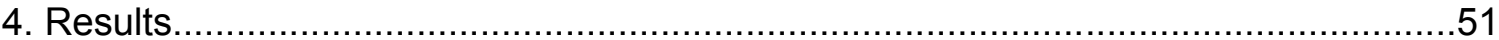

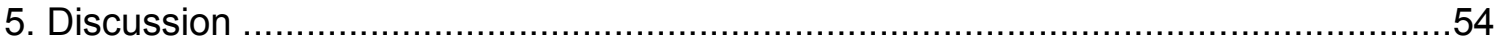

\section{CHAPTER IV}

1. Title: The therapeutic effects of a novel fibroblast growth factor 1 variant on nonalcoholic fatty liver disease in type 2 diabetes

2. Introduction 55

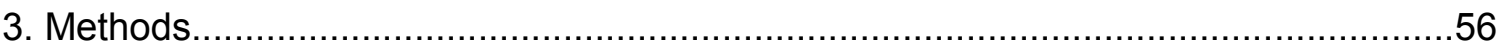

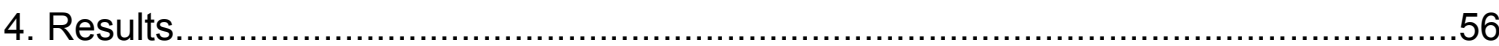

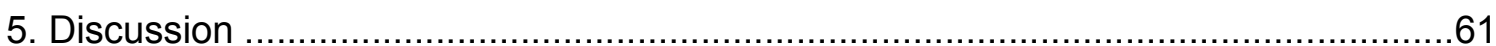

\section{CHAPTER V}

1. Title: Overall discussion and conclusion

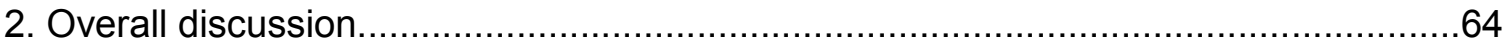

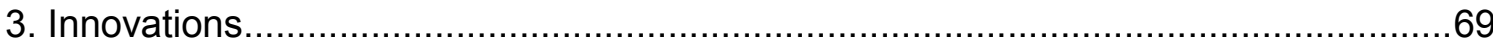

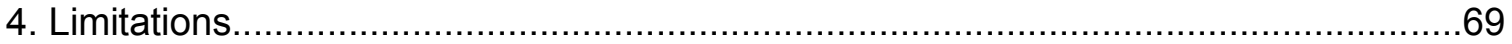

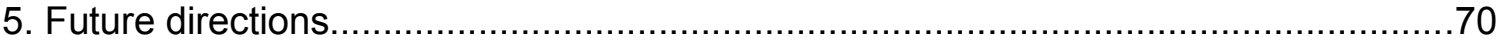

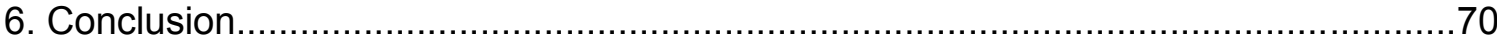




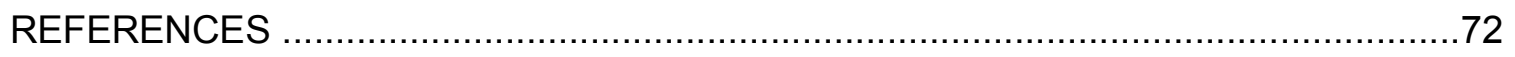

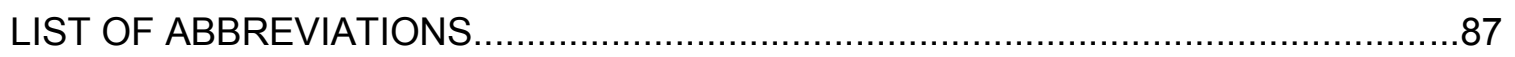

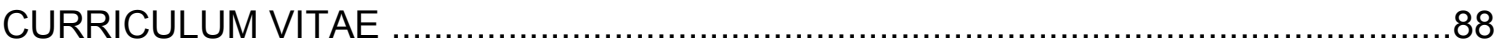




\section{LIST OF FIGURES}

PAGE

Fig. 1 The functional differences between paracrine and endocrine FGFs

Fig. 2 The effects of FGF1 $\triangle^{\mathrm{HBS}}$ on blood glucose, insulin sensitivity and liver injury in 2month-old $\mathrm{db} / \mathrm{db}$ mice.

Fig. 3 The preventive effects of FGF1 $\triangle^{\mathrm{HBS}}$ on hepatic inflammation and oxidative stress in 2-month-old $\mathrm{db} / \mathrm{db}$ mice.

Fig. 4 FGF1 $\triangle^{\mathrm{HBS}}$ activating Nrf2-mediated anti-oxidative signaling pathway in liver of 2month-old $\mathrm{db} / \mathrm{db}$ mice.

Fig. 5 FGF1 $\triangle^{\mathrm{HBS}}$ regulating lipid metabolic signaling pathway in liver of 2-month-old db/db mice.

Fig. 6 FGF1 preventing from Pal-induced hepatic oxidative stress in HepG2 cells. 38

Fig. 7 FGF1 preventing from Pal-induced oxidative stress via activating Nrf2-mediated anti-oxidative signaling pathway in HepG2 cells

Fig. 8 FGF1 preventing from Pal-induced hepatic lipotoxicity in HepG2 cells.

Fig. 9 FGF1 inhibiting lipogenesis and promoting lipid oxidation signaling pathway in Paltreated HepG2 cells.

Fig. 10 Knockdown of Nrf2 in the HepG2 cells attenuated the beneficial effects of FGF1 on Pal-induced oxidative stress in HepG2 cells.

Fig. 11 Knockdown of Nrf2 did not affect the beneficial effects of FGF1 on Pal-induced lipiotoxicity in HepG2 cells.

Fig. 12 AMPK silencing abolished the protective effects of FGF1 against Pal-Induced lipotoxicity in primary mouse hepatocyte.

Fig. 13 AMPK silencing abolished the protective effects of FGF1 against Pal-Induced oxidative stress in primary mouse hepatocyte.

Fig. 14 The effects of FGF1 $\triangle \mathrm{HBS}$ on blood glucose and insulin sensitivity in 9-month-old $\mathrm{db} / \mathrm{db}$ mice. 
Fig.15 The therapeutic effects of FGF1 $\triangle^{\mathrm{HBS}}$ on chronic NAFLD in 9-month-old $\mathrm{db} / \mathrm{db}$

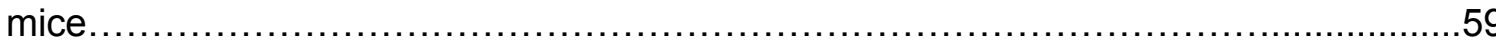

Fig.16 FGF1 ${ }^{\mathrm{HBS}}$ reversed hepatic oxidative stress in 9-month-old $\mathrm{db} / \mathrm{db}$ mice.............60

Fig.17 FGF1 $\triangle \mathrm{HBS}$ activated hepatic AMPK signaling pathway in 9-month-old db/db

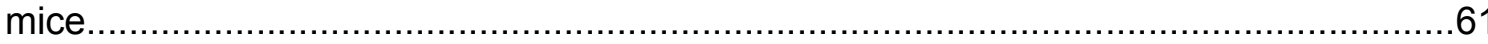

Fig. 18 A mechanistic illustration of FGF1 preventing diabetes-induced hepatic oxidative stress and lipid disorder via activating AMPK signaling pathways..............................71 


\section{OVERVIEW}

\section{FGF superfamily and FGF1 subfamily}

Fibroblast growth factors (FGFs) family contains 22 members that are found in organisms ranging from the nematodes to humans. Based on the differences in sequence homology and phylogeny, these 22 members are commonly grouped into 7 subfamilies: FGF1 subfamily (FGF1 and FGF2); FGF7 subfamily (FGF3, FGF7, FGF10, FGF22); FGF4 subfamily (FGF4, FGF5 and FGF6); FGF8 subfamily (FGF8, FGF17 and FGF18); FGF9 subfamily (FGF9, FGF16 and FGF20); and FGF15/19 subfamily (FGF19, FGF21 and FGF23); and FGF11 subfamily (FGF11,FGF12, FGF13 and FGF14)(1, 2). Among all these, the FGFs with low heparin-/heparan sulfate-binding capacities showing the increased diffusion from their source are defined as endocrine FGF ligands (FGF19, FGF2 and FGF23). Intracellular FGF ligands (FGF11 to FGF14) are not extracellularly secreted and perform an intracrine manner to involve in regulating the electrical excitability in neurons. The remaining FGFs are the paracrine FGFs ligands that have high affinity for heparan sulfate glycosaminoglycan (HSGAG), which lead them to perform a localized manner near the sources of their expressions. The FGF1 subfamily includes FGF1 and FGF2, which is

often called the "prototypical" FGF since they were the first of the FGFs to be isolated and identified around $1975^{(3)}$.

\section{FGF1 gene and gene products}

Fibroblast growth factor 1 (FGF1), also known as acidic fibroblast growth factor (aFGF), is a growth factor and signaling protein encoded by the FGF1 gene. The murine 
and human FGF1 were identified and characterized at the cDNA level in the early 90s. The murine gene locates on chromosome 18, and is encoded by a single copy gene, which spans over $30 \mathrm{~kb}$ of genomic sequence. FGF1 mouse recombinant protein produced in $E$. Coli is a non-glycosylated and single polypeptide chain that contains 161 amino acids (16-155 a.a) with the molecular mass about $18 \mathrm{kDa}^{(4,5)}$. The human FGF1 gene resides on chromosome 5q31, which spans over $100 \mathrm{~kb}$. FGF1 human recombinant protein produced in E. Coli is also a non-glycosylated and single polypeptide chain that contains 140 amino acids with the molecular mass of approximately $15.8 \mathrm{kDa}$. While the mature form of human FGF1 is synthesized as a polypeptide of 155 amino acids, with the molecular mass about 17-18 kDa. The mouse FGF1 genomic organization is very similar to that of human, since both genes are comprised of three protein coding exons of sizes 203, 104 and $192 \mathrm{bp}$. The sizes of the two introns are 11.4 and $4.9 \mathrm{~kb}^{(6)}$. The human FGF1 gene has a long 3'-untranslated region (3'-UTR) and a complex 5'-untranslated region (5'-UTR). In 3'-UTR, the mouse and human FGF1 genes share $60.4 \%$ similarity in sequence, with stretches having more than $80 \%$ similarity ${ }^{(7)}$.

\section{FGF1 receptors and their signaling}

The interaction between the ligand FGFs and its receptor is responsible and essential for the different biological activities of FGFs. FGF1 mediates biological responses by activating and binding to the cell surface FGF receptors (FGFRs). Heparan sulfate/heparin acts as a cofactor and is necessary for stable interactions between FGF1 and its FGFRs. Several major FGFR proteins (FGFRs 1b, 1c, 2b, 2c, 3b, 3c, and 4) are generated from FGFR1, FGFR2, FGFR3, and FGFR4 (FGFR1-FGFR4) genes by alternative splicing, with differing ligand-binding specificity, respectively, ${ }^{\left({ }^{8}\right)}$. FGF1 is considered as the universal ligand for FGFRs due to its ability to activate and bind with each of the alternatively spliced forms of FGFR1-FGFR4 ${ }^{(9,10)}$, in which FGFR1 is a common receptor for many ligands. 
FGF1-FGFR-heparin ternary complex has been demonstrated to activate four key intracellular signaling pathways that play a role in regulating the cell cycle, cell survival and apoptosis, namely the PI3k/Akt pathway, Ras/Raf/Mek/Erk pathway, JNK and p38 MAPK pathway, and STAT3 and NF-KB pathway ${ }^{(11)}$. The endocrine FGFs, such as FGF21, FGF15/19, also act their biological regulations in an FGFR-dependent manner with the presence of the cofactors ( $\alpha$-klotho or $\beta$-klotho) in their respective target tissues. The intracellular FGFs have high sequence identity with other FGF members but do not activate FGFRs.

\section{The potential effects of FGF1 in diseases}

FGF1 is a well characterized growth factor among the 22 members in FGF superfamily in animals and humans. As a paracrine FGF, FGF1 is involved in the cellular regulation of many biological processes such as cell growth, proliferation, migration, differentiation, and survival in different cell types ${ }^{(12)}$. Therefore, FGF1 is being explored for its therapeutic potential in cardiovascular disorders, ischemia conditions, nerve injuries and tissue repair(1). FGF1 shows angiogenic potential in improving myocardial flow, regional and global left ventricular function and artery growth and capillary proliferation under myocardial ischemia conditions ${ }^{(13-15)}$. FGF1 can also promote nerve regeneration. Data indicated that it enabled the functional and axonal regeneration in the transected rat spinal cord ${ }^{(16,17)}$. FGF1 recovered the rat's forelimb motor function after cord-root junction transection ${ }^{(18)}$. In addition, FGF1 stimulated cell proliferation and angiogenesis in vitro and in vivo, significantly accelerating the healing of rat burn wounds ${ }^{(19)}$. Although FGF1 is a well-known mitogenic factor, the recent discoveries of metabolic roles for FGF1 in glucose homeostasis have expanded the functions of those classically known mitogen. In 2012, Jonker and his colleagues discovered an unexpected metabolic role of FGF1. FGF1 was demonstrated to transduce of peroxisome proliferator-activated receptor gamma 
(PPARY) signaling that mediates the proper nutrient storage coupling in adaptive remodeling of adipose tissue ${ }^{(20)}$. In a follow-up study, this group further demonstrated that exogenous FGF1 could stimulate the glucose uptake in an insulin-dependent fashion in vitro and in vivo(9), much like the non-mitogenic endocrine-acting growth factor, FGF21, a candidate drug for obesity and diabetes treatment in clinical trials ${ }^{(21)}$. In recent years, additional studies have focused on the potential of FGF1 as a treatment for diabetes and diabetic complications. In general, the mitogenic effects of FGF1 in a variety of diseases has been most studied and subject to the clinical trial in humans ${ }^{(14)}$. However, the functions and mechanisms of its metabolic effects have been rarely clarified. To the advantage of metabolic activity of FGF1 and expand its value inpatients, studies of metabolic effects of FGF1 should be expanded.

\section{The effects of FGF1 at type 1 diabetes and type 2 diabetes}

Diabetes is a major and increasing metabolic disease throughout the world, which is clinically characterized by chronic hyperglycemia because of the absolute or relative insulin insufficiency and dysfunction ${ }^{(22)}$. The treatment of diabetes is determined by the etiopathology and is most commonly subdivided in type 1 diabetes (T1D, beta cell damage and/or absolute lack of insulin) and type 2 diabetes (T2D, insulin resistance and/or decreased secretion of insulin) $)^{(23)}$.

FGF1 has not only the mitogenic activity, but also metabolic activity, representing a potential novel anti-diabetic therapy. FGF1 was sufficient to attain normoglycemia in the severely hyperglycemic mice, such as the genetic induced ob/ob and db/db mice, dietinduced obese (DIO) and insulin-resistant T2D mice, administered through subcutaneous injection $^{(9,20,24)}$. However, FGF1 failed to decrease the blood glucose levels in STZ induced T1D mouse model whereas pretreatment with FGF1 in STZ mice markedly enhanced the glucose-lowering ability of exogenously supplied insulin ${ }^{(9)}$. Additional 
studies proved that FGF1 couldn't lower blood glucose levels in STZ-induced T1D model ${ }^{(25,}$

26). These results demonstrated that FGF1 might act as an insulin sensitizer. Further, intracerebroventricular (i.c.v.) injection of FGF1 also induced sustained diabetes remission in leptin-deficient ob/ob T2D mice ${ }^{(24)}$. Interestingly, i.c.v. injections of FGF1 reversed the hyperglycemia in T1D rats and promoted the insulin-independent plasma glucose lowering effects in T1D by suppressing the hypothalamic-pituitary-adrenal (HPA) axis $^{(27)}$. Taken together, the blood lowering effect of FGF1 in T2D, even in T1D, has been studied, however, the molecular mechanism of how FGF1 protects from the disorders in diabetes still needs further exploration.

\section{The role of FGF1 in diabetic complications}

The rising global prevalence of diabetes accompanies with an high burden of morbidity and mortality that is attributable to the chronic hyperglycemia in the complications, including a range of microvascular, macrovascular and metabolic complications $^{(28)}$. The diabetic complications include cardiovascular disease, stroke, foot ulcers, eye damage and chronic kidney disease, which occur in individuals with both T1D and T2D. Current therapeutic options for controlling the chronic hyperglycemia can reduce, but do not eradicate, the risk of these diabetic complications ${ }^{(29)}$.

\section{The effects of FGF1 on diabetic ulcers}

Diabetic ulcers are responsible for a large percentage of hospitalization among the complications of diabetes ${ }^{(30)}$, which is the major cause of nontraumatic lower extremity amputations and disability. Moreover, the mortality of diabetic ulcer is high and healed ulcers frequently recur( ${ }^{(31)}$. Diabetic ulcers occur because of various factors, such as some intrinsic factors (hyperglycemia, vascular insufficiency and peripheral neuropathy) and 
extrinsic factors (wound infection, callus formation and traumatic stress) ${ }^{(32-34)}$. The management of diabetic ulcers requires protecting the wound by using appropriate footwear and antibiotic therapy, providing a moist wound environment or receiving surgical debridement and revascularization when necessary ${ }^{(35,36)}$. However, it is difficult for diabetic ulcer patients to stop scratching the wound. They can be irritated by clothing or shoes, which increases risk for infection and increases discomfort in patients. Therefore, an understanding the pathogenesis of diabetic ulcers and development of more effective therapies that can enhance wound healing in diabetes is greatly needed.

FGF1 is known to exhibit mitogenic activity on various cells from different tissue origins including skin, vasculature and liver ${ }^{(1,11,37)}$. Many studies have demonstrated that topical application of FGF1 stimulated the growth of new blood vessels, proliferation of fibroblast and endothelial cells and formation of capillary, suggesting translational potential for FGF1 in diabetic ulcers. Early studies demonstrated that FGF1 stimulated DNA synthesis in cultured $\mathrm{db} / \mathrm{db}$ mouse skin biopsy specimens and accelerated wound closure in $\mathrm{db} / \mathrm{db}$ mice at a dose-dependent manner. FGF1 decreased the median time of wound closure from $46 \mathrm{~d}$ to $16 \mathrm{~d}$ and increased granular tissue formation, and reepithelialization throughout healing. Although wound healing in FGF1 treated diabetic mice was slower than that in nondiabetic littermates, these studies suggest the therapeutic potential for FGF1 in promoting healing of dermal ulcers in diabetes ${ }^{(38,39)}$. Recent studies further confirmed that FGF1 enhanced re-epithelialization and proliferation, thereby promoted diabetic dermal wound healing in the T2D model of NONcNZO10/LtJ mouse ${ }^{(40)}$.

The wound healing effect of FGF1 on T1D has also been studied. Xie and colleagues utilized an ulcer model in STZ-induced SD rats and topically treated the wound surface with FGF1 for 2 weeks. Their data indicated that FGF1 improved ulcer healing on day 7 and promoted the re-epithelialization on day 14. FGF1 treatment significantly increased capillaries and fibroblast in the wound. This study revealed that FGF1 promoting 
diabetic wound healing was possibly associated with enhancing the proteins expressions of TGF- $\beta$ and PCNA and preventing oxidative stress ${ }^{(41)}$.

Furthermore, the modification of FGF1 with chitosan-crosslinked collagen sponge (CCCS) or polyethylene glycol (PEGylation) was performed to improve even further the diabetic wound healing. Both CCCS and PEGylated modified FGF1 accelerated wound healing, collagen generation, increased the TGF- $\beta$ expression, and increased dermal cell proliferation in STZ-induced SD rats ${ }^{(25,42)}$. These results suggest that modification of FGF1 could provide a greater effective approach for the therapeutic application of native FGF1 in clinic.

\section{The effects of FGF1 on diabetic cardiovascular disease}

Diabetic cardiomyopathy (DCM) represents the leading cause of morbidity and mortality in diabetic patients. DCM consequent to various structural and functional changes, which is characterized by ventricular dilation, enlargement and impaired contractility of cardiomyocytes, prominent interstitial fibrosis and diastolic and systolic dysfunction ${ }^{(43,44)}$, eventually leading to heart failure without adequate medical treatment ${ }^{(45)}$. At present, there are no effective treatments for this common pathological condition in DCM. Current treatments of DCM focus on intense glycemic control of the diet, oral hypoglycemics, frequently insulin treat and heart failure symptoms management. Novel drugs and new strategies for improving therapeutic and prognostic values in DCM are still being explored ${ }^{(46)}$.

FGF1 is regarded as the angiogenic polypeptide mitogen for cells. It has been widely reported that FGF1 promoted the proliferation of vascular endothelial cells and smooth muscle cells and stimulated the capillary angiogenesis and migration, and significantly minimized infarct size, thus improving cardiac function ${ }^{(47-49)}$. Recent studies have indicated that FGF1 has beneficial effects on the heart under diabetic conditions. 
Zhang $\mathrm{C}$ et al. indicated that the native FGF1 and a novel non-mitogenic FGF1 (nmFGF1) could prevent DCM by suppressing oxidative stress and cell damage. T1D mice treated with nm-FGF1 intraperitoneally for either 1 or 6 months had no impact on body weight and blood glucose levels as compared to non-treated diabetic mice. nm-FGF1 prevented the diabetic-induced cardiac hypertrophy by decreasing the heart weight and the mRNA expressions of molecular hypertrophic markers (ANP, ANG and b-MHC) at 1 month and more obvious reduction at 6 months. The diabetes-induced cardiac fibrosis (Collage content, Fibronectin and TGF- $\beta 1$ ) were also decreased by nm-FGF1 treatment. In vitro studies using nm-FGF1 showed similar cardiac protection as native FGF1. Both native FGF1 and nm-FGF1 prevented the high glucose induced hypertrophy, fibrosis and even the DNA oxidative damage in cardiac cells ${ }^{(50,51)}$. This study provided evidence for protection of nm-FGF against DCM, implying that FGF1 might be a potential candidate for application in DCM therapy. In a following study, Zhang M et al demonstrated an improved FGF1 cardio-protective effect in DCM with nanoparticle modification and ultrasoundtargeted microbubble destruction technique. Similar with previous studies, this study showed that FGF1 protected the metabolism abnormalities and myocardial interstitial fibrosis, further preventing the left ventricle dysfunction in STZ-induced T1D rats ${ }^{(52,53)}$. In particular, this study indicated that prevention of FGF1 against DCM could be attributed to activating PI3K/Akt signaling pathway, in which the phosphorylated Akt reduced the myocardial apoptosis via inhibiting the caspaes-3 activity and increasing the expression of anti-apoptotic genes (Bax and BCL-2).

Taken together, these studies demonstrated the preclinical efficacy and mechanisms of novel strategies for FGF1 protection against DCM.

However, it is still too limited to understand the role of FGF1 in cardiac disorders under diabetic conditions. More specific role of FGF1 in DCM in T1D and T2D need to be further explored. 


\section{The effects of FGF1 on diabetic nephropathy}

Diabetic kidney disease, also known as diabetic nephropathy (DN), is the leading cause of renal failure in patients and is a chronic complication that take place in $20 \%$ to $40 \%$ of $\mathrm{T} 1 \mathrm{D}$ and $\mathrm{T} 2 \mathrm{D}^{(54,55)}$. $\mathrm{DN}$ is a microvascular complication in diabetics and characterized by increased glomerular basement membrane width, diffuse mesangial sclerosis, microaneurysm, tubulointerstitial fibrosis, and vascular sclerosis. Chronic hyperglycemia in diabetes induces dysfunction in various cell types of the kidney, which is a risk factor for chronic kidney disease and end-stage renal disease (ESRD), leading to progressive renal failure ${ }^{(56)}$. The incidence of $\mathrm{DN}$ is increasing each year and a significant number of patients who develop ESRD require renal replacement therapies ${ }^{(57,58)}$. Current therapies for DN are aimed at controlling blood glucose and blood pressure levels, inhibiting the renal artery stenosis and reducing or abrogating development of albuminuria and progression of DN. However, those therapies mentioned above might not be effective enough for DN patients who experience progressive kidney function decline resulting in ESRD. Hence, novel therapeutic strategies are urgently needed to improve clinical management.

Numerous growth factors and cytokines are implicated in the process of progressive renal disease. FGF2 has been proven to involve in the pathogenesis of renal disease by inducing the renal fibrosis ${ }^{(59,60)}$. However, the role of FGF1 in kidney disease has been rarely studied, especially in diabetic kidney disease. Previous studies demonstrated that FGF1 gene was expressed in the normal human kidneys but was downregulated in kidneys from DN patients, suggesting that FGF1 might play a role in kidney function ${ }^{(61-63)}$. Recently, Huang et al demonstrated that FGF1 could protect against DN in both T1D and T2D through an anti-inflammatory mechanism ${ }^{(26)}$. Interestingly, FGF1 only significantly decreased and maintained the blood glucose to the normal level in T2D mice. This is the 
first study to show that the renal protective effects of FGF1 is independent of its glucoselowering effects. However, the functions and mechanism FGF1 in DN are still limited.

\section{The effects of FGF1 on diabetic liver disease}

The prevalence of liver damage in patients with diabetes is much higher than that in the general individuals. Diabetes is strongly associated with major chronic liver diseases, including nonalcoholic fatty liver disease (NAFLD), chronic hepatitis $C(\mathrm{CHC})$, hemochromatosis, and alcoholic liver disease (ALD) $)^{(64)}$. Among these liver diseases, NAFLD represents a global epidemic mainly associated with obesity, insulin resistance and metabolic syndrome ${ }^{(65)}$. In T2D patients, the prevalence of NAFLD is as high as $75 \%{ }^{(66,}$ 67). Recent studies found that obesity also affected the clinical features of T1D, in which about $30 \%$ of patients were overweight or obese, thus increasing the susceptibility and incidence of NAFLD in diabetes ${ }^{(68)}$. NAFLD is a multifactorial disease, affecting extrahepatic organs and regulatory pathways ${ }^{(69)}$. The complex metabolic disturbances in NAFLD increase the risk and the difficulty of treatment in diabetes ${ }^{(65,70,71)}$.

In FGF family, the function and mechanism of FGF21 in liver diseases have been widely studied. Unlike FGF21, FGF1 has high affinity for heparan sulfate and thus acts locally as a mitogenic activator ${ }^{(72-74)}$. The role of FGF1 in metabolic diseases has been neglected. Recent studies draw an attention of FGF1 in liver under diabetic conditions. Jonker et al. revealed that HFD-fed $\mathrm{FGF}^{-1-}$ mice showed severer hepatic steatosis compared to wild-type controls ${ }^{(20)}$. Furthermore, they showed that FGF1 treatment decreased hepatic steatosis, increased the hepatic glycogen content and insulinsensitivity in DIO mice ${ }^{(9)}$. These results suggest that FGF1 play a critical role in the development of liver disease in diabetes. More recently, Liu et al showed that administration of FGF1 effectively suppressed the hepatic inflammation in the leptindeficient ob/ob mice and the choline-deficient diet mice, two etiologically different models 
of NAFLD. The suppression of hepatic steatosis was effectively showed in ob/ob mice, suggesting that FGF1 could stimulate hepatic lipid catabolism. Because the antiinflammatory effects were observed in both the presence and absence of the antisteatotic effects, these findings further suggest that the anti-inflammatory property of FGF1 is independent of its effect on lipid catabolism. These results indicate that, in addition to its potent glucose-lowering and insulin-sensitizing effects, FGF1 could be therapeutically effective in the treatment of NAFLD(75). However, the mechanism of FGF1 protection against NAFLD remains largely unknown.

\section{The effects of FGF1 on other diabetic complications}

FGF1 also involves in many other diabetic complications that has not been widely explored. For example, diabetic retinopathy (DR) is currently the leading cause of blindness in T1D and T2D. Lee-Anne Khuu et al observed the lower FGF1 expression in DR patients compared to the health subjects. This study firstly demonstrated that FGF1 was associated with the decreased retinal blood flow in early DR, suggesting that FGF1 might be predisposing for diabetic vascular diseases ${ }^{(76)}$. Melissa Skibba et al evaluated the effects of nmFGF1 on the testes in STZ-induced T1D. They found that nmFGF-1 ameliorated the diabetic induction of testicular cell death by decreasing the BAX/Bcl-2 ratio and endoplasmic reticulum stress, and upregulating nuclear factor E2-related factor 2 (Nrf2) activity ${ }^{(77)}$. The protective effects of FGF1 on other diabetic complications will be warranted in future studies.

\section{The limitation of FGF1 in diabetes}

The poor stability

As the multifunctional proteins, FGFs have low thermal stability and high sensitivity to proteases, which limit the potential pharmaceutical use of wild-type FGFs ${ }^{(78)}$. In addition 
to the powerful mitogen in numerous different cell types, FGF1 shows the locally restricted roles in adipose tissue as well as systemic glucose-lowering activities in vivo that shows much closely parallel to those of FGF $21^{(9,20)}$. However, FGF21 is a well-characterized endocrine FGF and circulates as a true endocrine hormone. Whereas the high affinity heparin-/heparan sulphate proteoglycan-binding activity and serum lability of FGF1 restrict its endogenous actions to local tissues, causing the rapid clearance of exogenous FGF1 from the systemic circulation(1). Thus, the novel FGF1 delivery system or the advanced protein design techniques to obtain new variants of FGF1 for the increased thermodynamic stability, prolonged half-life and improved proteolytic resistance are necessary, which can provide promising strategies for producing therapeutic effective FGF1.

It has been demonstrated that biopolymer encapsulation effectively sustains the controlled release and provides a long-term delivery of growth factors ${ }^{(79,80)}$. For example, Zhang et al used the FGF1 encapsulated nanoparticles (FGF1-NP) to treat DCM resulted a greater preventive effect due to the improved stability of FGF1 both during storage and in blood circulation. The preventive effects of FGF1-NP on DCM were further promoted by using the ultrasound-targeted microbubble destruction strategy, which helped to increase the selectivity and efficiency of FGF1-NP delivery to the heart ${ }^{(52,53)}$. In addition, the conjugation of FGF1 to polyethylene glycol (PEG) (PEGylated -FGF1) or chitosancrosslinked collagen sponge (CCCS-FGF1) could prolong the release and improve the biostability of FGF1, which had been used to accelerate the wound healing in diabetic $\operatorname{rats}^{(25,42)}$.

\section{Tumorigenic risk}

Native FGF1 could lead to tumorigenesis, tumor invasion and metastasis, showing great tumorigenic risk, especially in tumor latent diseases, such as diabetes ${ }^{(81-83)}$. To 
decrease the potential side effects of FGF1 caused by its broad-spectrum mitogenic activity, a non-mitogenic form of FGF1 had been developed to show decreased mitogenic $\operatorname{activity}^{(50,84)}$. Several studies proved that this non-mitogenic FGF1 had preventive effects on DCM and diabetic ulcer in T1D.

Recently, we have engineered a novel FGF1 variant by uncoupling the mitogenic and metabolic functions of wild type FGF1 (FGF1 ${ }^{\mathrm{WT}}$ ). This FGF1 partial agonist carrying triple mutations (FGF1 ${ }^{\mathrm{HBS}}$ ) that diminished its ability to induce heparan sulfate $(\mathrm{HS})$ assisted FGF receptor (FGFR) dimerization and activation. FGF1 $\triangle$ HBS dramatically reduced the proliferative activity, while still preserving the full metabolic activity of FGF1 ${ }^{\mathrm{WT}}$ in vitro and in vivo. Most importantly, both FGF1 $\triangle^{\mathrm{HBS}}$ and FGF ${ }^{\mathrm{WT}}$ could reverse fatty liver in $\mathrm{db} / \mathrm{db}$ mice, implying the potential of FGF1 for liver disease therapy ${ }^{(85)}$.

\section{Conclusion}

FGF1 is involved in the regulation of diverse pathophysiological processes in various metabolic syndrome. In addition to the functions of FGF1 in angiogenesis and cell proliferation, FGF1 is also associated with the inhibition of inflammation, oxidative stress and apoptosis in diabetic complications. Recently, the blood glucose lowering and insulinsensitizing capability of FGF1 in diabetes revealed the unexpected metabolic function of FGF1, which expanded the functions and potential application of FGF1 in metabolic syndrome. The following issues need to be addressed to apply FGF1 in metabolic syndrome and its complications: 1) the mechanisms of FGF1 in metabolic syndrome; 2) the strong mitogenic activity of FGF1 triggering high tumorigenic risk; 3) the weak stability and low bioavailability of FGF1 under pathophysiological conditions. 
CHAPTER I

THE PREVENTIVE EFFECTS OF A NOVEL FIBROBLAST GROWTH FACTOR 1

VARIANT ON NON-ALCOHOLIC FATTY LIVER DISEASE IN TYPE 2 DIABETES

\section{INTRODUCTION}

\section{Non-Alcoholic Fatty Liver Disease}

As the global epidemic liver disorder, NAFLD represents a spectrum of liver disease that ranges from simple steatosis to non-alcoholic steatohepatitis (NASH) and cirrhosis, ultimately leads to the hepatocellular carcinoma (HCC) and liver failure. NAFLD is the pathological fat accumulation in the liver without alcohol intake, that strongly linked to the metabolic syndrome including obesity, insulin resistance, dyslipidemia and type 2 diabetes $(T 2 D)^{(69)}$. Nowadays, the complex and strong association between of NAFLD and obesity and T2D results to the particularly high prevalence of NAFLD in individuals with T2D, corresponding with the worldwide increase in obesity of childhood ${ }^{(86)}$. Current populationbased prevalence of NAFLD is approximately $30-40 \%$ in men and $15-20 \%$ in women ${ }^{(70)}$.

NAFLD is multifactorial diseases, affecting extrahepatic organs and regulatory pathways, in which the insulin resistance as a common pathophysiological mechanism ${ }^{(69)}$. The excess lipid accumulation in the hepatocyte due to increased inflow of free fatty acids and de novo lipogenesis causes insulin resistance, chronic inflammation that, in turn, contributes to further abnormal hepatic metabolism. These metabolic disturbances in NAFLD increase the risk of progressive liver disease to fibrosis, cirrhosis and HCC, as well as the increased risk of $\mathrm{T}_{2} \mathrm{D}^{(65)}$. As the second hit in $\mathrm{NASH}$, oxidative stress in the liver exacerbates inflammation and hepatic fibrosis, and causes impairment of cellular 
bioenergetics, leading to further disruption of hepatic lipid metabolism and cell death ${ }^{(87-92)}$. Nowadays, there are no licensed therapies specifically for the management of NAFLD. Current treatments for NAFLD include lifestyle management such as diet control, exercise and behavior modification, pharmacological therapies that manage the underlying metabolic risk factors, bariatric surgery and liver transplantation of those with end stage liver disease ${ }^{(93)}$.

\section{Type 2 diabetes}

Diabetes is a chronic disease that have three major types: type 1 diabetes (T1D), $\mathrm{T} 2 \mathrm{D}$, and gestational diabetes. Among these types of diabetes, T2D is the most common and prevalent diabetic diseases in the world. The latest study estimated that the worldwide number of adult diabetes will increase by $54 \%$, from 285 million to 439 million from 2010 to 2030 , with the increasing rate in youth ${ }^{(94)}$. In T2D, body cannot use the insulin properly which leads to the insulin resistance augmented by lifestyle habits, environmental factors and multiple genetic factors ${ }^{(95,96)}$. The increased action of insulin resistance results in high blood glucose also called hyperglycemia. Meanwhile, hyperglycemia may deteriorate both insulin resistance and insulin secretion abnormalities, thus enhancing the transition from impaired glucose tolerance to diabetes ${ }^{(97)}$. T2D is tightly associated with many complications without the appropriate intervention approaches. Hyperglycemia induced higher risk for the complications (cardiovascular disease, liver dysfunctions, retinopathy and nephropathy) and multiple metabolic disorders (oxidative stress, inflammation and endoplasmic reticulum stress). The long-term persistence of metabolic disorders increases the risk development of many specific complications. Meanwhile, older diabetic patients have a higher burden of comorbidities, diabetes-related complications, physical disability, cognitive impairment and malnutrition, and more sensitive to the complications 
of dysglycemia and polypharmacy. These complications contribute to the excess morbidity and mortality in older individuals with diabetes ${ }^{(98-103)}$.

The prevalence of diabetes mellitus in patients with liver damage is higher compared to that in the general population. Diabetes is strongly associated with major chronic liver diseases, including NAFLD, chronic hepatitis $\mathrm{C}(\mathrm{CHC})$, hemochromatosis, and alcoholic liver disease (ALD) ${ }^{(64)}$. Among these liver diseases, NAFLD has been widely studied with diabetes, especially in T2D ${ }^{(65)}$. In T2D patients, the prevalence of NAFLD may be as high as $75 \%(66,67)$. Nowadays, there has no certain explanation for the substantial increased risk of mortality from cirrhosis of any etiology in patients with T2D. In NAFLD, the excess of fatty acids and impaired hepatic fatty acid oxidation exacerbate the insulin resistance, further increase the hepatic fat accumulation. High glucose levels, obesity and insulin resistance in diabetes may be independent factors contributing to progression of NAFLD and the ultimate development of cirrhosis ${ }^{(104)}$. These complex metabolic disturbances between NAFLD and T2D increased risk and difficulty in treatment of NAFLD in T2D (70,71) (65).

\section{The novel fibroblast growth factor 1 variant- $-\mathrm{FGF} 1 \triangle^{\mathrm{HBS}}$}

As introduced in the OVERVIEW, FGF1 is a well-known mitogenic factor that has been widely studied for its therapeutic potential in cardiovascular disorders, ischemic conditions and nerve injury ${ }^{(1)}$. Interestingly, FGF1 recently showed an unexpected metabolic function in diabetes by regulating the glucose homeostasis and insulin sensitivity $(9,20)$. However, FGF1 induces hyperproliferation leading to increased tumorigenic risk ${ }^{(105)}$, becoming the primary obstacle for its wide application, particularly for chronic cancer prone diseases, such as diabetes. Therefore, uncoupling of the mitogenic and metabolic function of FGF1 could make it to be a safe and potent agent for diabetes therapy. 
Structure-function relationship study demonstrated that paracrine FGFs, such as FGF1, transmit their signals by binding, dimerizing and activating four FGF receptor tyrosine kinases (FGFR1-4) in a heparin sulfate (HS)-dependent fashion ${ }^{(106-108)}$; by contrast, endocrine FGFs, such as FGF21, rely on Klotho co-receptors to bind, dimerize and activate their cognate FGFRs ${ }^{(12,}$ 109-112). Paracrine FGFs facilitate much stronger FGFRs tyrosine transphophorylation and intracellular kinase domains activation via HSdependent dimerization of FGFRs than that of endocrine FGFs via Klotho-dependent dimerization of FGFRs ${ }^{(113)}$ (Fig. 1).

According to the understanding of the molecular basis for the divergence in the biological activity of

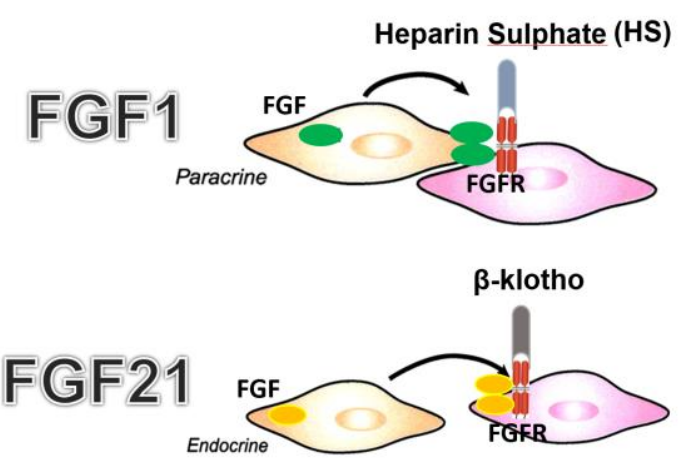

Fig 1. The functional differences between paracrine and endocrine FGFs. FGF1, as a member of paracrine FGFs, has a high affinity with heparin sulphate as its coreceptor, which acts in a localized manner near the source of its expression. While the endocrine FGF, FGF21 has $\beta$-klotho as its coreceptor with a weak affinity with heparin sulphate leading to increased diffusion of FGF21 from its source.

paracrine and endocrine FGFs, we hypothesized that submaximal FGFR activation by a weak endocrine FGF-FGFR dimer is sufficient to evoke a metabolic response (such as FGF21), whereas full FGFR activation by stable and sustained paracrine FGF-FGFR dimerization is required to elicit a mitogenic response (such as FGF1), and the mitogenic and metabolic function of paracrine FGF1 could be uncoupled by manipulation of its HSassociated receptor dimerization. To test this hypothesis, we engineered a novel FGF1 variant, with reduced ability of inducing HS-dependent FGFR dimerization by replacing the three key residues from the HS-binding site of FGF1, namely Lys127, Lys128 and Lys133 with residues that are less optimal for HS binding (Lys127Asp, Lys128Gln and Lys133Val), termed FGF1 $\triangle \mathrm{HBS}$. In an initial study, we found that FGF1 ${ }^{\mathrm{HBS}}$ had significantly 
decreased receptor binding affinity compared to wild-type FGF1 (FGF1 ${ }^{\mathrm{WT}}$ ), which was accompanied by significant attenuation of the proliferative potency. While FGF1 $\triangle \mathrm{HBS}$ retained full metabolic activity of FGF1 ${ }^{\mathrm{WT}}$, including sensitization of insulin activity, improvement of hepatic lipid and glucose metabolism, induction of adipose remodeling, and prevention of diabetes-induced systemic, hepatic and adipose inflammation in $\mathrm{db} / \mathrm{db}$ mice, leading to therapeutic efficacy for T2D without mitogenic and hyperplastic activity of FGF $1^{\mathrm{WT}(85)}$.

Recent studies demonstrated that high fat diet feeding induced serve hepatic steatosis in $\mathrm{FGF}^{-1-}$ mice compared to wild-type controls ${ }^{(20)}$, while liver function and pancreatic function appeared normal. Furthermore, FGF1 treatment decreased hepatic steatosis and increased the insulin-stimulated Akt signaling in diet-induced obese (DIO) mice $^{(9)}$. Liu et al indicated the potent antisteatotic and anti-inflammatory effects of FGF1 on NAFLD in leptin-deficient ob/ob mice ${ }^{(75)}$. In addition, our recent study indicated that FGF1 prevented diabetic nephropathy largely via the anti-inflammatory effects in both T1D and T2D ${ }^{(26)}$. These works have brought FGF1 to the forefront as a potential new therapeutic agent for insulin sensitization and treatment of T2D, and NAFLD therapy ${ }^{(114)}$. However, the functions and mechanism of FGF1-mediated metabolic actions in diabetic livers remain largely unknown. To investigate the metabolic activity of FGF1 and explore a safe treatment for NAFLD, we therefore hypothesize that the novel mitogenic and metabolic function uncoupled variant $F G F 1{ }^{\mathrm{HBS}}$ has potential to replace the use of FGF $1{ }^{\mathrm{WT}}$ to treat NAFLD in T2D.

\section{MATERIALS AND METHODS}

\section{Animal models and drug administration}

db/db (BKS.Cg-Dock7m +/+ Lepr ${ }^{\mathrm{db}} / \mathrm{J}$, Stock \# 000642) mice were purchased from Jackson Laboratory (Bar Harbor, ME). 2-month-old male $\mathrm{db} / \mathrm{db}$ mice were administered 
with $\mathrm{FGF} 1 \triangle \mathrm{HBS}(0.5 \mathrm{mg} / \mathrm{kg})$ or vehicle phosphate buffered solution (PBS) via intraperitoneal injection every other day for 2 months. At the indicated time-points, the blood glucose levels were determined by FreeStyle complete blood glucose monitor (Abbott Diabetes Care Inc., Alameda, CA). All mice were housed under a 12:12-h light/dark cycle at controlled temperature. All experimental procedures were approved by the Institutional Animal Care and Use Committee of the University of Louisville.

\section{Glucose-tolerance tests (GTTs)}

Blood glucose levels were determined as described above. For GTTs, mice were fasting for $9 \mathrm{~h}$, and then were injected with glucose solution (1 $\mathrm{g} / \mathrm{kg}$ body weight) intraperitoneally. Blood glucose levels were measured at 0, 15, 30, 60, 90, and 120 min after glucose injection.

\section{Biochemical analysis}

Plasma ALT (Cayman Chemical, Ann Arbor, MI) and AST (BioVision, Milpitas, CA) levels were measured using enzymatic assay kits according to the manufacturer's instruction. Liver TG was determined using commercially available colorimetric kits (Thermo Scientific, Waltham, MA). Briefly, liver tissues were homogenized in $50 \mathrm{mM} \mathrm{NaCl}$ and the samples were extracted with extract reagent (Chloroform: Methanol $=2: 1$ ) at $4{ }^{\circ} \mathrm{C}$ overnight. The next day, the samples were vortexed and centrifuged for $20 \mathrm{mins}$, and the lower chloroform layer were collected. Then, $500 \mu \mathrm{l}$ of lower chloroform layer were placed in new tubes and evaporated to dryness in the hood. The dried samples were dissolved in TG reagent and measured with plate reader at $500 \mathrm{~nm}$. 


\section{Liver histopathological analysis}

Liver paraffin sections were processed as previously described ${ }^{(85)}$. Liver tissues were fixed in $10 \%$ formalin and processed to embed in paraffin. After deparaffinization and rehydration, the paraffin sections $(5 \mu \mathrm{m})$ were subjected to hematoxylin and eosin (H\&E). oXLipid accumulation in the liver tissues was further analyzed by Oil Red $\mathrm{O}$ staining. For Oil-Red-O staining, frozen sections $(10 \mu \mathrm{m})$ of liver tissues were fixed in $10 \%$ formalin for 10 min and rinsed in water. Then the slides were immersed in $60 \%$ isopropanol and incubated in Oil-Red O solution (saturated Oil Red O isopropanol solution diluted 4:6 into $60 \%$ isopropanol, Sigma-Aldrich) at room temperature for 40 mins. The slides were washed in $60 \%$ isopropanol twice. All the stained sections were quantitated for Oil-Red $\mathrm{O}$ positive staining area using a Nikon Eclipse E600 microscopy system (Nikon, Tokyo, Japan).

\section{Quantitative determination of oxidative stress}

To detect the reactive oxygen species (ROS) levels of diabetic livers after FGF1 treatment, the cell permeable fluorescent dye, dihydroethidium (DHE, Molecular Probes, Eugene, OR) was used to determine the superoxide generation in the liver sections. DHE can react with superoxide to form ethidium, which in turn intercalates with DNA and produces nuclear fluorescence ${ }^{(115)}$. For DHE staining in frozen liver sections, cryosections were incubated with $5 \mu \mathrm{M} \mathrm{DHE}$ for $30 \mathrm{~min}$ at $37^{\circ} \mathrm{C}$ in dark, washed with PBS and captured at $\times 200$ magnification (XI 71 Olympus, Tokyo, Japan).

Malondialdehyde (MDA) is the most frequently used biomarker of oxidative stress in many health problems ${ }^{(116)}$. MDA content test was performed to further confirm the ROS of

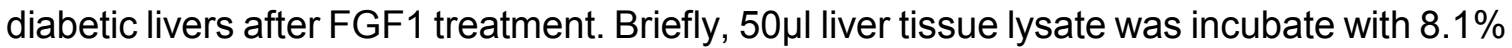
SDS, $20 \%$ Acetic acid and $0.57 \%$ TBA at $90^{\circ} \mathrm{C}$ for $70 \mathrm{~min}$. Then cold in ice and centrifuged at $4000 \mathrm{x} \mathrm{g}$ for $15 \mathrm{~min}$. The fluorescence intensity of final MDA content in each sample 
was detected by a microplate reader (SpectraMax M3; Molecular Devices, Sunnyvale, CA) under specific wavelength conditions $(O D=540 \mu \mathrm{m})$. The final MDA content in each sample was calculated as: $M D A=(O D$ of Sample-OD of Standard) *178/pro-concentration $(\mathrm{mmol} / \mathrm{mg})$.

\section{RNA extraction, cDNA synthesis and quantitative RT-PCR}

Total RNA was extracted from liver tissues with TRIzol reagent (Invitrogen, Carlsbad, CA). After quantified using a Nanodrop ND-1000 spectrophotometer, $1 \mu \mathrm{g}$ total RNA was used to synthesize first-strand complimentary DNA (cDNA) using reverse transcription kit (Promega, WI) following the manufacturer's instructions. Quantitative RT-PCR reactions were performed in duplicate on an ABI Prism 7500HT (PE Applied Biosystems) and were normalized to GAPDH. All TaqMan® assay-on-demand primers were from Thermo Fisher Scientific Inc. (Grand Island, NY). Sequences were as follows: GAPDH, Mm99999915_g1; PAI-1, Mm00436753_m1; TNFa, Mm00443259_g1; VCAM-1, Mm01320970_m1; ICAM1, Mm00516023_m1; SREBF1, Mm00550338_m1; FAS, Mm00662319_m1 and SCD-1, Mm00772290_m1.

\section{Western blot analysis}

The liver tissues from $\mathrm{db} / \mathrm{db}$ mice were collected and homogenized. Protein lysates from liver tissues were separated using 8-12\% SDS-PAGE and electro-transferred onto a nitrocellulose membrane. The protein blots were probed with antibodies against $\mathrm{HO}-1$, phosphorylated AMPKa/AMPKa, phosphorylated ACC/ACC, and phosphorylated SREBP-1 (Cell Signaling Technology, Danvers, MA), CAT, NQO-1, PGC-1 $\alpha$, CPT-1 $\alpha, \beta-$ actin, and GAPDH (Santa Cruz biotechnology, Dallas, TX), Nrf2, SREBP-1, FAS, SCD-1

and PPARa (Abcam, Cambridge, MA). The immunoreactive bands were then detected by incubating with the secondary antibody (Santa Cruz Biotechnology, Dallas, TX) 
conjugated with horseradish peroxidase and visualizing using enhanced chemiluminescence $(E C L)$ reagents (Bio-Rad, Hercules, CA). The amount of the proteins was analyzed using Image Lab analysis software and normalized against their respective loading controls.

\section{Statistical analysis}

Statistical analyses were performed using the statistical software package GraphPad Prism version 6 (GraphPad Software Inc., San Diego, CA, USA). Data are expressed as mean \pm SEM. Statistical significance was evaluated using the unpaired twotailed Student $t$ test or one-way analysis of variance. Differences were considered significant at a $P$ value $<0.05$.

\section{RESULTS}

\section{FGF1 $\triangle^{H B S}$ prevents NAFLD in $\mathrm{db} / \mathrm{db}$ mice}

Consistent with the findings in our previous study ${ }^{(85)}$, FGF1 $\triangle^{\mathrm{HBS}}$ treatment at 0.5 $\mathrm{mg} / \mathrm{kg}$ every other day for 2 months greatly lowered blood glucose levels (Fig. 2A), along with significant improvement in insulin sensitivity (Fig. 2B, C) in db/db mice. FGF1 $\triangle^{H B S}$ treatment did not change body weight (Fig. 2D), but markedly lowered liver weight (Fig. 2E) and prevented liver injury reflected by decreased ALT (Fig. 2F) and AST activity (Fig. 2G). Furthermore, FGF1 $\triangle^{\mathrm{HBS}}$ treatment significantly decreased hepatic TG content (Fig. $2 \mathrm{H})$, showing improved hepatic lipid metabolism.

Histological examination using H\&E staining and Oil Red O staining confirmed the antisteatotic effect of FGF1 $\triangle^{\mathrm{HBS}}$ (Fig. 3A). Hepatic steatosis is associated with hepatic inflammation and oxidative stress. In addition to its potent antisteatotic action, FGF1 $\triangle \mathrm{HBS}$ also suppressed hepatic inflammation and oxidative stress reflected by reduced mRNA expression of hepatic inflammatory markers including TNFa, PAI-1, ICAM-1 and VCAM-1 
(Fig. 3B-E) and inhibited super oxide generation (Fig. 3F, G) and MDA production (Fig. $3 \mathrm{H})$ in $\mathrm{db} / \mathrm{db}$ mice.

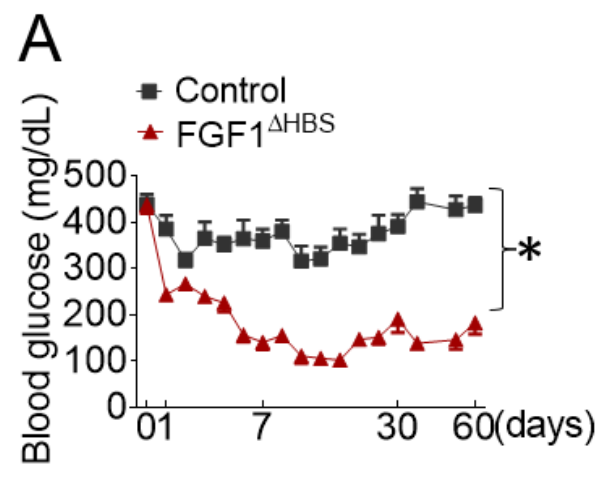

$\mathrm{D}$

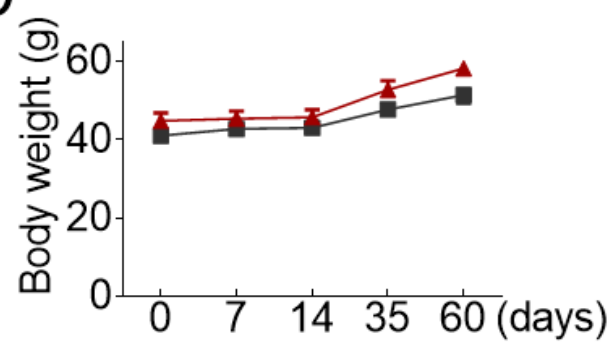

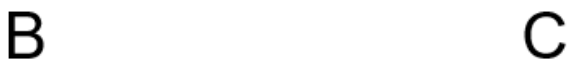
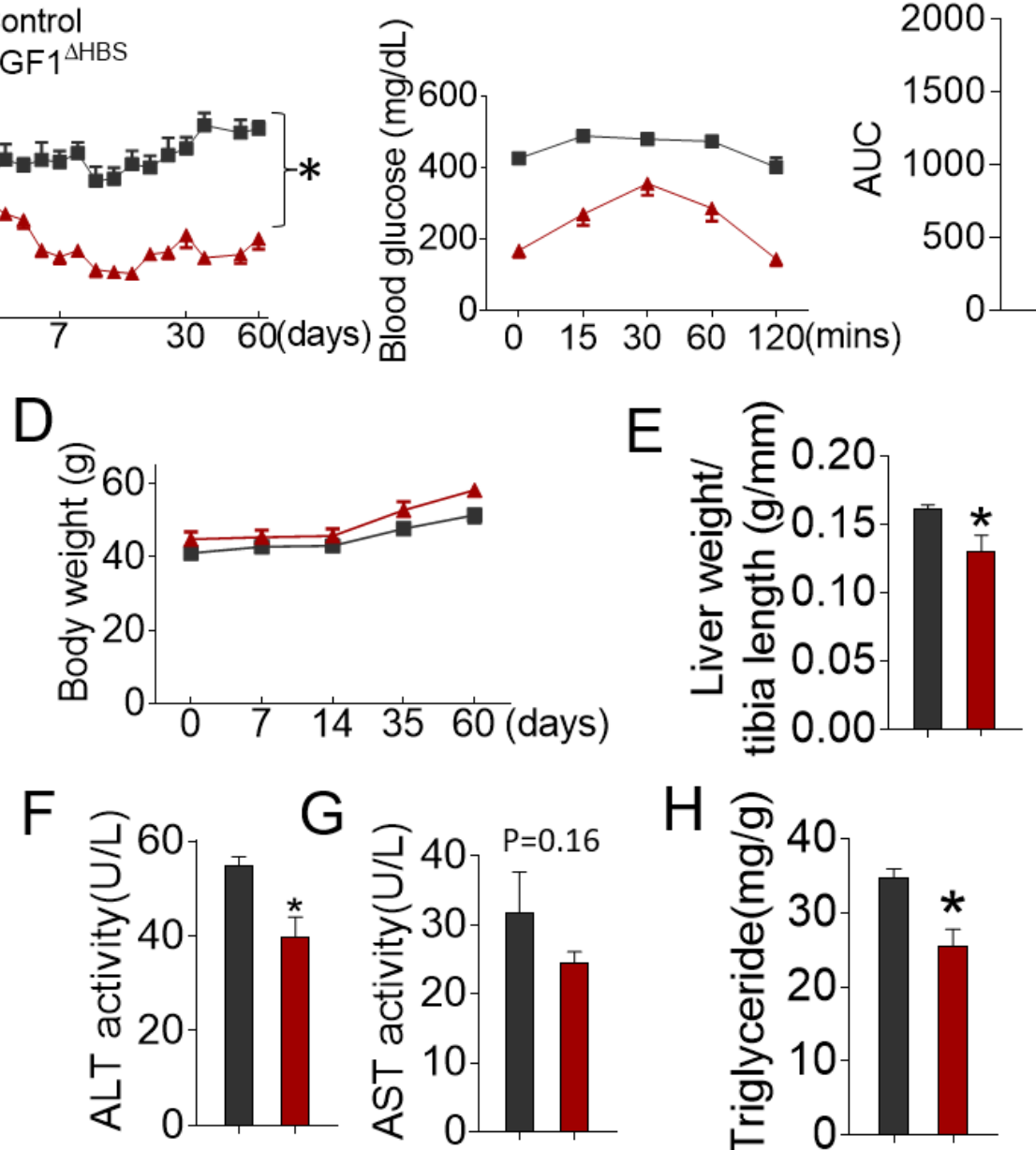

$\mathrm{H}$ क़े 40

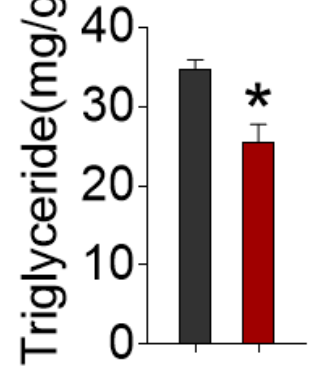

Fig. 2 The effects of FGF1 $\triangle^{H B S}$ on blood glucose, insulin sensitivity and liver injury in 2-month-old db/db mice. (A) The blood glucose over the course of 2 months treatment of $\mathrm{db} / \mathrm{db}$ mice with $\mathrm{FGF1}{ }^{\mathrm{HBS}}(0.5 \mathrm{mg} / \mathrm{kg}$ body weight, every other day). ( $B$ and C) The Blood glucose levels in IPGTT and integrated area under the curve (AUC) for changes in blood glucose levels. ( $D$ and E) The body weight and liver weight changes in $\mathrm{db} / \mathrm{db}$ mice. (F and G) Plasma levels of ALT and AST. (H) Triglyceride contents in livers. Quantitative data are expressed as mean \pm SEM, $n=10-13 .{ }^{*} P<0.05 \mathrm{vs} . \mathrm{db} / \mathrm{db}$ mice. 

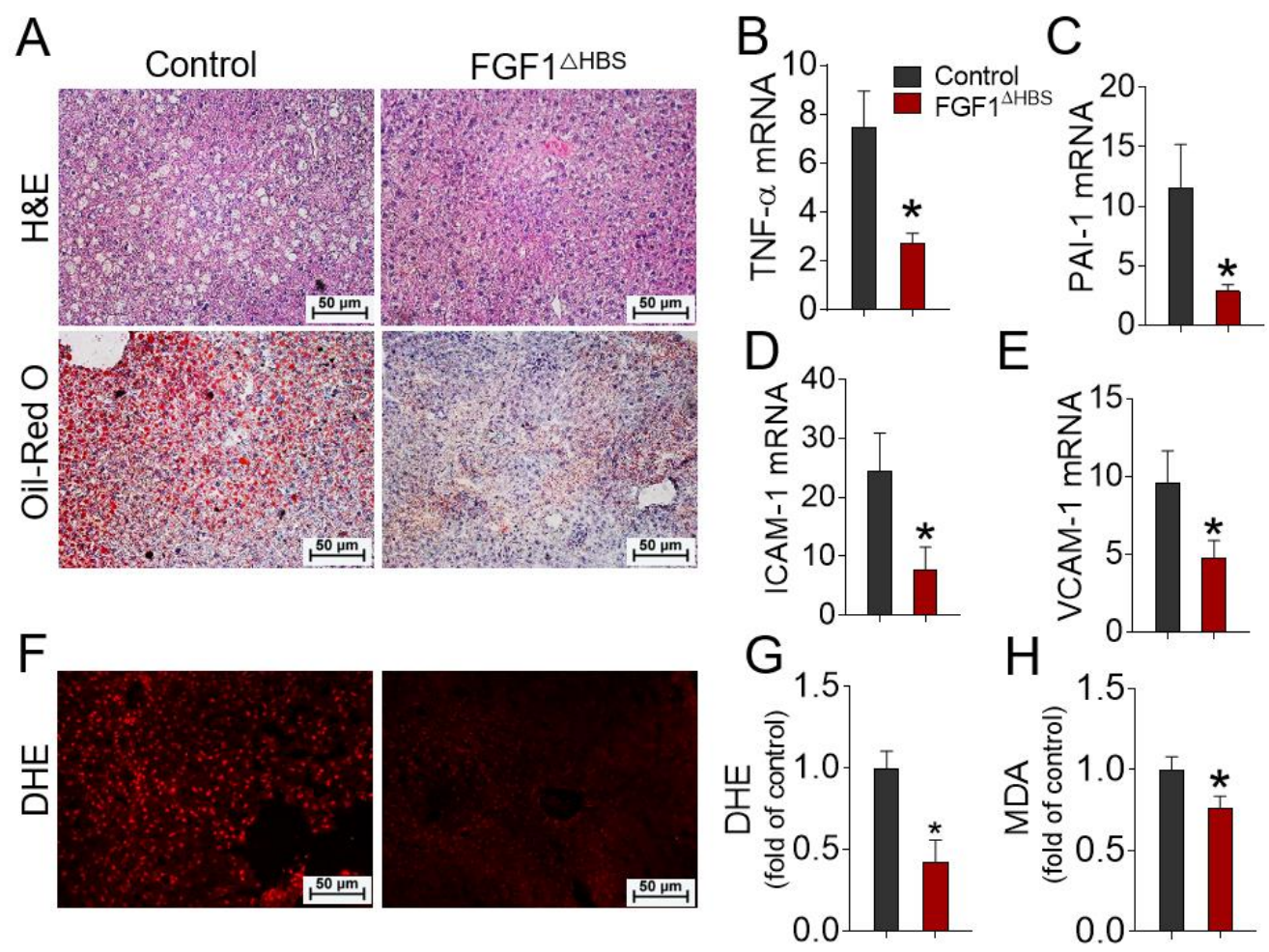

Fig. 3 The preventive effects of FGF1 $\triangle^{H B S}$ on hepatic inflammation and oxidative stress in 2-month-old db/db mice. (A) Representative images of H\&E and Oil Red O staining of liver sections (magnification: X200). (B-E) The hepatic mRNA levels of TNFa, PAI-1, ICAM-1 and VCAM-1 in db/db mice. ( $F$ and G) Representative images of DHE staining of liver frozen sections (magnification: X200) and quantitative analysis of fluorescent intensity of DHE staining. (H) MDA contents in liver tissues. Quantitative data are expressed as mean $\pm S E M, n=10-13 .{ }^{*} P<0.05 v s$. $d b / d b$ mice.

\section{FGF1 $\triangle{ }^{H B S}$ preserves hepatic antioxidant in $\mathrm{db} / \mathrm{db}$ mice}

To investigate the molecular basis of FGF1 ${ }^{\mathrm{HBS}}$ for hepatic antioxidative effects, we observed the activation of $\mathrm{Nrf2}$, an essential transcription factor in antioxidative responses $^{(117,118)}$, in FGF1 $\triangle \mathrm{HBS}$ treated and non-treated $\mathrm{db} / \mathrm{db}$ mice. As expected, the expression of nuclear Nrf2 in db/db mice was elevated significantly after FGF1 $\triangle \mathrm{HBS}$ 
treatment for 2 months (Fig. 4A, B). Furthermore, the expression of Nrf2-mediated antioxidative downstream genes catalase (CAT), NAD(P)H Quinone Oxidase 1 (NQO-1) and Heme Oxygenase 1 (HO-1), were significantly higher in FGF1 $\triangle \mathrm{HBS}^{\mathrm{HB}}$-treated $\mathrm{db} / \mathrm{db}$ mice than those in PBS-treated db/db mice (Fig4. A and C-E). These results indicate that FGF1 $\triangle \mathrm{HBS}$ reduce the hepatic oxidative stress by activating Nrf2-mediated antioxidative signaling pathways.
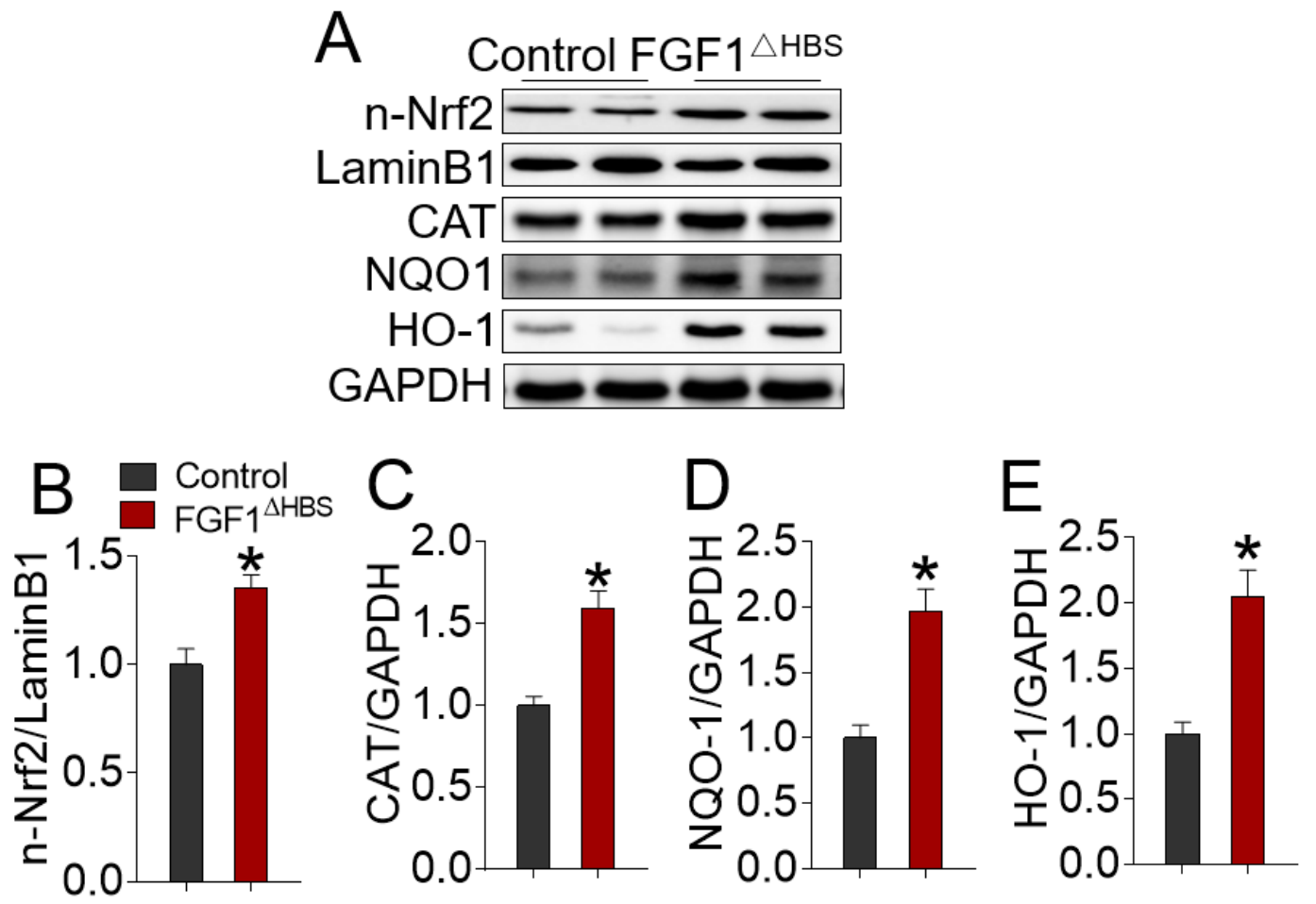

Fig. 4 FGF1 $\triangle^{H B S}$ activating Nrf2-mediated anti-oxidative signaling pathway in liver of 2-month-old db/db mice. (A) Protein expressions of nuclear Nrf2 and its downstream target genes catalase (CAT), heme oxygenase-1 (HO-1) and $N A D(P) H$ dehydrogenase (quinone 1) (NQO-1) were determined by Western blot. (B-E) The quantitative analysis of nuclear-Nrf2 (n-Nrf2), CAT, NQO-1 and HO-1 in Western blot results by densitometry. Quantitative data are expressed as mean \pm SEM, $n=10-13^{\star} P<0.05 \mathrm{vs.} d b / d b$ mice. 


\section{FGF1 $\triangle^{\mathrm{HBS}}$ promotes hepatic lipid metabolic signaling in T2D}

To decipher how FGF1 ${ }^{\mathrm{HBS}}$ regulates hepatic lipid metabolism in T2D, the key lipid metabolism related signaling was evaluated in this study. As the key factors in de novo fatty acid synthesis, FAS, SCD-1 and SREBP-1 at mRNA levels in $\mathrm{db} / \mathrm{db}$ mice were markedly reduced after FGF1 $\triangle \mathrm{HBS}$ treatment (Fig. 5A), as well as their expression at protein levels were inhibited as indicated by western-blot (Fig. 5B-E). In addition, CPT-1a, PPAR $\alpha$ and PGC-1 $\alpha$, which play major roles in regulating fatty acid oxidation ${ }^{(119)}$, were significantly increased in FGF1 $\triangle{ }^{H B S}$-treated $\mathrm{db} / \mathrm{db}$ mice compared to the control $\mathrm{db} / \mathrm{db}$ mice (Fig. 5B and 5F-H).

Notably, FGF1 $\triangle \mathrm{HBS}$-mediated lipid metabolic regulation was accompanied by a significant up-regulation of AMPK phosphorylation in db/db mice (Fig. 5B and 5I). The phosphorylation of ACC and SREBP-1, which are the downstream targets of AMPK, were also obviously upregulated by FGF1 $\triangle \mathrm{HBS}$ treatment in $\mathrm{db} / \mathrm{db}$ mice (Fig. $5 B$ and $5 \mathrm{~J}, \mathrm{~K}$ ), suggesting that FGF1 ${ }^{\mathrm{HBS}}$ regulation of hepatic lipid metabolism was associated with AMPK signaling pathway. 

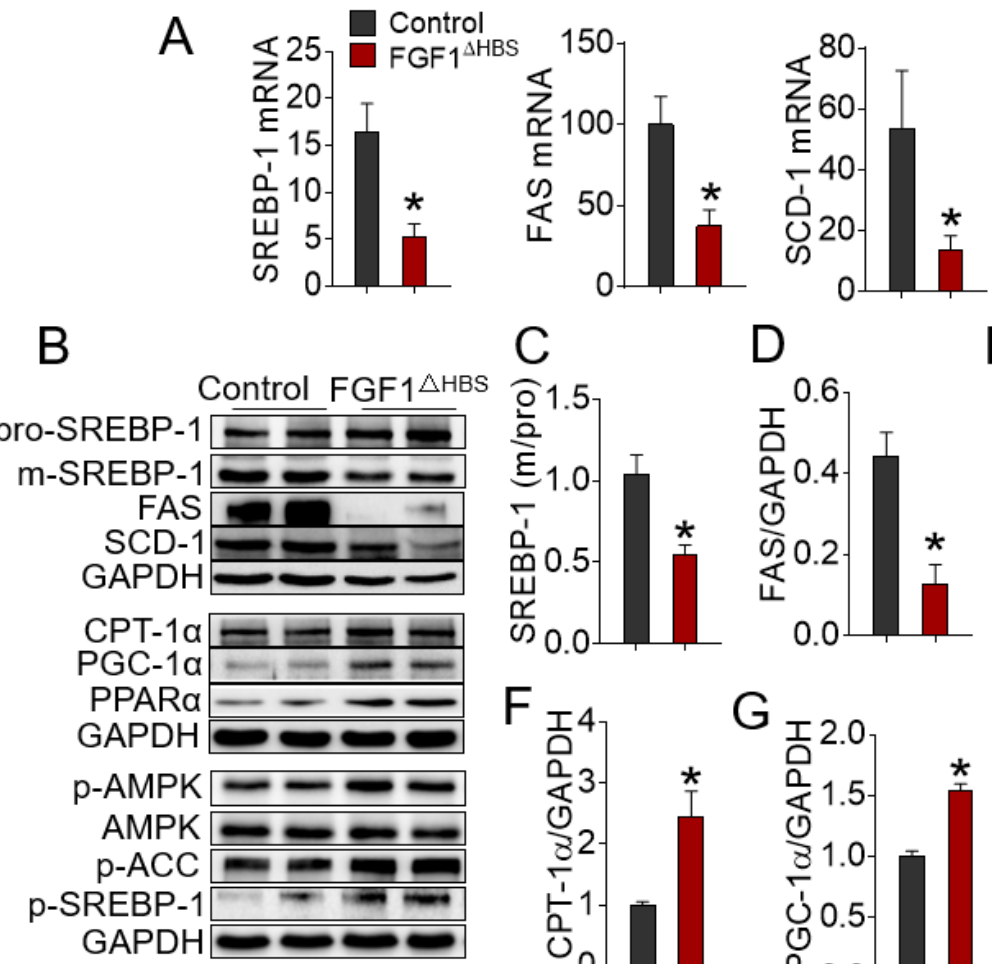

C

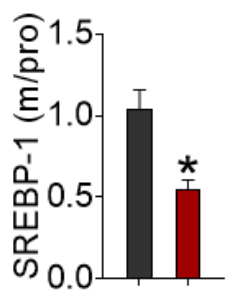

D
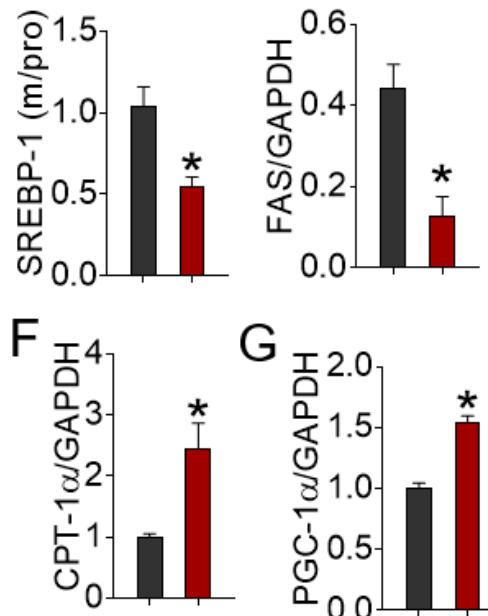

$\mathrm{G}$

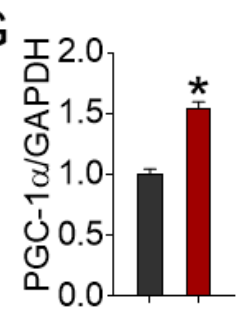

$\mathrm{H}$

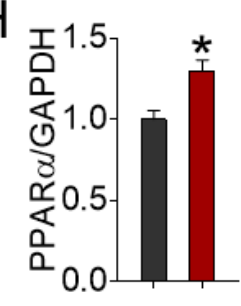

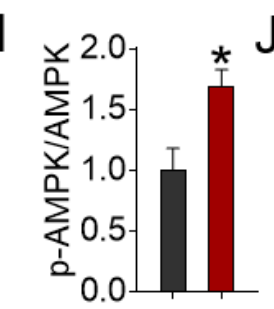
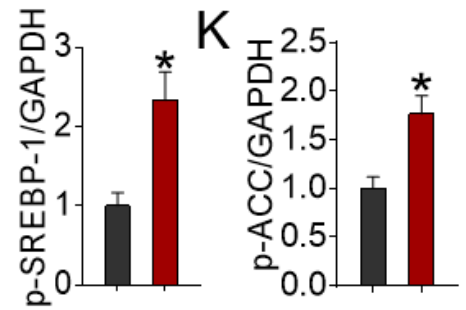

Fig. 5 FGF1 $\triangle^{H B S}$ regulating lipid metabolic signaling pathway in liver of 2-month-old db/db mice. (A) The hepatic mRNA levels of SREBP-1, FAS and SCD-1 in $d b / d b$ mice. (B) Protein expressions of hepatic lipogenic genes (m/pro SREBP-1, FAS, SCD-1),

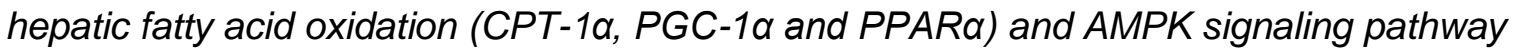
( $p$-AMPK/AMPK, $p-A C C$ and $p$-SREBP-1) related genes were determined by Western blot. (C-K) The quantitative analysis of Western blot results by densitometry. Quantitative data are expressed as mean \pm SEM, $n=10$-13. ${ }^{*} P<0.05 \mathrm{vs} . \mathrm{db} / \mathrm{db}$ mice. 


\section{DISCUSSION}

NAFLD is highly associated with T2D. Considering the interaction between T2D and NAFLD, it is certain that NAFLD is an increased risk for the development of T2D, while T2D result in the progression of NAFLD to NASH, even to the end-stage of liver disease ${ }^{(64,}$ 104). However, the therapeutic options for NAFLD with T2D are rather limited. In the present study, we demonstrated that FGF1 $\triangle^{\mathrm{HBS}}$, a novel variant of FGF1 uncoupled mitogenic and metabolic functions, effectively prevented hepatic steatosis, inhibited the oxidative stress via Nrf2-mediated signaling pathway and promoted the hepatic lipid metabolism possibly attributed to stimulation of AMPK-mediated signaling pathway in T2D.

As a paracrine FGF, FGF1 is known to be mitogenic and involved in the regulation of diverse pathophysiological processes. The recent discovery of metabolic roles for FGF1 in adaptive adipose remodeling, metabolic homeostasis and insulin sensitivity has expanded the functions of this classically known mitogen ${ }^{(9,20)}$. The liver is the critical metabolic organ strongly involved in the major metabolic dysfunction in diabetes. Increasing studies suggested the role of FGF1 in managing the metabolic dysfunction in diabetes $^{(9,20)}$, and demonstrated anti-steatosis and anti-inflammation effects for FGF1 protection against NAFLD in diabetes ${ }^{(24,75)}$. In addition to its potent glucose lowering and insulin sensitizing effects, FGF1 would be a promising agent for NAFLD therapy. However, the mechanism of FGF1 protection against NAFLD remains largely unknown. In the present study, FGF1 ${ }^{\mathrm{HBS}}$ was used to define how FGF1 protects against NAFLD in T2D.

We used 2-month-old $\mathrm{db} / \mathrm{db}$ mice to determine the preventive effects of FGF $1 \triangle \mathrm{HBS}$ on diabetes-induced fatty liver disease. We demonstrated that FGF1 protected the T2D mice from hepatotoxicity by inducing the antioxidant capacity and promoting the lipid metabolism in livers. Our results showed that $\mathrm{FGF} 1 \triangle \mathrm{HBS}$ significantly attenuated the hyperglycemia and promoted the insulin sensitivity in this early-stage $\mathrm{db} / \mathrm{db}$ mice (Fig. 2 A-C). Moreover, FGF1 $\triangle^{\mathrm{HBS}}$ significantly prevented injury, ameliorated the pathologic 
abnormality and reduced the hepatic lipid accumulation and inflammation in $\mathrm{db} / \mathrm{db}$ mice (Fig.2D-H and Fig. 3A-E). These results further confirmed the blood glucose lowering capability and hepatic protective effects of FGF1 ${ }^{\mathrm{HBS}}$ were similar as that FGF ${ }^{\mathrm{WT}}$ showed in our previous studies ${ }^{(75,85)}$.

Oxidative stress refers to various deleterious processes resulting from an imbalance between the excessive formation of ROS and limited antioxidant defenses ${ }^{(89)}$, which is a major factor responsible for the dysfunction of diabetic livers ${ }^{(88)}$. In the present study, the $\mathrm{db} / \mathrm{db}$ mouse models exhibited robust oxidative stress in liver, indicated by upregulated superoxide generation and MDA production, all of which were greatly inhibited by FGF1 ${ }^{\mathrm{HBS}}$ (Fig.3 F-H). Among the mechanism responsible for the oxidative stress, Nrf2mediated signaling pathway plays a critical role in antioxidative responses by upregulating multiple antioxidant components ${ }^{(117,118)}$. Our findings clearly demonstrated that Nrf2 activation was upregulated by $\mathrm{FGF}{ }^{\triangle \mathrm{HBS}}$ in livers of $\mathrm{T} 2 \mathrm{D}$, as indicated by increased nuclear translocation of Nrf2 and upregulation of Nrf2 downstream anti-oxidative genes, CAT, NQO-1 and HO-1 (Fig. 4). These finding suggest that the anti-oxidative functions of FGF1 $\triangle^{H B S}$ are linked to Nrf2 pathway.

Lipid metabolic disturbance is common in diabetic and NAFLD, which is characterized by the excess fatty acid synthesis and impaired lipid catabolism ${ }^{(120,121)}$. Activation of AMPK leads to the phosphorylation of key metabolic enzymes and transcriptional regulators that are linked to cellular metabolism, such as glucose uptake, fatty acid synthesis and oxidation ${ }^{(122)}$. In addition to reduction of TG and lipid accumulation in $\mathrm{FGF} 1 \triangle^{\mathrm{HBS}}$-treatment $\mathrm{db} / \mathrm{db}$ mice, FGF1 $\triangle^{\mathrm{HBS}}$ also downregulated the important lipogenesis transcription gene, SREBP-1 and its downstream genes, FAS and SCD-1 (Fig.5A-E). Moreover, FGF1 $\triangle^{\mathrm{HBS}}$ significantly upregulated the fatty acid oxidation related genes, CPT-1 $\alpha$, PPAR $\alpha$ and PGC-1 $\alpha$ (Fig.5B and 5F-H). These findings indicate that 
FGF1 $\triangle$ HBS protection against NAFLD is associated with AMPK-mediated lipogenesis inhibition and fatty acid oxidation activation.

These data firstly indicate that the potent preventive effects of FGF1 $\triangle$ HBS against NAFLD in T2D were strongly associated with the Nrf2 mediated-anti-oxidative pathway and AMPK mediated lipid metabolism pathway. 
CHAPTER II

THE ROLE OF NUCLEAR FACTOR ERYTHROID 2-RELATED FACTOR 2 IN

FIBROBLAST GROWTH FACTOR 1 PROTECTION AGAINST NON-ALCOHOLIC

FATTY LIVER DISEASE

\section{INTRODUCTION}

\section{Oxidative stress in diabetes}

Oxidative stress refers to increased cellular production of reactive oxygen (ROS) and nitrogen (RNS) species and impaired clearance of such species by antioxidant defense systems that cause damage to lipids, proteins and DNA ${ }^{(123)}$. Numerous studies have indicated that oxidative stress as a key regulator in chronic pathological status including cancer, cardiovascular diseases, chronic inflammation, autoimmune disorders and diabetes ${ }^{(124)}$. In particular, increasing evidence has established the role of oxidative stress in the development of diabetic complications including diabetic cardiomyopathy, retinopathy, nephropathy, neuropathy, and microvascular disease ${ }^{(125)}$. The causes of increased oxidative stress in the diabetic complications are partially known by the activation of transcription factors, advanced glycated end products (AGEs), and protein kinase $C^{(126,127)}$. In diabetes, the hyperglycemia increases the production of free radicals. The excess free radicals and the imbalance of antioxidant defense mechanisms result to the damaged cellular organelles and enzymes, increased lipid peroxidation, and insulin resistance. These consequences of oxidative stress aggressive cause the damage of diabetic complications ${ }^{(126)}$. Meanwhile, oxidative stress has the strong cross-talk with the 
fibrosis, inflammation, cell death and metabolic stress, which accelerate the tissue damage in diseases ${ }^{(128,129)}$. Therefore, antioxidant therapy has been attractive treatment options for diabetes treatment.

\section{Oxidative stress in NAFLD}

NAFLD is characterized by excess fatty acid in hepatocytes because of the increased inflow of free fatty acids and/or de novo lipogenesis, and decreased fatty acid oxidation caused by initial metabolic disturbance. As the "the first hit", this marked hepatic fat accumulation is the risk for the development of NAFLD, which increases the susceptibility of the liver to secondary damages ${ }^{(92)}$. Excess lipids in the hepatocyte impairs the mitochondria oxidation, inactivates the electron transport chain complexes and stimulates peroxisomal and microsomal pathways of fat oxidation. The consequent generation of ROS and reactive aldehydic derivatives causes oxidative stress and cell death, via multiple factors such as ATP, nicotinamide adenine dinucleotide, glutathione depletion, DNA, and lipid damage ${ }^{(89)}$. There has a vicious circle between the abnormal lipid peroxidation and the excess ROS in NAFLD, which continually aggravates the oxidative stress and abnormal metabolic regulation, further exacerbates the cell death in NAFLD. As the critical "second hit" in NAFLD, oxidative stress also triggers production of inflammatory cytokines, causing inflammation leading to the progression of steatohepatitis and cirrhosis. This ultimately results in the progress of NAFLD and end-stage liver failure. Application of antioxidants suggests a rational curative strategy to prevent the liver injury from oxidative stress $^{(88,130)}$.

\section{The role of nuclear factor E2-related factor 2 in diseases}

Nrf2 is a transcription factor that widely distributed in the liver, kidney, muscle, lung, heart and other organs. Nrf2 is an important sensor in response to the toxic substances 
and oxidants in the body that is critical for cellular defense mechanisms. In non-stressed cells, Nrf2 is inactive in the cytoplasm because of the repressive effect of kelch like $\mathrm{ECH}$ associated protein 1 (Keap1). Once activated by ROS or electrophilic agents, Nrf2 translocate into the nucleus and binds to the promoters of a variety genes including the genes relevant to anti-inflammation, anti-apoptosis and anti-aging ${ }^{(131)}$. Nrf2 mainly binds to antioxidant response element (ARE) to regulate its target genes, such as $\mathrm{NAD}(\mathrm{P}) \mathrm{H}$ quinone oxidase 1 (NQO1), heme oxygenase $1(\mathrm{HO} 1)^{(132,133)}$. The potential protective roles of Nrf2-mediated antioxidant activation in diabetic complications, such as diabetic nephropathy, cardiomyopathy and limb ischemia, have been widely studied ${ }^{(134-136)}$.

Recently, Nrf2 pathway has been investigated as a potential target to metabolic syndrome, such as obesity, insulin resistance and $\operatorname{T2}^{(137,138)}$. For example, the liver expression of Nrf2 and its downstream genes were decreased in high fat diet fed mice. Nrf2 knockout mice have TG and ROS accumulation in liver ${ }^{(139)}$. The Nrf2 activator, such as sulforaphane, can activate Nrf2 to inhibit the hepatic oxidative stress and inflammation, following with the protection against the hepatic lipid accumulation ${ }^{(140)}$. Xue et al demonstrated that adipocyte-specific ablation of Nrf2 in ob/ob mice resulted in reduced antioxidant response, but increased plasma triglyceride and aggravated insulin resistance $(137,141,142)$. All these results demonstrate that in addition to the anti-oxidant stress, Nrf2 is also involved in regulating insulin sensitivity and maintaining the glucose and lipid homeostasis.

In the present study, we found that FGF1 $\triangle^{\mathrm{HBS}}$ significantly ameliorated the hepatic oxidative stress in $\mathrm{db} / \mathrm{db}$ mice associated with the upregulation of nuclear Nrf2, and its downstream target genes. Base on the previous studies, we hypothesize that Nrf2mediated signaling pathway might play a critical role in FGF1 protection against NAFLD in T2D. 


\section{MATERIALS AND METHODS}

\section{Cell treatment}

The human hepatocellular carcinoma cell line (HepG2) was purchased from the American Type Culture Collection. Palmitate (Pal) provided by Sigma-Aldrich (St. Louis, MO, USA) was used to mimic diabetes-induced hepatic lipid toxicity including oxidative damage and lipid metabolism disorder seen in db/db mice. HepG2 cells were cultured in DMEM containing $5.5 \mathrm{mM}$ D-glucose, 10\% fetal bovine serum, 100 units/ml penicillin, and $100 \mu \mathrm{g} / \mathrm{ml}$ streptomycin, and incubated in a humidified atmosphere of $5 \% \mathrm{CO} 2$ at $37{ }^{\circ} \mathrm{C}$ and passaged every 2 days by trypsinization. After serum starvation for 24 hours, HepG2 cells and Nrf2 knockdown-HepG2 cells were treated with $100 \mu \mathrm{M}$ Pal or control with/without insulin in serum free medium for 12 hours, followed by incubation with FGF 1 WT

and FGF $1 \triangle{ }^{\mathrm{HBS}}$ for additional 12 hours, respectively. Cells were collected for the following experiments. All cell culture experiments were carried out under the guidelines of biosafety and approved by the Biosafety Committee of the University of Louisville.

\section{Palmitate preparation}

Pal was dissolved in $50 \%$ ethanol solution at $60{ }^{\circ} \mathrm{C}$, and further dissolved in $2 \%$ fatty acid-free bovine serum albumin (BSA) to make $10 \mathrm{mM}$ Pal stock solution, then filtered and stored at $-20^{\circ} \mathrm{C}$.

\section{Oil-Red $O$ analysis for cells}

Cells were seeded in 6-well plate at a density of $10^{4}$ cells per well. After stimulated with Pal in the presence of insulin for 12 hours, followed by incubation with or without FGF $1^{\mathrm{WT}}$ and $\mathrm{FGF} 1{ }^{\mathrm{HBS}}$ for additional 12 hours, cells were washed with PBS for three times, and then fixed in $4 \%$ paraformaldehyde for 20 mins. After washing with PBS three times, cells were stained with $0.5 \%$ Oil Red $\mathrm{O}$ for 10 mins at room temperature. Then the 
additional Oil Red O was removed by washing with PBS. To quantify Oil Red O content, isopropanol $(1 \mathrm{ml})$ was added into each well, shaking the plate for 10 mins at room temperature. The intensity of Oil Red $\mathrm{O}$ content in each sample was detected by a microplate reader under specific wavelength conditions $(O D=520 \mathrm{~nm})$.

\section{Quantitative determination of oxidative stress}

HepG2 cells were cultured and treated as described above, then incubated with 5 $\mu \mathrm{M}$ DHE in HBSS medium for 30 minutes at $37^{\circ} \mathrm{C}$. Nuclear DHE positive staining indicates superoxide generation in cells. The fluorescence intensity was detected using a microplate reader (SpectraMax M3; Molecular Devices, Sunnyvale, CA) under specific wavelength conditions (excitation, $518 \mathrm{~nm}$; fluorescence, $605 \mathrm{~nm}$ ).

For MDA analysis in vitro, $50 \mu$ proteins from cells were incubate with $8.1 \%$ SDS, $20 \%$ Acetic acid and $0.57 \%$ TBA at $90^{\circ} \mathrm{C}$ for 70 mins. Then centrifuged at $4000 \mathrm{x}$ for 15 mins. The calculation of the fluorescence intensity finally MDA content in each sample was same as that performed in vivo.

\section{SiRNA transfection}

knockdown of Nrf2 was performed using small interfering RNAs (siRNAs) targeting Nrf2 and control siRNA (Santa Cruz Biotechnology, CA) according to the manufacturer's protocol. HepG2 cells were seeded at a density of $20 \times 10^{4}$ cells/well in 6 -well plates and were transfected with Nrf2-siRNA using lipofectamine 2000 reagent (Invitrogen) at a final concentration of $100 \mathrm{nmol} / \mathrm{L}$ in Opti-MEM (GIBCO BRL) for 6 hours, respectively. Then cells were cultured with normal medium for additional 16 hours to determine the knockdown efficiency. 


\section{Triglyceride content determination in cells}

Cells were seeded in 6 -well plate at a density of $20 \times 10^{4}$ per well. After stimulated with Pal and treated with FGF1 ${ }^{\mathrm{WT}}$ and $\mathrm{FGF} 1{ }^{\mathrm{HBS}}$ in the present of insulin, cells were washed with PBS for three times and then incubated with $0.3 \mathrm{ml}, 0.25 \mathrm{M} \mathrm{NaOH}$ for 10 mins. Cells were scraped into the tube and incubated with hexane/isopropanol mixture (3:1) for 1 hour, then centrifuged at $10000 \mathrm{~g}$ for 5 mins and then transferred the supernatants to a new tube. The supernatant was evaporated at room temperature overnight. A TG kit (Thermo Scientific, Waltham, MA) was used to solubilize the lipid pellet. After incubation with TG buffer for 10 mins at $37^{\circ} \mathrm{C}$, the levels of TG content in each well was detected by a microplate reader under specific wavelength conditions $(O D=505 \mathrm{~nm})$.

\section{Western blot analysis}

The above cultured HepG2 cells were collected and lysed. Lysate proteins from liver tissues and cells were separated using $8-12 \%$ SDS-PAGE and electro-transferred onto a nitrocellulose membrane.

\section{Statistical analysis}

Statistical analyses were performed using the statistical software package, GraphPad Prism version 6, (GraphPad Software Inc., San Diego, CA, USA). Data are expressed as mean \pm SEM. Statistical significance was evaluated using the unpaired twotailed Student $t$ test or one-way analysis of variance. Differences were considered significant at a $\mathrm{P}$ value $<0.05$. 


\section{RESULTS}

FGF1 prevents Pal-induced oxidative stress in an insulin-dependent manner in

\section{HepG2 cells}

As shown in DHE staining result, the hepatic superoxide production was higher in Pal-induced HepG2 cells compared to the Control. The ROS accumulation in Pal-induced HepG2 cells was not decreased by FGF1 ${ }^{\mathrm{WT}}$ or FGF1 ${ }^{\mathrm{HBS}}$ (FGF1) treatment alone, but obviously inhibited by FGF1 treatment in the present of insulin (Fig. 6A). In agreement with DHE result, FGF1 effectively inhibited the oxidative stress in an insulin dependent manner in Pal-induced HepG2 indicated by MDA analysis (Fig. 6B, C). Compared to the control, Pal significantly suppressed the expression of nuclear Nrf2 in HepG2 cells. Treatment with FGF1 significantly preserved Pal-induced reduction of nuclear Nrf2 in HepG2 cells. The marked upregulation of nuclear Nrf2 was shown in Pal-induced HepG2 cells after FGF1 treatment with insulin, which was accompanied by a significant increase in expression of its downstream anti-oxidative genes, CAT, HO-1 and NQO-1 (Fig. 7). These results suggest that FGF1 prevents Pal-induced hepatic oxidative stress possibly by restoring the antioxidant capability via Nrf2-mediated signaling. 


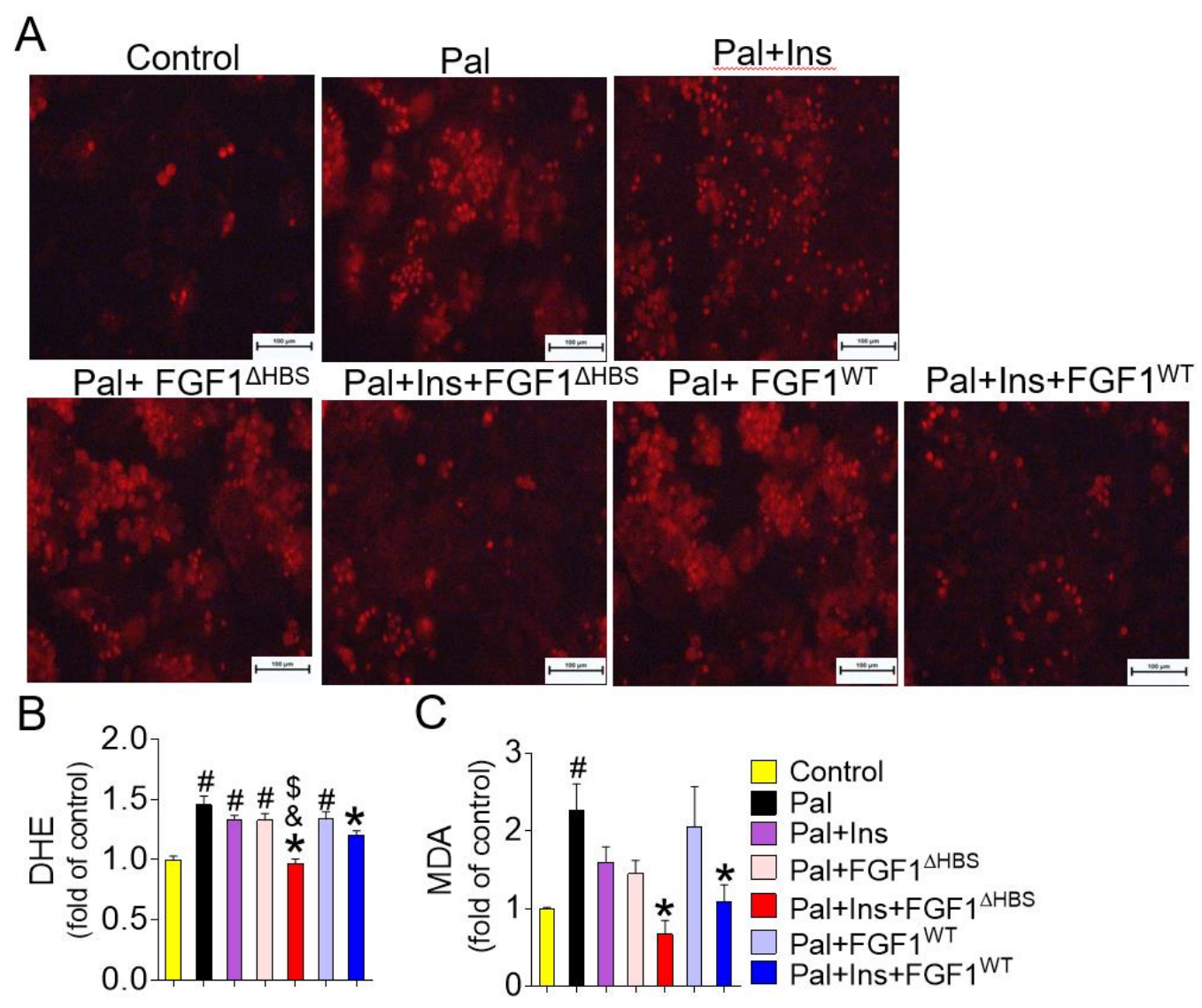

Fig. 6 FGF1 preventing from Pal-induced hepatic oxidative stress in HepG2 cells. ( $A$ and $B$ ) Representative images (magnification: $X 100)$ and quantitative analysis of fluorescent intensity of DHE staining in Pal-induced HepG2 cells. (C) MDA content. Quantitative data are expressed as mean \pm SEM, $n=3-5 .{ }^{\#} P<0.05$ vs. Ctrl; ${ }^{\star} P<0.05$ vs. Pal; ${ }^{\&} P<0.05$ vs. Pal+Ins; ${ }^{\$} P<0.05$ vs. Pal+FGF1 ${ }^{H B S}$ or Pal+FGF1wT. 

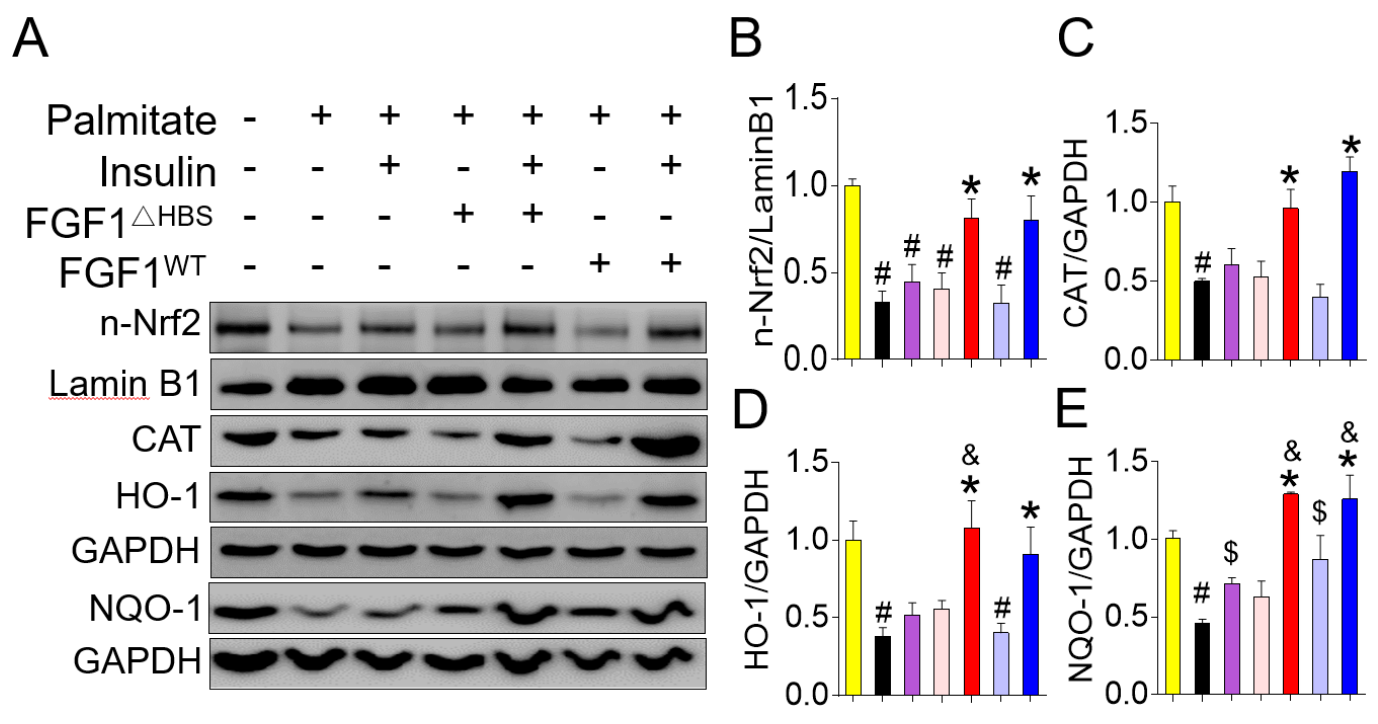

Fig. 7 FGF1 preventing from Pal-induced hepatic oxidative stress via activating Nrf2-mediated anti-oxidative signaling pathway in HepG2 cells. (A) The protein expressions of nuclear Nrf2 and Nrf2 target genes CAT, HO-1 and NQO-1 in HepG2 cells were determined by Western blot. (B-E) The quantitative analysis of Western blot results by densitometry. Quantitative data are expressed as mean \pm SEM, $n=3-5 .{ }^{\#} P<0.05$ vs. Ctrl; ${ }^{\star} P<0.05$ vs. Pal; ${ }^{\&} P<0.05$ vs. Pal+Ins; ${ }^{\$} P<0.05$ vs. Pal+FGF1 ${ }^{H B S}$ or Pal+FGF1WT.

\section{FGF1 prevents Pal-induced lipotoxicity in an insulin-dependent manner in HepG2 cells}

Pal treatment caused a clear increase of TG accumulation in HepG2 cells compared with the Control (Fig. 8A). Furthermore, both FGF1 $\triangle^{\mathrm{HBS}}$ and FGF ${ }^{\mathrm{WT}}$ treatment prevented Pal-induced lipid accumulation in HepG2 cells in an insulin-dependent manner, reflected by intracellular TG content analysis and Oil-Red O staining (Fig. 8A and 8B). In the presence of insulin, FGF1 dramatically decreased the expression of m/proSREBP-1, FAS and SCD-1 (Fig. 9A-D) and increased the expression of CPT-1 $\alpha$, PGC1 $\alpha$ and PPAR $\alpha$ (Fig. 9A, E-G). In addition, the dramatic reduction of phosphorylated AMPK by Pal in 
HepG2 cells was preserved by FGF1 treatment, along with the increased phosphorylation of its downstream genes ACC and SREBP-1 (Fig. 9A, H-J).
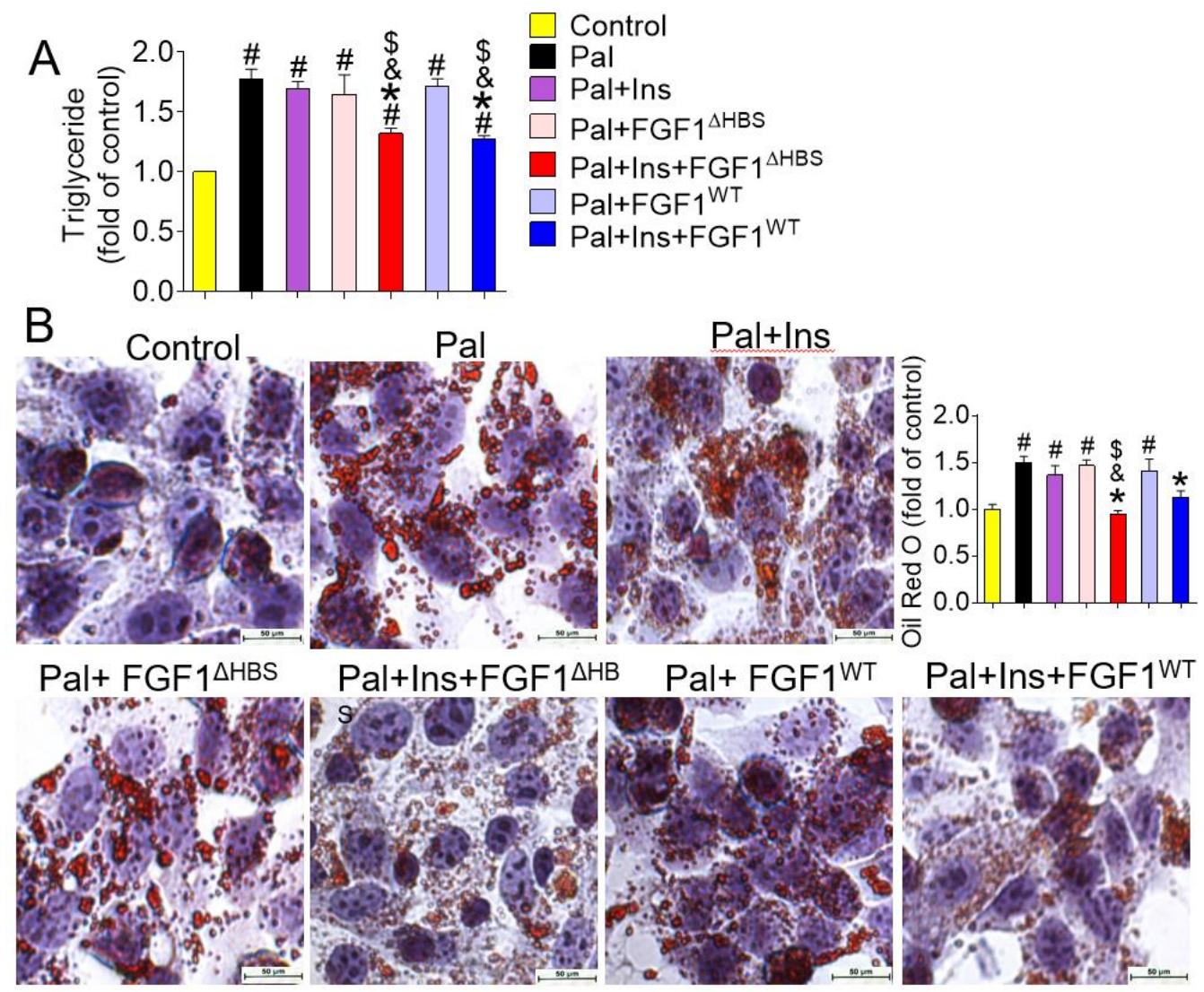

Fig. 8 FGF1 preventing from Pal-induced hepatic lipotoxicity in HepG2 cells. (A) Triglyceride contents. (B) Representative images of Oil Red O staining and Oil Red O content analysis. Quantitative data are expressed as mean \pm SEM, $n=3-5$. ${ }^{\sharp} P<0.05$ vs. Ctrl; ${ }^{*} P<0.05$ vs. Pal; ${ }^{\&} P<0.05$ vs. Pal+Ins; ${ }^{\$} P<0.05$ vs. Pal+FGF1 ${ }^{H B S}$ or Pal+FGF1 ${ }^{W T}$. 


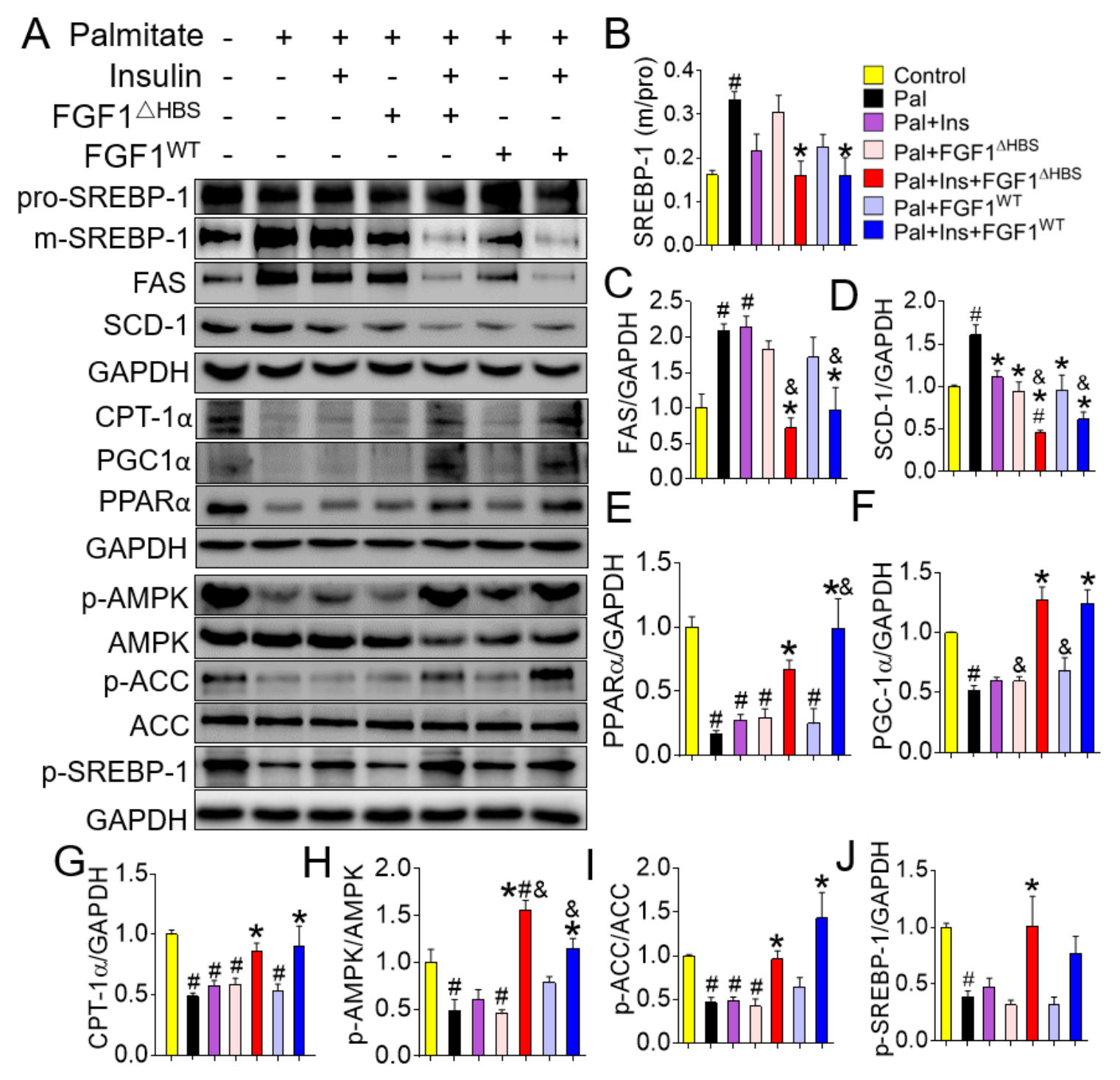

Fig. 9 FGF1 inhibiting lipogenesis and promoting lipid oxidation signaling in PalHepG2 cells. (A) Protein expressions of lipogenic genes (m/pro SREBP-1, FAS, SCD-1),

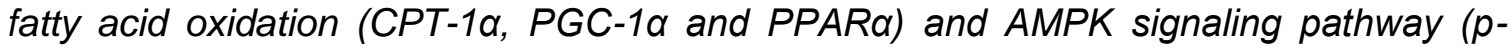
AMPK/AMPK, $p-A C C / A C C$ and $p-S R E B P-1)$ in HepG2 cells were detected by Western blot. (B-J) The quantitative analysis of Western blot results by densitometry. Quantitative data are expressed as mean \pm SEM, $n=3-5 .{ }^{\#} P<0.05$ vs. Ctrl; ${ }^{*} P<0.05$ vs. $P$ al; ${ }^{\&} P<0.05$ vs. Pal+Ins; ${ }^{\$} P<0.05$ vs. Pal+FGF1 ${ }^{H B S}$ or Pal+FGF1 ${ }^{W T}$. 


\section{Nrf2 silencing abolishes the protective effects of FGF1 against oxidative stress but not lipotoxicity}

In addition to playing a central role in responding to oxidative stress, Nrf2is also a target for regulating lipid metabolism ${ }^{(143)}$. Nrf2 knockdown significantly aggravated the oxidative damage compared to Control-siRNA group, neither FGF1 ${ }^{\mathrm{HBS}}$ nor FGF1 ${ }^{\mathrm{WT}}$ decreased the MDA content after Nrf2 knockdown in HepG2 cells (Fig. 10A). Moreover, FGF1 did not affect the protein levels of nuclear Nrf2, HO-1, CAT and NQO-1 in Palinduced HepG2 cells transfected with Nrf2-siRNA compared to Control-siRNA group (Fig. 10B-G), suggesting Nrf2 silencing abolished the preventive effects of FGF1 from Pal-induced oxidative damage. However, Nrf2 knockdown did not affect FGF1 prevention from TG accumulation in Pal-induced HepG2 cells (Fig. 11A). Meanwhile, FGF1 inhibiting Pal-induced upregulation of m/pro-SREBP-1, FAS, and SCD-1 also was not affected by Nrf2 knockdown in cells (Fig. 11B-E). Taken together, our results indicate that Nrf2 is not required for the inhibitory effects of FGF1 on Pal-induced lipid disorder in HepG2 cells. 

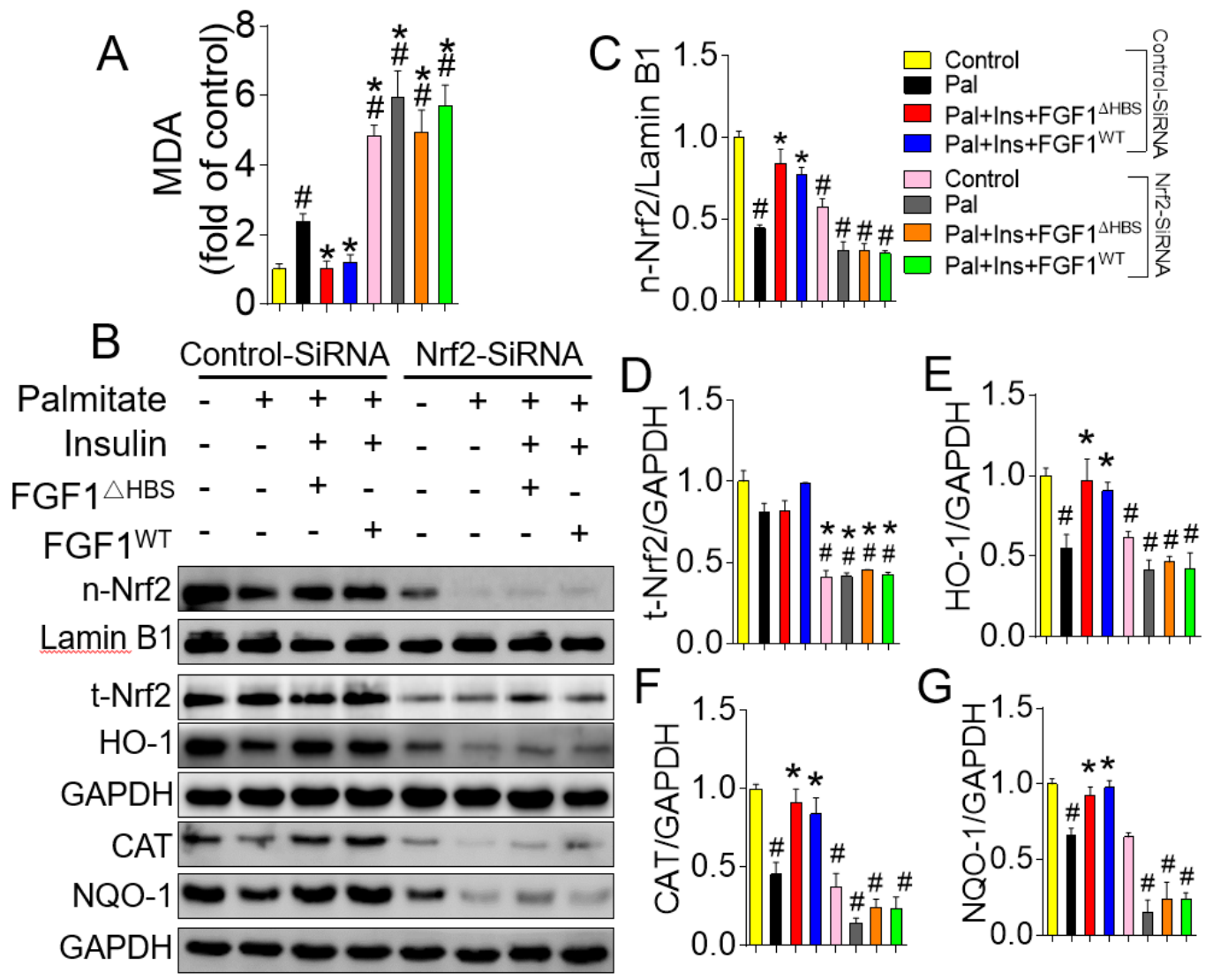

Fig. 10 Knockdown of Nrf2 in the HepG2 cells attenuated the beneficial effects of FGF1 on Pal-induced oxidative stress in HepG2 cells. (A) MDA contents in Pal-induced HepG2 cells. (B) The expressions of nuclear Nrf2, total Nrf2 (t-Nrf2), HO-1, CAT and NQO1 were determined by Western blot. (C-G) The quantitative analysis of nuclear Nrf2, $t$-Nrf2 and HO-1 western blot results by densitometry. Quantitative data are expressed as mean \pm SEM, $n=3-5 .{ }^{\#} P<0.05$ vs. Control-Control-SiRNA; ${ }^{*} P<0.05$ vs. Pal-Control-SiRNA; ${ }^{\&} P$ $<0.05$ vs. Control-Nrf2-SiRNA; ${ }^{\$} P<0.05$ vs. Pal-Nrf2-SiRNA. 

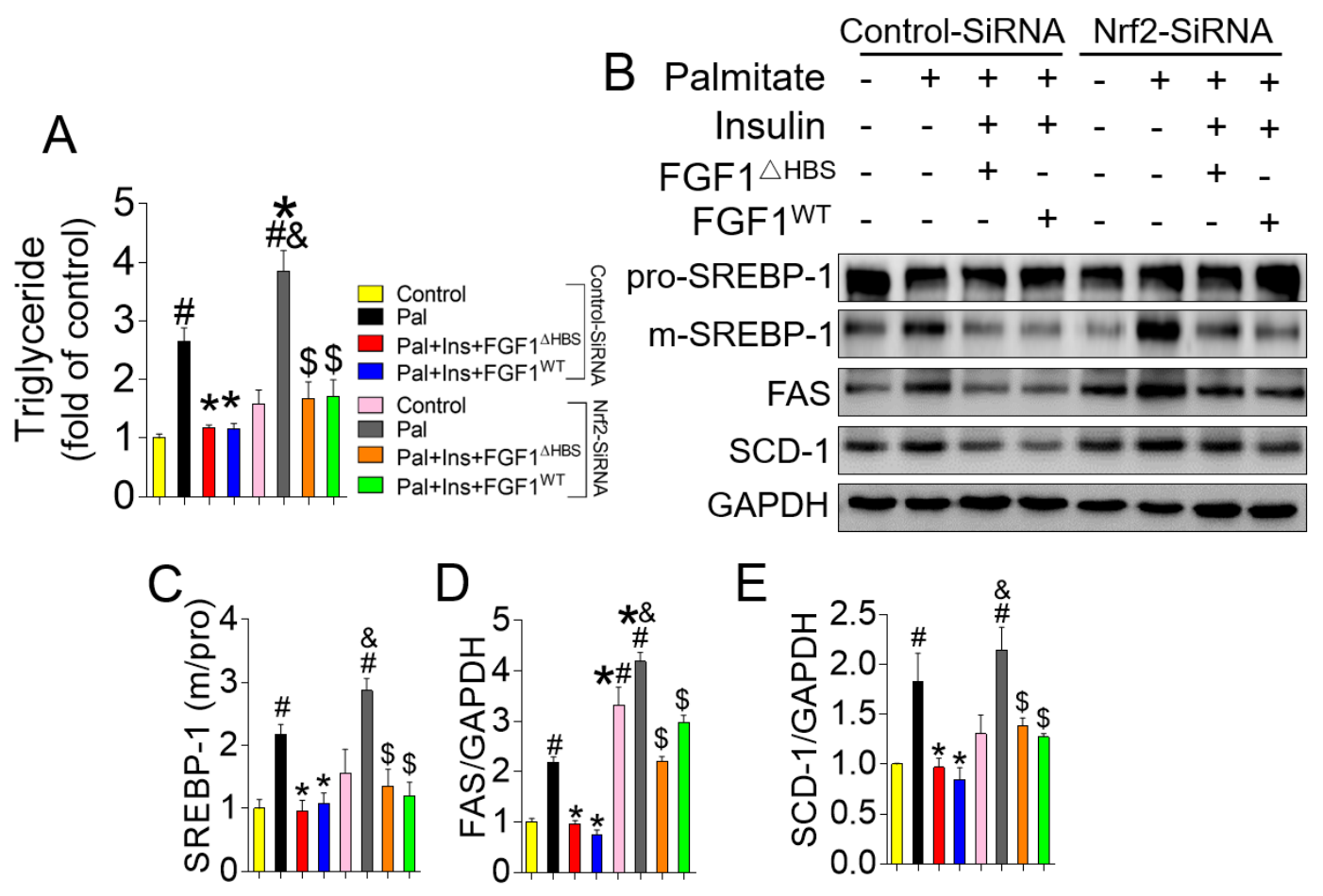

Fig. 11 Knockdown of Nrf2 cells affect the beneficial effects of FGF1 on Pal-induced lipiotoxicity in HepG2 cells. (A) TG content in HepG2 cells. (B) Protein expressions of lipogenic genes (m/pro SREBP-1, FAS, SCD-1) were determined by Western blot. (C-E) The quantitative analysis of m/pro SREBP-1, FAS, SCD-1 Western blot results by densitometry. Quantitative data are expressed as mean \pm SEM, $n=3-5 .{ }^{\#} P<0.05$ vs. Control-Control-SiRNA; ${ }^{\star} P<0.05$ vs. Pal-Control-SiRNA; ${ }^{\circledR} P<0.05$ vs. Control-Nrf2SiRNA; ${ }^{\$} P<0.05$ vs. Pal-Nrf2-SiRNA.

\section{DISSISION}

Among the many potential pathogenic mechanisms responsible for the progression of NAFLD, oxidative stress is recognized as a secondary hit driving the pathogenesis of NAFLD. Oxidative stress exacerbates hepatic inflammation and fibrosis, leading to further disruption of hepatic lipid metabolism ${ }^{(87-92)}$. It suggests a close relationship between dysregulated lipid homeostasis and oxidative stress in the pathogenesis of $\operatorname{NAFLD}^{(142,143)}$. 
In the intracellular signaling system that regulates oxidative stress responses, Nrf2 is a well-known master regulator of the cellular adaptive response to oxidative damage ${ }^{(137)}$. Emerging evidence indicated that, in addition to regulating hepatic antioxidant defenses, Nrf2 plays a critical role in regulating the hepatic energy metabolism pathways ${ }^{(137,141,144)}$. To further understand the protective effects of FGF1 against lipotoxicity in hepatocytes, Pal was used to mimic T2D-induced lipotoxicity to explore the protective mechanism of $\operatorname{FGF1}(145,146)$.

Pal-induced HepG2 cells successfully mimicked the phenotype of diabetes-induced oxidative stress and lipid toxicity. Both FGF1 $\triangle \mathrm{HBS}$ and FGF1 ${ }^{\mathrm{WT}}$ protected Pal-induced HepG2 cells against hepatic lipotoxicity in an insulin dependent manner (Fig.6 and Fig.8), following with a significant increase in Nrf2 signaling and AMPK signaling (Fig. 7 and Fig. 9). These results further confirmed the protection of FGF1 against NAFLD was associated with Nrf2- and AMPK-mediated signaling pathways.

Accordingly, we detected the role of Nrf2 for FGF1 treatment in NAFLD. As expected, FGF1 could not reverse Pal-induced ROS accumulation after Nrf2 silencing in HepG2 cells after Nrf2 knockdown (Fig. 10). This result suggests that Nrf2 play a critical role in the antioxidative stress action of FGF1 in hepatic cells. However, FGF1 administration still attenuated lipid accumulation and lipogenesis genes expression in Pal-induced HepG2 cells with Nrf2 knockdown (Fig. 11). These results suggest that Nrf2 silencing was not required for FGF1 protection against Pal-induced lipid disorder. 
CHAPTER III

THE ROLE OF AMP-ACTIVATED PROTEIN KINASE a IN FIBROBLAST GROWTH FACTOR 1 PROTECTION AGAINST NON-ALCOHOLIC FATTY LIVER DISEASE

\section{INREODUCTION}

\section{Lipid metabolism in liver}

Lipid metabolism is a process of lipid synthesis and degradation in cells. The liver is a central metabolic organ in the regulation of glucose and lipid metabolism. Lipid metabolism in hepatocytes can be summarized by three processes: (1) lipid absorption, including lipids and fatty acids uptake and fatty acid synthesis (de novo lipogenesis); (2) lipid storage, including triglyceride synthesis and lipid droplets formation; and (3) lipid catabolism, including lipolysis, $\beta$-oxidation, and the very low-density lipoproteins (VLDL) secretion $^{(120,121)}$. Lipid metabolic disorders are characterized by a change in the concentration and/or composition of lipoproteins in the blood, such as low-density lipoprotein (LDL), cholesterol, VLDL, and TG ${ }^{(147)}$.

\section{Lipid metabolic dysregulation in diabetes and NAFLD}

Lipid metabolic dysregulation is common in diabetic and NAFLD patients. Insulin deficiency, insulin resistance, obesity, and genetic factors are related the lipoprotein production and catabolism. T2D has an increased prevalence of lipid abnormalities. T2D patients usually show decreased HDL level and elevated VLD. LDL levels is usually not significantly different in T2D patients compared with nondiabetic individuals ${ }^{(148)}$. The liver plays a particularly important role in lipid metabolism that involves in the lipoprotein 
synthesis, lipid transport and is the main site for fatty acid oxidation and ketone body formation. NAFLD is characterized by excessive fat accumulation in the liver, showed by the increased flux of free fatty acids (FFA), lipoprotein lipase (LPL) and TG accumulation $^{(149)}$.

Generally, the mechanism contributing to the pathogenesis of NAFLD includes the extrahepatic mechanisms and intrahepatic mechanisms. The extrahepatic mechanism includes the adipose tissue that increases FFA transporting to the liver and many dietary macro- and micro-nutrients, such as saturated fatty acids, polyunsaturated fatty acids (n3PUFAs), and carbohydrate protein, participating in the increased de novo fatty acid synthesis. While some key enzymes, such as acetyl-CoA carboxylase (ACC), fatty acid synthase (FAS), stearoyl-CoA desaturase-1 (SCD-1) and diacylglycerol acyltransferase2 (DGAT-2), and some key transcription factors, such as sterol regulatory element-binding protein 1 (SREBP-1), insulin induced gene-1 (Insig-1) and carbohydrate-responsive element-binding protein (ChREBP), play important roles in de novo lipogenesis as the intrahepatic mechanisms in NAFLD ${ }^{(66)}$. The excessive fat depositions in the liver not only due to increased fatty acid synthesis, but also affected by the decreased mitochondrial $\beta$ oxidation, decreased clearance of VLDL or these factors in combination ${ }^{(150)}$. Studies showed that hepatic fat from the de novo pathway is less than $5 \%$ under basal conditions, however, up to $30 \%$ of fat deposited from de novo lipogenesis in the liver under pathological conditions $(66,151)$.

In addition, lipid metabolic disturbance in liver is also associated with the Inflammation, oxidative stress, fibrosis and ER stress ${ }^{(152)}$, increasing the complexity of the molecular and pathological mechanism of liver. It is still difficult to understand the lipid metabolism in the development of NAFLD. The common management of lipid disorder in diabetes and NAFLD is directed at improving glycemic control, altering dietary composition, 
and reducing calories intake ${ }^{(153)}$. Hence, study on drug development for lipid metabolic regulation in liver is of great importance to the prevention and treatment of NAFLD.

\section{The role of AMP-activated protein kinase (AMPK) in diseases}

The AMP-activated protein kinase (AMPK) is a ubiquitously expressed serine/threonine protein kinase that is well-known as a central regulator of multiple metabolic pathways and may have therapeutic importance for treating obesity, insulin resistance, T2D, NAFLD, and cardiovascular disease. AMPK plays a critical role in increasing glucose uptake, fatty acid oxidation (FAO), mitochondrial biogenesis, and autophagy, and suppressing the synthesis of fatty acids, cholesterol, via regulating metabolic related proteins ${ }^{(154-156)}$. AMPK is a heterotrimeric complex composed of catalytic $\alpha$-subunit $(\alpha 1, \alpha 2)$ and regulatory $\beta-(\beta 1, \beta 2)$ and $\gamma$-subunits $(\gamma 1, \gamma 2, \gamma 3)$ with multiple isoforms for each subunit. These subunits are encoded by distinct genes and have unique tissue specific expression profiles ${ }^{(122,157)}$. Compelling evidences indicate that AMPK plays an essential role in the development of NAFLD. Liver specific overexpression of AMPK $\alpha 1$ in T2D protected against the steatosis reflected by reduction of lipogenic gene expression and TG content ${ }^{(158)}$. Overexpression of AMPK $\alpha 1$ in hepatocytes not only increased the fatty acid clearance via mitochondrial FAO as indicated by CPT-1 expression, but also decreased TG accumulation ${ }^{(159)}$. Liver-specific knockout of AMPKa2 showed hyperglycemia and elevated hepatic glucose production compared to controls ${ }^{(160)}$. Mechanistically, AMPK promotes the lipid metabolism in liver via regulating the important enzymes and transcription factors of lipid biosynthesis and FAO, such as FAS, ACC, SREBP-1 and SREBP-2 ${ }^{(155,161)}$. AMPK also regulates some mediators for the control of total mitochondrial content, quality, and function, such as PPAR-y1 coactivator (PGC-1 $\alpha$ ) and histone deacetylases (HDAC) and the unc-51-like autophagy activating kinase $1(\mathrm{ULK} 1)^{(162)}$. In addition to altering metabolic pathways, AMPK also triggers key proteins 
in controlling inflammatory cell proliferation, ER stress and oxidative stress pathways, including NF-kB, mTOR, and Nrf2 activity ${ }^{(133,163,164)}$. Therefore, AMPK would be a critical therapeutic target for NAFLD.

The relationship between AMPK and Nrf2-mediated metabolic regulation has been investigated for many years. Many recent studies found that Nrf2 and AMPK interacted to regulate each other under different pathological and physiological conditions. For example, Mo et al showed that berberine activated the AMPK and Nrf2 pathway against inflammation in both lipopolysaccharide-shocked macrophages and mice, in which AMPK worked at the upstream of $\mathrm{Nrf}^{(165)}$. However, Sids et al demonstrated that $\mathrm{Nrf2}$ was independent of AMPK signaling pathways in human hepatocarcinoma cells treated with AMPK activator AICAR ${ }^{(117)}$. In Yang's study, alpha-lipoic acid improved high-fat dietinduced hepatic steatosis by modulating Nrf2-mediated antioxidation and SIRT1/LKB1/AMPK pathway-mediated lipid metabolism ${ }^{(87)}$. Thus, the interaction of Nrf2 and AMPK has not been clearly clarified, especially after stimulation by FGF1.

In this study, our results showed that FGF1 prevented NAFLD along with upregulation of Nrf2- and AMPK-mediated signaling pathways. However, Nrf2 silencing only abolished FGF1 protection against Pal-induced hepatic oxidative stress. Thus, we hypothesized that AMPK-mediated signaling pathway would be critical for FGF1 protection against NAFLD in T2D.

\section{MATERIALS AND METHODS}

\section{Primary mouse hepatocyte isolation and culture}

Primary mouse hepatocytes were isolated using a method described previously ${ }^{(166)}$. Briefly, Hepatocytes were isolated from C57/BL6J mice by in situ digestion under aseptic conditions. The liver was perfused with ethylene glycol-bis(2-aminoethylether)-N,N,N',N'tetraacetic acid (EGTA) solution (10 mM HEPES, $5 \mathrm{mM}$ glucose, $138 \mathrm{mM} \mathrm{NaCl}, 5.4 \mathrm{mM}$ 
$\mathrm{KCl}, 28.3 \mathrm{mM}$ NaHCO3, 0.12 mM Na2HPO4, 0.56 mM NaH2PO4 and 0.5 mM EGTA, pH 7.4) and collagenase solution (10 mM HEPES, $138 \mathrm{mM} \mathrm{NaCl}, 5.4 \mathrm{mM} \mathrm{KCl}, 28.3 \mathrm{mM}$ $\mathrm{NaHCO}$, 0.12 mM Na2HPO4, $0.56 \mathrm{mM} \mathrm{NaH2PO4,} \mathrm{containing} 0.0857 \mathrm{U} / \mathrm{ml}$ collagenase D (Roche Diagnostics, Indianapolis, IN) and $3.8 \mathrm{mM} \mathrm{CaCl} 2, \mathrm{pH} 7.4$ ). The isolated hepatocytes were washed with HBSS (Gibco BRL, Life Technologies, Inc., NY) and then were cultured at a density of $20 \times 10^{4}$ cells/dish after the cell viability was assessed by the trypan blue exclusion test. Primary mouse hepatocyte was cultured in Waymouths medium supplemented with $5 \%(\mathrm{w} / \mathrm{v})$ fetal bovine serum (FBS) (Gibco BRL, Life Technologies, Inc.), antibiotic-antimycotic (Gibco 100 units $/ \mathrm{mL}$ of penicillin, $100 \mu \mathrm{g} / \mathrm{mL}$ of streptomycin, $0.25 \mu \mathrm{g} / \mathrm{mL}$ of Fungizone) and ITS supplement (VWR).

After AMPKa1/2-siRNA transfection, primary mouse hepatocytes were induced by $100 \mu \mathrm{M}$ Pal with or without FGF1 ${ }^{\mathrm{WT}}$ and FGF1 $\triangle^{\mathrm{HBS}}$ treatment for 12 hours as described in HepG2 cells. Then cells were collected to observe the oxidative stress and lipid metabolism after FGF $1^{\mathrm{WT}}$ and $\mathrm{FGF} 1{ }^{\mathrm{HBS}}$ administration when AMPK silencing.

\section{AMPKa1/2-siRNA transfection}

Knockdown of AMPKa1/2 was performed using small interfering RNAs (siRNAs) targeting AMPKa1/2 (Santa Cruz Biotechnology, CA) according to the manufacturer's protocol. The scramble siRNA sequences were used as control. HepG2 cells or primary hepatocytes were seeded at a density of $20 \times 10^{4}$ cells/well in 6 -well plates were transfected with AMPKa1/2-siRNA using lipofectamine 2000 reagent (Invitrogen) at a final concentration of $100 \mathrm{nmol} / \mathrm{L}$ in Opti-MEM (GIBCO BRL) for 6 hours, respectively. Then, cells were cultured in normal medium for additional 16 hours to determine the knockdown efficiency. 


\section{Statistical analysis}

Statistical analyses were performed using the statistical software package, GraphPad Prism version 6, (GraphPad Software Inc., San Diego, CA, USA). Data are expressed as mean \pm SEM. Statistical significance was evaluated using the unpaired twotailed Student $t$ test or one-way analysis of variance. Differences were considered significant at a $\mathrm{P}$ value $<0.05$.

\section{RESULTS}

\section{AMPK silencing abolished the protective effects of FGF1 against Pal-induced oxidative stress and lipid disorder in primary hepatocytes}

To detect the role of AMPK in FGF1-mediated inhibiting effects on hepatic lipotoxicity, AMPK knockdown was performed using specific siRNA against AMPKa in mouse primary hepatocyte. Compared to control-siRNA, AMPKa-siRNA-mediated knockdown of AMPKa remarkably reduced AMPK expression (Fig. 12B,C) and phosphorylation (Fig. 12B,D), which was accompanied by downregulation of its downstream target genes ACC (Fig. 12B,F) and SREBP-1 (Fig. 12B,E) phosphorylation. Furthermore, knockdown AMPKa dramatically aggravated Pal-induced lipid accumulation, reflected by increased TG content compared with control-siRNA treatment (Fig. 12A), and completely abolished the preventive effects of both FGF1 $\triangle$ HBS and FGF1 ${ }^{\text {WT }}$ against lipid accumulation (Fig. 12A) and lipogenic genes upregulation (Fig. 12B,H-J), and FAO gene downregulation. More importantly, knockdown AMPKa also aggravated Pal-induced oxidative stress, reflected by MDA production compared with control-siRNA treatment (Fig. 13A), and completely abolished the preventive effects of both $\mathrm{FGF} 1^{\triangle \mathrm{HBS}}$ and $\mathrm{FGF} 1^{\mathrm{WT}}$ against oxidative stress-induced by Pal in primary hepatocytes (Fig. 13A). This was accompanied by almost complete attenuation of Nrf2 nuclear translocation (Fig. 13B,C) and its downstream genes expression (Fig. 13B,D-F) 
under basal and both FGF1 ${ }^{\mathrm{HBS}}$ and FGF1 ${ }^{\mathrm{WT}}$ stimulated conditions, but without significant effects on total Nrf2 (Fig. 13B,D) and CAT (Fig. 13B,G) expression. These results support the notion that AMPK plays a central role in FGF1 preventing from Palinduced hepatic lipid metabolic disorder and oxidative stress.

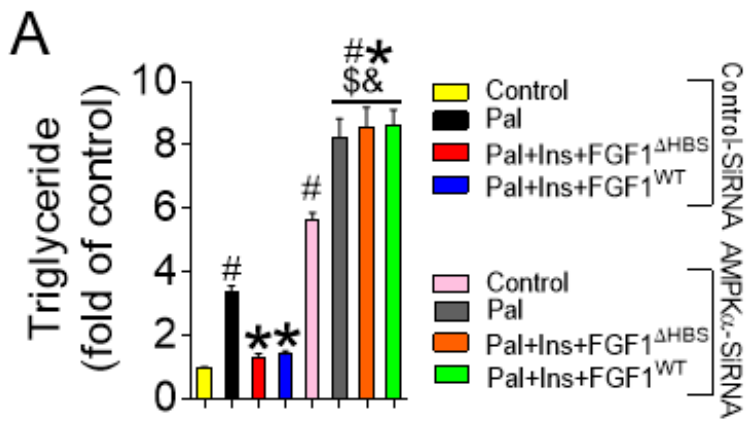

B

Control-SiRNA AMPKa-SiRNA Palmitate $-+++++++\leqslant$ Insulin - - + + - + +

FGF1 $\triangle$ HBS - - + - - + FGF1WT
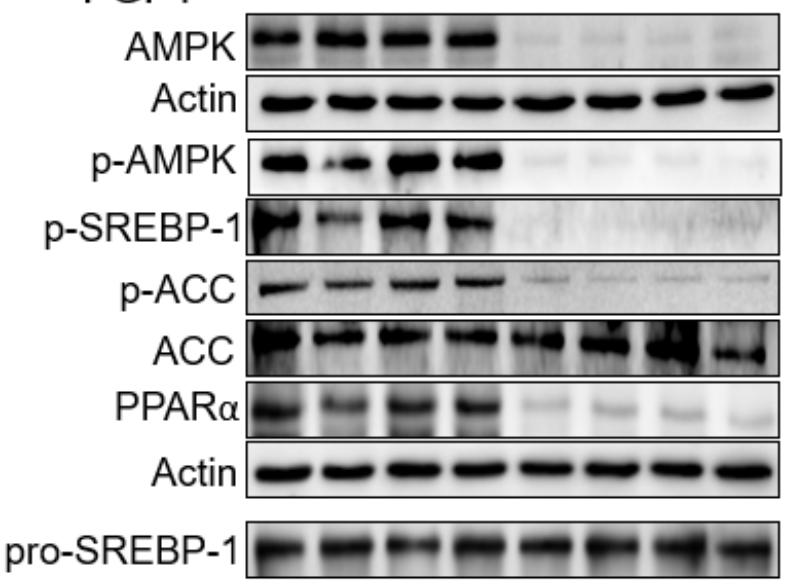
m-SREBP-1

FAS SCD-1 Actin
C

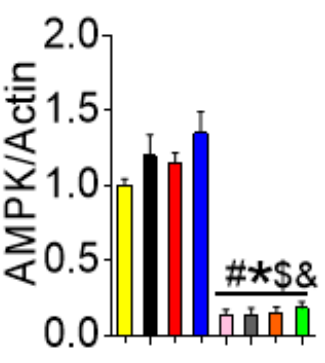

E
D

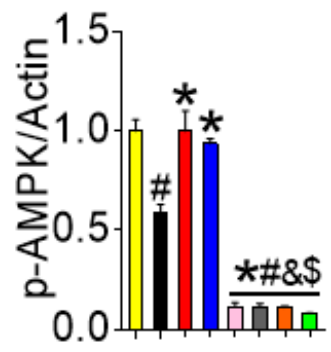

$\mathrm{F}$ 20.0 ||W|||

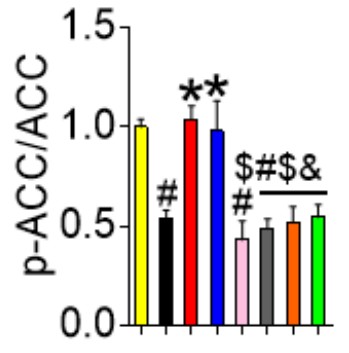
G

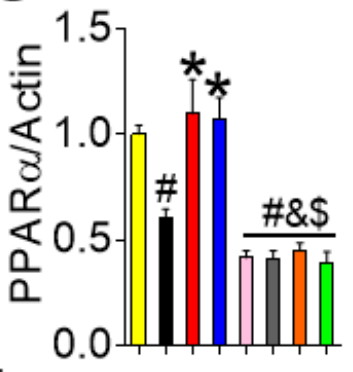

$\mathrm{H}$
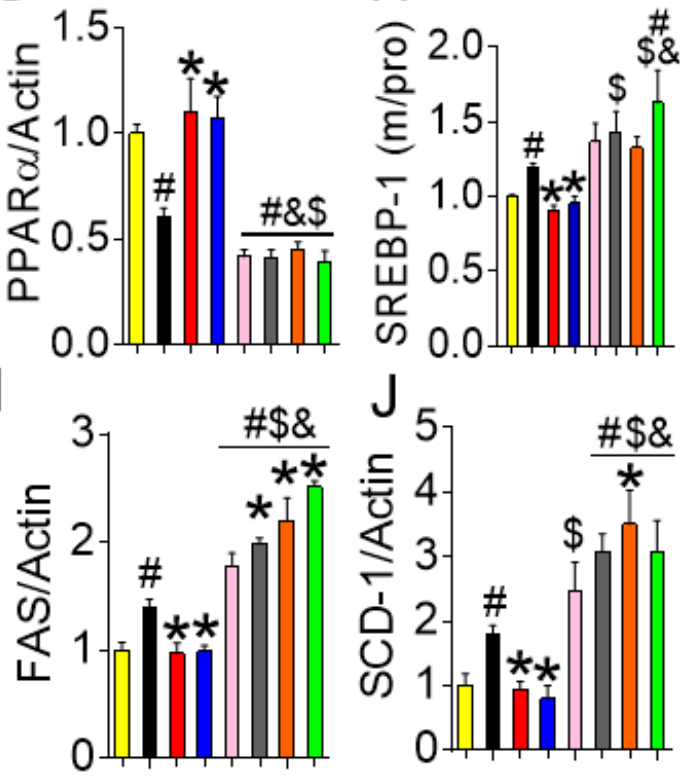
Fig. 12 AMPK silencing abolished the protective effects of FGF1 against PalInduced lipotoxicity in primary mouse hepatocyte. (A) Triglyceride contents. (B) Protein expressions of AMPK signaling pathway ( $p-A M P K / A M P K, p-A C C$ and $p$-SREBP-1), PPARa and lipogenic genes (m/pro SREBP-1, FAS, SCD-1) in primary mouse hepatocyte. (C-J) The quantitative analysis of Western blot by densitometry. Quantitative data are expressed as mean \pm SEM, $n=3-5 .{ }^{\#} P<0.05$ vs. Control-Control-SiRNA; ${ }^{*} P<0.05$ vs. PalControl-SiRNA; ${ }^{\&} P<0.05$ vs. FGF1 ${ }^{W T}$-Control-SiRNA; ${ }^{\$} P<0.05$ vs. FGF1 ${ }^{H B S}$-ControlSiRNA.

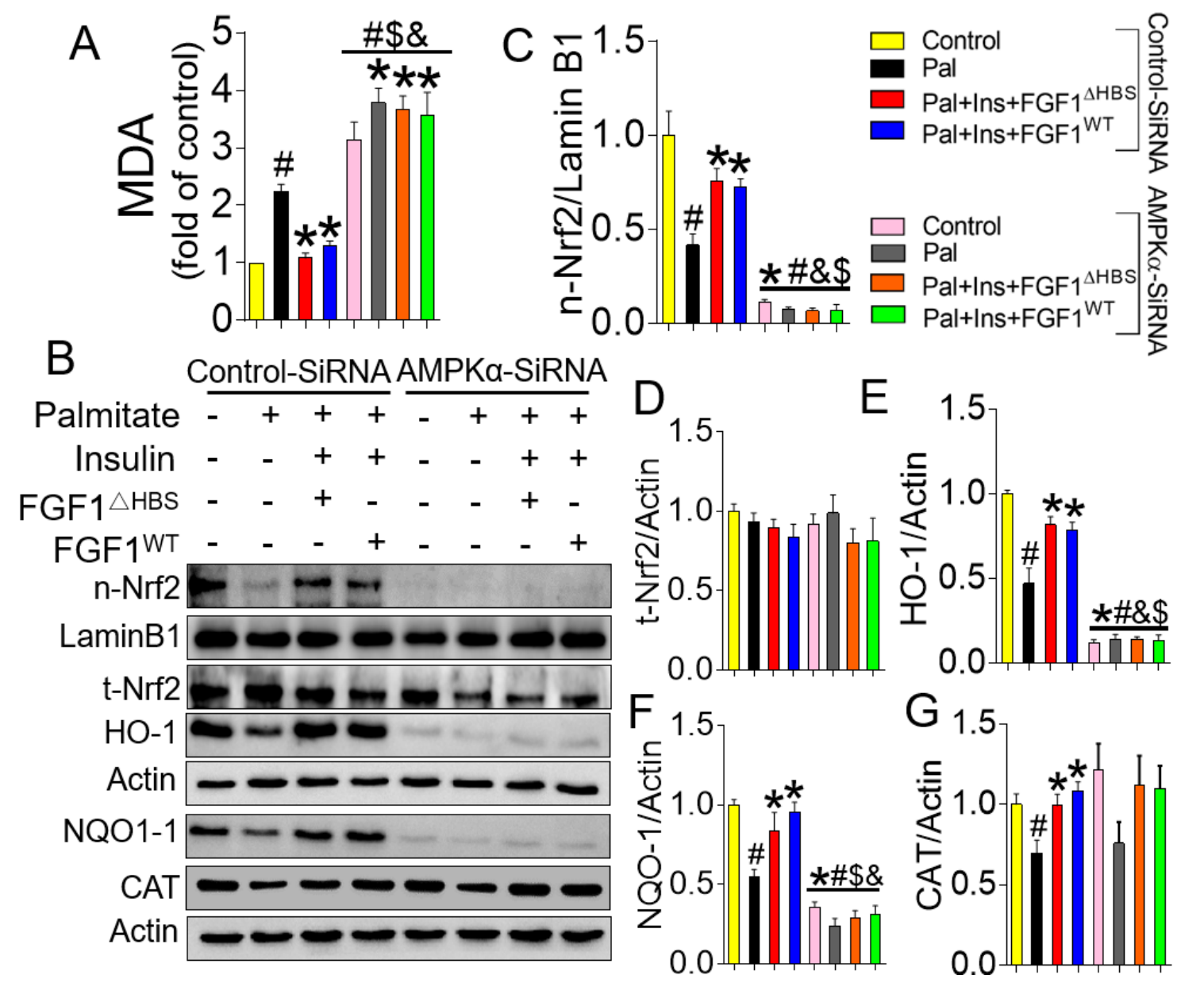

Fig. 13 AMPK silencing abolished the protective effects of FGF1 against PalInduced oxidative stress in primary mouse hepatocyte. (A) MDA contents in primary 
hepatocyte. (B) Protein expressions of Nrf2-mediated anti-oxidative stress signaling pathway (n-Nrf2, t-Nrf2, HO-1, NQO-1 and CAT) in primary mouse hepatocyte. (C-G) The quantitative analysis of $n-N r f 2, t-N r f 2, H O-1, N Q O-1$ and CAT Western blot results by densitometry. Quantitative data are expressed as mean \pm SEM, $n=3-5 .{ }^{\#} P<0.05$ vs. Control-Control-SiRNA; ${ }^{*} P<0.05$ vs. Pal-Control-SiRNA; ${ }^{\circledR} P<0.05$ vs. FGF1 ${ }^{W T}$-ControlSiRNA; ${ }^{\$} P<0.05$ vs. FGF $1{ }^{\text {HBS }}$-Control-SiRNA.

\section{DISSISION}

AMPK is a central metabolic regulator of lipid and glucose metabolic homeostasis in many metabolic diseases. Activation of AMPK leading to the phosphorylation of key metabolic substrates and transcriptional regulators plays a critical role in fatty acids synthesis, glucose uptake, FAO and mitochondrial biogenesis. In addition, AMPK also involves in the regulation of the inflammation, oxidative stress and apoptosis through direct phosphorylation of multiple targets ${ }^{(122,154,167)}$.

The results in Chapter III indicated that knockdown of Nrf2 abolished the antioxidative stress effects of FGF1 but did not affect the inhibition on lipid accumulation and upregulation on AMPK-signaling pathway of FGF1 in hepatic cells. In this study, we further demonstrated that knockdown of AMPKa abolished not only FGF1 protection against Palinduced oxidative stress and Nrf2-mediated antioxidative signaling pathway, but also FGF1 protection against Pal-induced lipid disorder and lipid metabolic signal dysregulation (Fig.12A and 13A).

Collectively, these findings suggest that AMPK is required for FGF1 protection against Pal-induced lipid metabolic dysregulation and oxidative stress in hepatic cells. 


\section{CHAPTER IV}

THE THERAPTUTIC EFFECTS OF A NOVEL FIBROBLAST GROWTH FACTOR 1 VARIANT ON NON-ALCOHOLIC FATTY LIVER DISEASE IN TYPE 2 DIABETES

\section{INTRODUCTION}

With the increasing incidence of obesity and T2D in every age group, the global prevalence of NAFLD varies from $20-30 \%{ }^{(168)}$. A report from the Mayo Clinic pointed out that people in their age of 40 s and 50 s show the highest incidence of either NAFLD or T2D, which can be mainly explained by the delayed diagnosis ${ }^{(168)}$. In NAFLD, most people have no symptoms until they come to the medical attention. The progression of NAFLD can be prevented in patients at the early stage with symptoms of enlarged liver, fatigue and pain in the abdomen. Without the timely intervention, inflammation and scarring of the liver can occur over time. The advanced symptoms that are not easy to be cured include the abdominal swelling, enlarged blood vessels and spleen, yellow skin and eyes ${ }^{(169)}$. In T2D, the signs and symptoms often develop slowly. People can have T2D and not know it for years until an acute medical condition occurs because of the unawareness of the diabetic symptoms including the increased thirst and hunger, weight loss, fatigue and blurred vision ${ }^{(170-174)}$. Patients may take attention to T2D management only when the complications appear.

All aged diabetic patients have a high burden of comorbidities, and more susceptible to complications, as well as patients with NAFLD. T2D is associated with chronic complications throughout the body and with significantly accelerated rates of several microvascular complications such as nephropathy, retinopathy, and neuropathy, and 
atherosclerosis, leading to the physical disability, cognitive impairment and malnutrition $(175,176)$. NAFLD progresses to NASH in about $20 \%$ of cases, of which $20-25 \%$ may progress on to hepatic fibrosis and cirrhosis $^{(93)}$. A small proportion of individuals develop advanced fibrosis, cirrhosis can lead to fluid buildup in the abdomen, veins swelling, drowsiness and worsen to hepatic encephalopathy, even end stage liver disease, hepatocellular carcinoma $(\mathrm{HCC})^{(177)}$. All these complications contribute to the excess morbidity and mortality in aged individuals with NAFLD and diabetes.

Therefore, clinically, it is urgent and important to pay more attention to discover therapeutic drugs. To ensure greater clinical relevance, we thus choose the aged $\mathrm{db} / \mathrm{db}$ model to determine the therapeutic effects of FGF1 $\triangle^{\mathrm{HBS}}$ against NAFDL in T2D.

\section{MATERIALS AND METHODS}

\section{Animal model}

Late-stage 9-month-old male $\mathrm{db} / \mathrm{db}$ mice were administered with FGF1 $\triangle^{\mathrm{HBS}}$ or PBS via intraperitoneal injection $(0.5 \mathrm{mg} / \mathrm{kg})$ every other day for 3 months. At the indicated timepoints, the blood glucose levels were determined by FreeStyle complete blood glucose monitor (Abbott Diabetes Care Inc., Alameda, CA). All mice were housed under a 12:12h light/dark cycle at controlled temperature. All experimental procedures were approved by the Institutional Animal Care and Use Committee of the University of Louisville. All the other experiments were performed following the same protocol as described in CHAPTER I.

\section{RESULTS}

\section{Therapeutic Effects of FGF1 ${ }^{\mathrm{HBS}}$ on NAFLD in aged $\mathrm{db} / \mathrm{db}$ mice}

To explore the clinic translational potential, we further investigate whether FGF1 ${ }^{\mathrm{HBS}}$ is sufficient to reverse the exacerbated liver injury in late-stage $\mathrm{db} / \mathrm{db} T 2 \mathrm{D}$ 
mice. We treated 9-month-old $\mathrm{db} / \mathrm{db}$ mice with $\mathrm{FGF}{ }^{\triangle \mathrm{HBS}}(0.5 \mathrm{mg} / \mathrm{kg}$ body weight $)$ every other day for 3 months. Pharmacological administration of FGF1 ${ }^{\triangle H B S}$ almost completely normalized the blood glucose levels (Fig. 14A) and significantly improved insulin sensitivity (Fig. 14B, C). FGF1 $\triangle \mathrm{HBS}$ treatment slightly reduced body weight (data not shown), but markedly reduced liver seizes and weight (Fig. 15A, B) and reversed liver steatosis (Fig. 15C) and lipid accumulation (Fig. 15D). Furthermore, FGF1 $\triangle^{\mathrm{HBS}}$ treatment also prevented liver injury (Fig. 15E, F) and suppressed hepatic inflammation (Fig. 15GJ) and oxidative stress (Fig. 16A).

To validate the universal mechanism of the efficacy of FGF1 ${ }^{\triangle H B S}$ on NAFLD, the hepatic antioxidative and lipid metabolic markers were also examined. Likewise, FGF1 $\triangle \mathrm{HBS}$ treatment markedly increased Nrf2 nuclear translocation (Fig. 16B, C) and upregulated the expression of its downstream target genes (Fig. 16B, D-F). Furthermore, FGF1 $\triangle{ }^{\mathrm{HBS}}$ treatment significantly suppressed the activation of SREBP-1 (Fig. 17A, B) and the expression of its downstream target genes FAS, SCD-1 (Fig. 17C, D). In

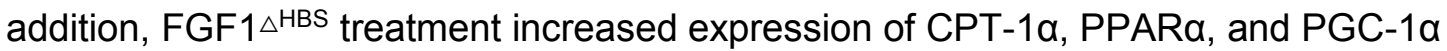
(Fig. 17A, E-G), which were accompanied by significant upregulation of AMPK (Fig. 17A, H) and ACC (Fig. 17A, I) and SREBP-1 (Fig. 17A, J). These results suggest that FGF1 ${ }^{\triangle \mathrm{HBS}}$ reverses NAFLD in late-stage T2D through the similar molecular pathways as seen in early-stage T2D. 

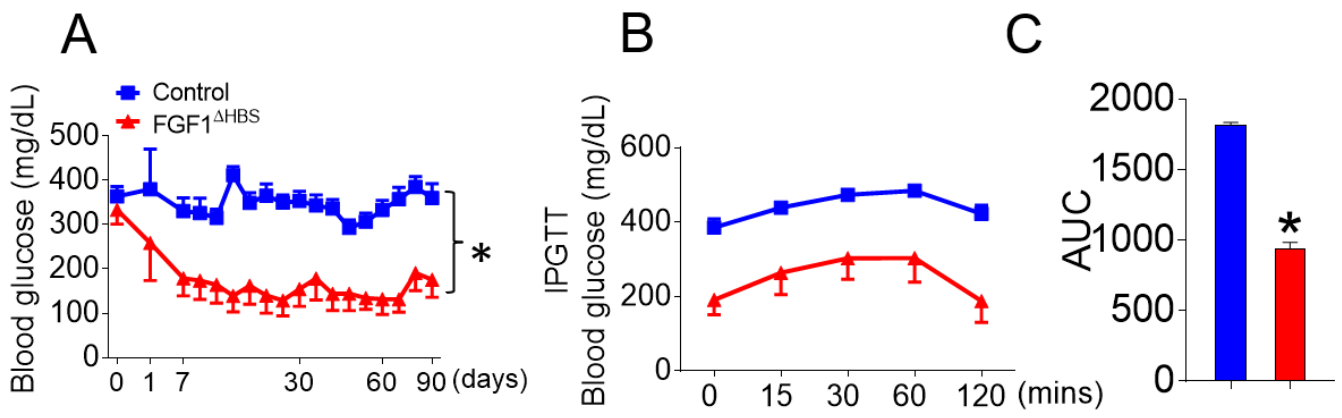

$\mathrm{B}$

C

Fig. 14 The effects of FGF1 $\triangle^{H B S}$ on blood glucose and insulin sensitivity in 9-monthold $d b / d b$ mice. (A) The blood glucose over the course of 3 months treatment of $d b / d b$ mice with $F G F 1^{A H B S}(0.5 \mathrm{mg} / \mathrm{kg}$ body weight, every other day). ( $B$ and $C)$ The Blood glucose levels in IPGTT and integrated area under the curve (AUC) for changes in blood glucose levels. Quantitative data are expressed as mean \pm SEM, $n=5-10$. ${ }^{*} P<0.05$ vs. $d b / d b$ mice. 


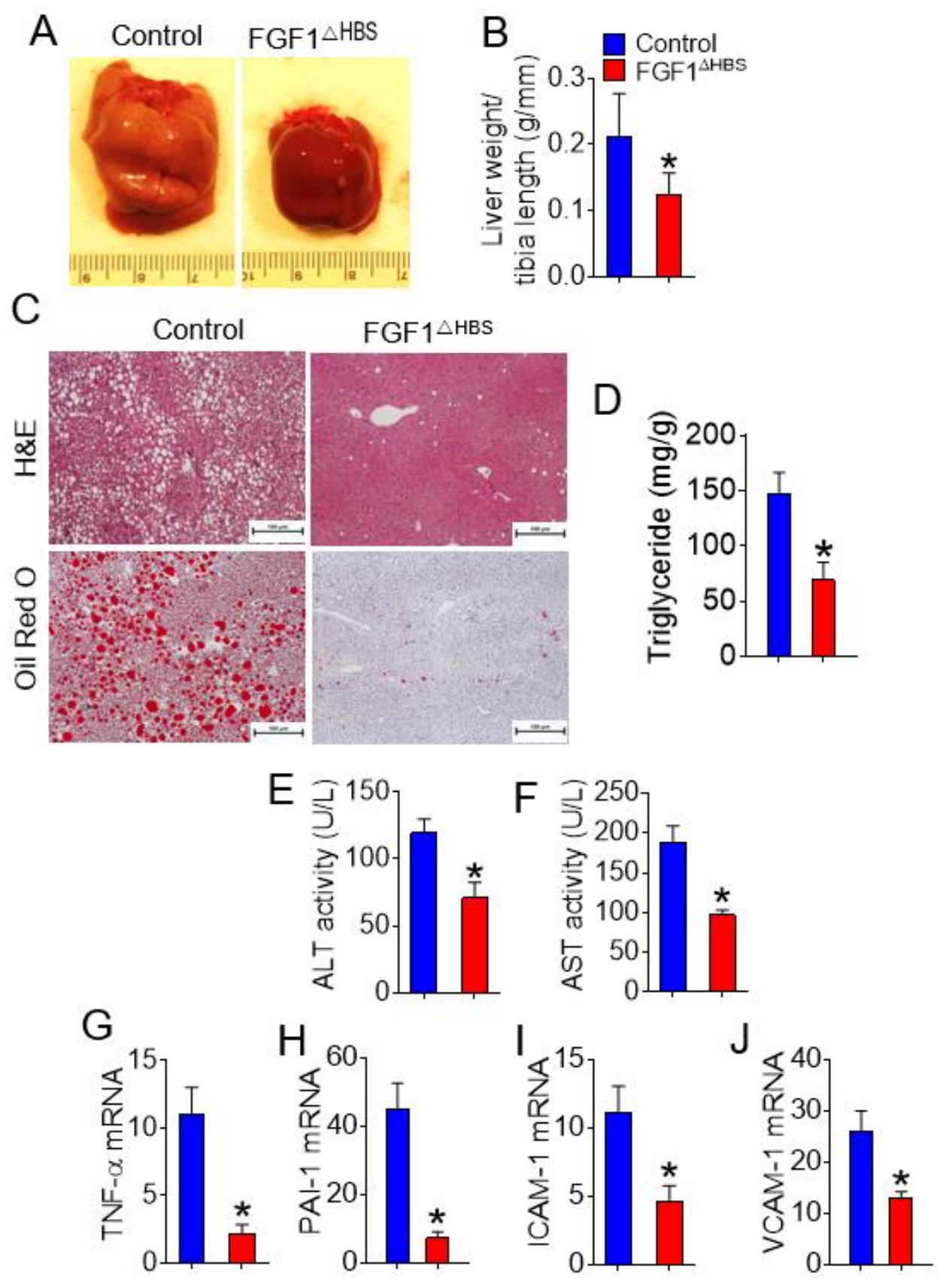

Fig. 15 The therapeutic effects of FGF1 ${ }^{H B S}$ on chronic NAFLD in 9-month old db/db mice. 9-month old db/db mice treated with FGF1 $\triangle^{H B S}(0.5 \mathrm{mg} / \mathrm{kg}$, every other day) for 3 months. ( $A$ and $B$ ) The liver size and weight. (C) Representative images of H\&E-staining and Oil Red O staining of liver sections (magnification: X100). (D) Hepatic TG content in db/db mice. (E and F) The serum ALT and AST. (G-J) Analysis for mRNA levels of hepatic 
inflammatory marker (TNFa, PAI-1, ICAM-1 and VCAM-1). Quantitative data are expressed as mean \pm SEM, $n=5-10 .{ }^{*} P<0.05 \mathrm{vs}$. $d b / d b$ mice.
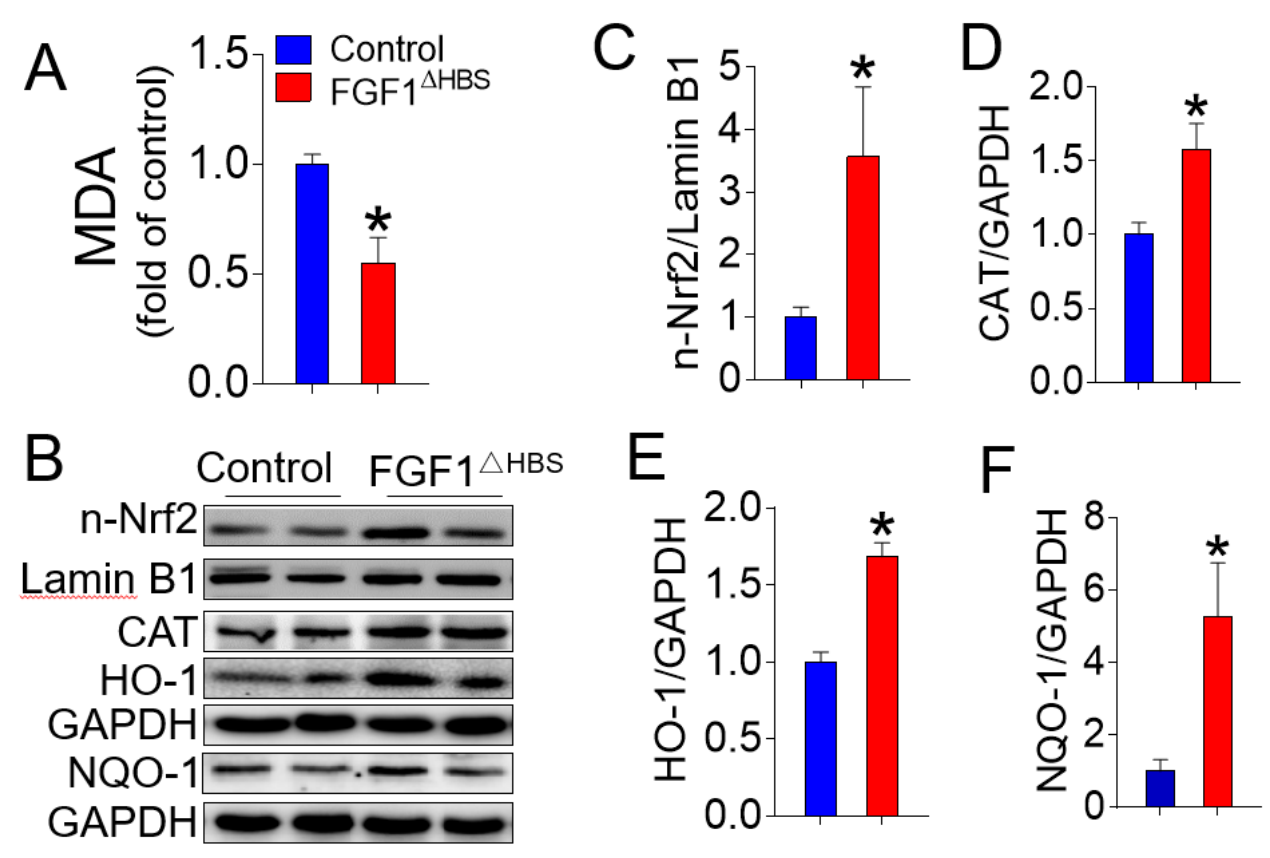

Fig.16 FGF1 $\triangle^{H B S}$ reversed hepatic oxidative stress in 9-month old db/db mice. (A) The hepatic TG content in db/db mice. (B) FGF1 $\triangle^{H B S}$ stimulated the Nrf2-mediated antioxidative stress signaling genes in on chronic NAFLD in $d b / d b$ mice. The protein expressions of $n-N r f 2, C A T, H O-1$ and NQO-1 were determined by Western blot. (C-F) The quantitative analysis of n-Nrf2, CAT, HO-1 and NQO-1 Western blot results by densitometry. Quantitative data are expressed as mean \pm SEM, $n=5-10 .{ }^{*} P<0.05$ vs. $d b / d b$ mice. 


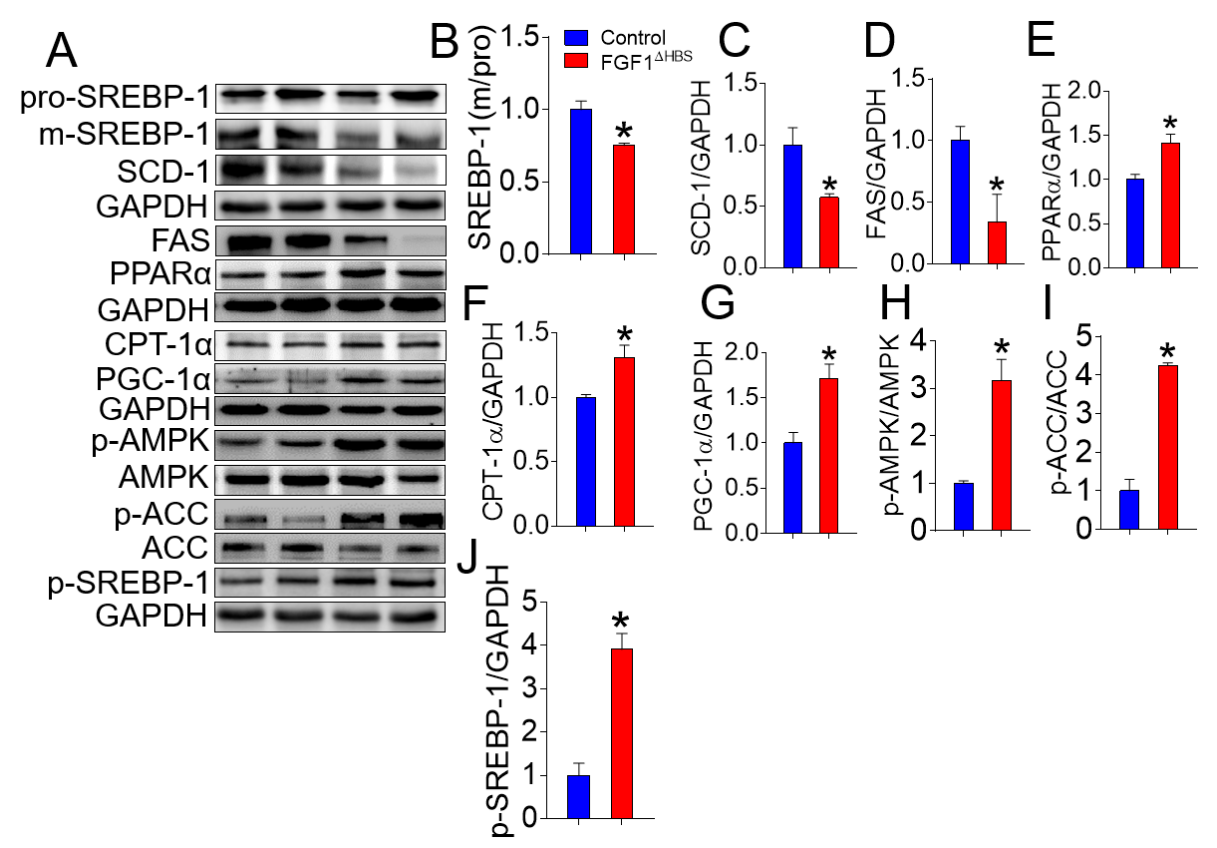

Fig.17 FGF1 $\triangle^{H B S}$ activated hepatic AMPK signaling pathway in 9-month old $d b / d b$ mice. (A) The expressions of AMPK signaling pathway related proteins (SREBP-1, FAS and SCD-1, CPT-1a, PGC-1a, PPARa, p-AMPK/AMPK, p-ACC and p-SREBP-1) were detected by Western blot. (B-J) The quantitative analysis of Western blot results by densitometry. Quantitative data are expressed as mean \pm SEM, $n=5-10$. ${ }^{*} P<0.05$ vs. $d b / d b$ mice.

\section{DISSISION}

Consistent with the preventive effects of FGF1 $\triangle{ }^{\mathrm{HBS}}$ on early-stage $\mathrm{db} / \mathrm{db}$ mice, here we clearly demonstrated that FGF1 $\triangle^{\mathrm{HBS}}$ normalized blood glucose levels, improved insulin sensitivity and markedly prevented liver injury in these late-stage $\mathrm{db} / \mathrm{db}$ mice, indicated by decreased hepatic TG levels, ALT and AST activity, and inflammatory marker expression (Fig. 14-15). These results validated the protection of FGF1 $\triangle \mathrm{HBS}$ against the late-stage NAFLD. Importantly, the mechanism studies showed that FGF1 $\triangle^{\text {HBS }}$ effectively activated AMPK-mediated Nrf2-antioxidative stress signaling pathways and lipid metabolic signaling pathways in those chronic liver diseases of aged db/db mice (Fig.16 and Fig. 17). 
Combined with the preventive data found above, we demonstrate that FGF1 $\triangle \mathrm{HBS}$ could be promising candidate drug for prevention and therapeutic against NAFLD in T2D without the undesired mitogenic side effects of FGF1 ${ }^{\mathrm{WT}}$. 


\section{CHAPTER V \\ OVERALL DISCUSSION AND CONCLUSIONS}

Several studies have indicated the potential metabolic function of FGF1 in diabetes and steatosis. However, the use of FGF1 in the treatment of metabolic syndrome is still limited due to its undefined mechanism and its potential risk of tumorigenesis. The goals of the study in this dissertation are to evaluate the preventive and therapeutic effects of a novel FGF1 non-mitogenic variant, FGF1 ${ }^{\triangle \mathrm{HBS}}$, on NAFLD in T2D, and to explore the underlying mechanisms. The outcomes of these studies strongly suggest that FGF1 ${ }^{\triangle H B S}$ can be a promising therapeutic agent for NAFLD therapy in T2D. Our results can be summarized as follows:

- FGF1 $\triangle^{\mathrm{HBS}}$ treatment prevented the liver injury and inhibited the hepatic oxidative stress via activation of Nrf2-mediated antioxidative signaling pathways.

- FGF1 $\triangle{ }^{\mathrm{HBS}}$ treatment reduced hepatic lipid accumulation by inhibiting lipogenesis and increasing fatty acid oxidation mediated via AMPK signaling pathways.

- Nrf2 activation played an important role for the anti-oxidative effect of FGF1, but was not required for the protective effects of FGF1 against palmitate-induced lipid metabolic disorder in HepG2 cells.

- AMPK played a critical role in FGF1 protection against Pal-induced oxidative stress and lipid disorder possibly via activating Nrf2-mediated antioxidative pathway and inhibiting SREBP-1-mediated lipid metabolic pathway in primary hepatocytes. 
FGF $1{ }^{\mathrm{HBS}}$ completely reversed the phenotype of NAFLD along with activation on Nrf2 and AMPK signaling pathways in late-stage T2D.

\section{Overall discussion}

As discussed above, our study demonstrated that $\mathrm{FGF} 1 \triangle \mathrm{HBS}$ is a promising therapeutic agent in the prevention/treatment of NAFLD in T2D. However, there are several limitations and questions remain to be answered. Some special findings should be further annotated:

\section{Whether the effect of FGF1 on NAFLD depends on its glucose lowering capability?}

In this dissertation, a typical type 2 diabetes model, $\mathrm{db} / \mathrm{db}$ mice are chosen to explore the functions and mechanisms of FGF1 in NAFLD. FGF1 ${ }^{\mathrm{HBS}}$ treatment not only reverse the hepatic injuries but also significantly lower the blood glucose to the normal levels in $\mathrm{db} / \mathrm{db}$ mice. One of the significant questions is if the effect of FGF1 on NAFLD depends on its glucose lowering ability. There are several possible explanations:

a) To exclude the influence of blood glucose in vivo, our study used palmitatetreated hepatic cell culture in vitro models, which could determine the direct effect of FGF1 on hepatocyte. The results suggested that FGF1 protected against the palmitate-induced oxidative stress and lipid disorder in both HepG2 cells and primary hepatocytes.

b) Our previous study demonstrated that FGF1 could ameliorate diabetic nephropathy in both T1D and T2D even without any effect on the blood glucose levels in T1D, suggesting that FGF1 protection against DN was independent of its blood glucose lowering capacity ${ }^{(26)}$.

c) As described in the OVERVIEW, several studies have showed that FGF1 exhibited protective effect against other diabetic complications in T1D without lowering the blood glucose. For examples, FGF1 ameliorated left ventricle dysfunction and reduced the 
myocardial apoptosis in diabetic cardiomyopathy of STZ-induced T1D(52, 53). FGF1 promoted wound healing in diabetic ulcer of T1D by enhancing the expression of TGF- $\beta$ and PCNA and inhibiting oxidative stress ${ }^{(41)}$.

Based on these studies, we speculate that the effect of FGF1 $\triangle^{H B S}$ on NAFLD is related to, but independent of its glucose lowering capability. NAFLD models without hyperglycemia should be considered to determine the direct effects and mechanisms of FGF1 $\triangle{ }^{\mathrm{HBS}}$ in fatty liver diseases in future studies.

\section{Whether FGF1 directly regulates hepatic de novo lipogenesis and fatty acid $\beta$ - oxidation in the protection against NAFLD?}

Several studies have demonstrated that exogenous excessive palmitate induced hepatic lipotoxicity, which was characterized by ROS accumulation, mitochondrial dysfunction, damaged fatty acid oxidation, and increased triglyceride accumulation $(178,179)$. This dissertation utilized this model to mimic diabetes-induced lipotoxicity in liver in T2D. Our results showed that both $\mathrm{FGF} 1^{\mathrm{WT}}$ and FGF1 ${ }^{\mathrm{HBS}}$ prevented Pal-induced oxidative stress via upregulating Nrf2 mediated antioxidative signaling pathway and prevented Palinduced lipid metabolic disorder via increasing fatty acid oxidation and inhibiting the lipogenic signaling pathways.

Although this dissertation and other previous studies have shown Pal treatment could induce hepatic lipogenesis and inhibit fatty acid $\beta$-oxidation ${ }^{(159,180,181)}$, this Palinduced model is not a direct and specific in vitro model to define the mechanism of FGF1 in lipid metabolism, especially in de novo lipogenesis. Hepatic de novo lipogenesis is the biosynthetic process of fatty acids from acetyl-CoA subunits that are produced from the dietary glucose, high-carbohydrate or fructose ${ }^{(182)}$. Many key enzymes and transcription factors, such as ACC, FAS, SREBP-1, are strongly involved in the de novo lipogenesis by converting the acetyl-CoA into malonyl-CoA, subsequently, to fatty acids. Therefore, 
glucose is the main and direct lipogenic substrate that drives de novo lipogenesis ${ }^{(66)}$ and nutritionally regulate the key enzymes and transcription factors ${ }^{(183,184)}$. To fully understand the mechanism of FGF1 in regulating lipid metabolism, the high glucose plus insulin cell culture models $^{(155,185)}$ should be considered in future studies.

\section{Whether AMPK plays a critical role in FGF1 protects against NAFLD in vivo?}

AMPK is a well-known central regulator and therapeutic target for many metabolic diseases. In addition to activating metabolic processes, AMPK inhibits inflammation, ER and oxidative stress, and activates autophagy ${ }^{(167)}$. The question becomes whether AMPK plays a critical role in FGF1 protection against NAFLD in vivo.

a) The metabolic functions of FGF1 are newly discovered and its target organs and/or tissues have not been clearly defined. This dissertation firstly indicated that FGF1 significantly activated the phosphorylation of hepatic AMPK and its downstream genes in vivo and in vitro. Reference to the well-studied endocrine growth factor FGF21, its energy metabolic functions are strongly associated with AMPK pathways ${ }^{(72,186)}$.

b) The present study also indicated that FGF1 inhibited the oxidative stress in NAFLD via activating Nrf2-mediated antioxidative signaling pathway. Recent studies suggested that Nrf2 is not only an important anti-oxidative factor, but also a potential target to the metabolic syndrome ${ }^{(137,138)}$. Distinguishing the functions between AMPK and Nrf2 is important to define the targets for FGF1. According to previous studies, Nrf2 and AMPK can interact to regulate each other at different pathological and physiological conditions ${ }^{(87}$, 117, 165, 187). According to our in vitro study, knockdown of AMPK in hepatocyte abolished both Nrf2-mediated anti-oxidative signaling pathway and SREBP-1-mediated lipid metabolic pathway, suggesting that AMPK is an upstream factor of Nrf2 and SREBP-1 for FGF1 protection against Pal-induce hepatic lipotoxicity. To elucidate the critical role of 
AMPK in FGF1 protection against NAFLD, liver-specific AMPK knockout model could be considered in future studies.

\section{Which FGF receptor mediates the function of FGF1 $\triangle^{H B S}$ in the activation of AMPK against NAFLD?}

FGFs carry out their diverse functions by binding and activating specific FGF receptors (FGFRs) ${ }^{(12)}$. In addition, AMPK as a central metabolic sensor can be regulated by many major upstream kinases, such as liver kinase B1 (LKB1), calmodulin-dependent protein kinase kinase 2 (CaMKK2) and TGF- $\beta$-activated kinase (TAK1) ${ }^{(188,189)}$. The goal of present study was not to define the binding partners of FGF1 $\triangle^{\mathrm{HBS}}$. However, several explanations are possible based on previous studies:

a) As introduced in the OVERVIEW, FGF1 is considered the universal ligand that actively bind to the four different FGFRs (FGFR1-FGFR4) ${ }^{(9,10)}$. FGFR1-FGFR4 are positively expressed in normal liver ${ }^{(190)}$ and these receptors-mediated signaling pathways are essential for liver pathophysiology ${ }^{(191)}$. In hepatocytes, FGFR4 is the most abundant FGFR that acts as a regulator of bile acid homeostasis and protects liver from fibrosis ${ }^{(192)}$. Loss or overexpression of FGFR1, FGFR2 and FGFR3 in hepatocytes also strongly impairs the liver homeostasis and regeneration ${ }^{(191,193)(194)}$.

b) Previous studies suggested that the endocrine FGF15/19 acts on the FGFR4/ $\beta$ Klotho complex showing the beneficial effects on liver metabolism. however, it also stimulated hepatocyte proliferation through an FGFR4-dependent mechanism ${ }^{(195)}$. Meanwhile, FGFR1c isoform is important for the in vivo actions of endocrine FGF21. A previous study showed that the endocrine FGF21 activated the AMPK signaling pathway in the target tissues through FGFR1/ $\beta$-klotho signaling directly ${ }^{(196)}$.

c) Recent study showed that the blood glucose-lowering effects of FGF1 were mediated through FGFR1, FGF1 failed to lower glucose levels in the FGFR1 knockout 
mice $^{(9)}$. Consistent with this, a FGF1 analogue FGF1 ${ }^{\Delta N T}$ (FGF1 L29-D155) similarly failed to affect blood glucose levels in FGFR1 knockout mice ${ }^{(9)}$, further supporting the notion that FGFR1-mediated signaling is required for the glucose-lowering effects of parenteral FGF1 ${ }^{(9)}$.

d) In our previous study, we found that compared to the FGF1 ${ }^{\mathrm{WT}}$, FGF1 $\triangle \mathrm{HBS}$ diminished its ability to induce heparan sulfate-assisted FGFR1 dimerization and activation, resulting in a diminished ability to induce FRS2 phosphorylation, the major substrate of FGFRs, and the downstream ERK activation, in both adipoctyes and hepatocytes $^{(85)}$.

Taken together, we speculate that FGFR1 is the major receptor mediating the metabolic function of FGF1 in liver, as well as in adipose tissue, which needs to be verified in future studies.

\section{The optimal dose of FGF1 ${ }^{H B S}$}

The dose-response results in our previous study clearly showed that an acute injection of FGF1 ${ }^{\mathrm{WT}}$ and FGF1 ${ }^{\mathrm{HBS}}$ at the dose of $0.5 \mathrm{mg} / \mathrm{kg}$ body weight significantly lowered blood glucose levels, and this effect lasted up to to 24 hours in $\mathrm{db} / \mathrm{db}$ mice without further lowering effects by increasing the dose to $1 \mathrm{mg} / \mathrm{kg}$ body weight(85). Furthermore, treatment of $\mathrm{db} / \mathrm{db}$ mice with $\mathrm{FGF} 1^{\mathrm{WT}}$ and $\mathrm{FGF} 1{ }^{\mathrm{HBS}}$ at a dose of $0.5 \mathrm{mg} / \mathrm{kg}$ every other day for 4 weeks resulted in the sustained glucose lowering and attenuating the hepatic steatosis $^{(85)}$. Hence, FGF1 $\triangle$ HBS delivery at the dose of $0.5 \mathrm{mg} / \mathrm{kg}$ every other day was applied in the present study. However, this dose might not be the optimal one for liver

protection, although we observed that $\mathrm{FGF} 1 \triangle \mathrm{HBS}$ at the dose of $0.5 \mathrm{mg} / \mathrm{kg}$ exhibited an antisteatotic effect. To achieve the optimal effects and establish the fundamental dose 
regime for future FGF1 $\triangle^{\mathrm{HBS}}$ clinical use, the dose- and time-dependent effects of FGF $1 \triangle \mathrm{HBS}$ on the prevention and reversal of NAFLD need to be addressed in future studies.

\section{Innovations}

The innovations in this dissertation can be summarized as follows:

- FGF1 $\triangle^{\mathrm{HBS}}$ can effectively prevent and reverse NAFLD by inhibiting oxidative stress and regulating lipid metabolism in T2D.

- AMPK may be a novel therapeutic target for FGF1 ${ }^{\mathrm{HBS}}$ prevention and reversal of NAFLD.

- The novel non-mitogenic variant $\mathrm{FGF} 1^{\triangle \mathrm{HBS}}$ may be an effective and safe alternative of $\mathrm{FGF} 1^{\mathrm{WT}}$ for the prevention and treatment of NAFLD and other diabetic complications.

\section{Limitations}

As above discussed, several limitations should be clarified in this dissertation.

1) NAFLD model: to elucidate the direct functions and mechanisms of FGF1 in the fatty liver, non-diabetic NAFLD models are needed in the future study.

2) Cell culture model: to understand the mechanism of FGF1 regulating lipid metabolism, the high glucose plus insulin-induced cell model should be considered.

3) Hepatic AMPK inactive model: to dissect the critical role of AMPK in FGF1 protection against NAFLD, liver specific AMPK knockout model should be used.

4) Side effects: the safety for FGF1 $\triangle^{\mathrm{HBS}}$ treatment of NAFLD should be evaluated systemically. 


\section{Future directions}

- Mechanistic study: In addition to regulating lipid metabolism in NAFLD of T2D, FGF1 is a potent insulin sensitizer that lowers the blood glucose and increases the insulin sensitivity in diabetes. The understanding of how FGF1 increases insulin sensitivity, as well as how FGF1 regulates glucose and lipid metabolism will be the key objects in our future studies.

- Clinical translation: this dissertation demonstrates that the novel non-mitogenic variant FGF1 $\triangle{ }^{\mathrm{HBS}}$ is a promising candidate drug to replace FGF1 ${ }^{\mathrm{WT}}$ to treat NAFLD in T2D without the risk of tumorigenesis. We will continually explore its potential for preventing other metabolic syndrome and their complications, such as obesity, and diabetic cardiovascular diseases in animals and even apply for a phase I clinical observation for the prevention of NAFLD for T2D patients.

\section{Conclusion}

In summary, our findings indicate that, in addition to its potent glucose-lowering and insulin-sensitizing effects, the novel non-mitogenic variant FGF1 $\triangle \mathrm{HBS}$ has not only preventive and but therapeutic effects on NAFLD in T2D via effectively inhibiting oxidative stress and improving lipid metabolism, which shows a great potential to replace the use of FGF1 ${ }^{\mathrm{WT}}$ to treat NAFLD in diabetes. Importantly, our studies provide new insight into the mechanisms by which FGF1 $\triangle \mathrm{HBS}$ prevents hepatic oxidative stress and steatosis in T2D. AMPK, that activates Nrf2-mediated antioxidative pathway and inhibits SREBP-1mediated lipid metabolic pathway, is a critical target for FGF1 protection against NAFLD in T2D (Fig. 18). From our perspective, a full understanding of FGF1 function in metabolic disorders requires further investigation of the multiple aspects of roles of AMPK or other molecular targets in these pathophysiological processes. This project provides 
fundamental evidence for FGF1 as a novel therapeutic approach to prevention of NAFLD via activating hepatic AMPK.

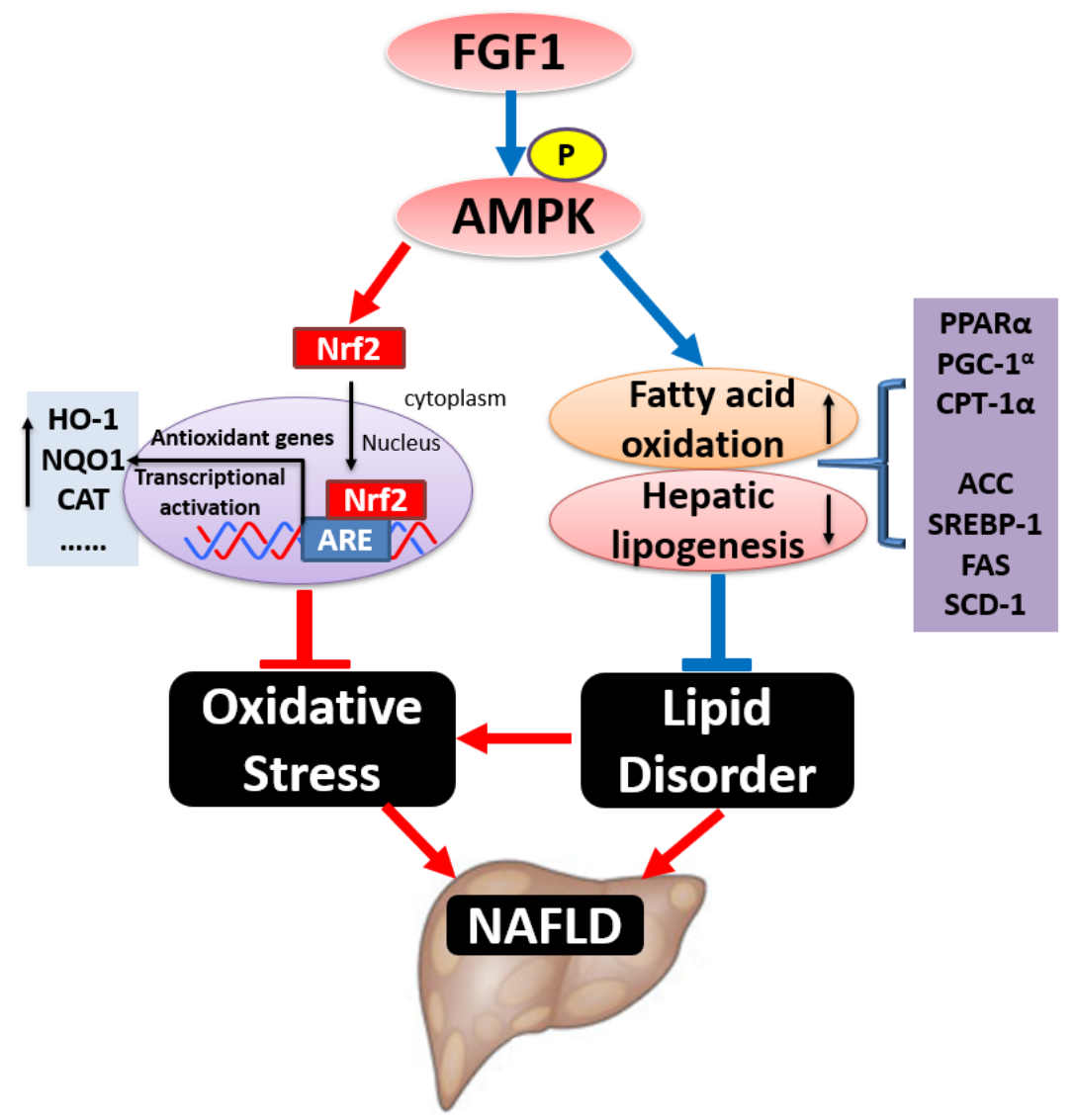

Fig. 18 A mechanistic illustration of FGF1 preventing diabetes-induced hepatic oxidative stress and lipid disorder via activating AMPK signaling pathways. FGF1 activates AMPK-mediated lipid metabolism and anti-oxidative stress signaling via inhibiting the lipid accumulation and upregulating lipid oxidation, as well as Nrf2-mediated anti-oxidative signaling pathway, thus prevents diabetes-induced hepatic lipid disorder and oxidative stress, resulting in prevention and therapeutic against NAFLD in T2D. 


\section{REFERENCES}

1. Beenken A, Mohammadi M. The FGF family: biology, pathophysiology and therapy. Nat Rev Drug Discov 2009;8:235-253.

2. Ohta H, Itoh N. Roles of FGFs as Adipokines in Adipose Tissue Development, Remodeling, and Metabolism. Front Endocrinol (Lausanne) 2014;5:18.

3. Itoh N, Ornitz DM. Functional evolutionary history of the mouse Fgf gene family. Dev Dyn 2008;237:18-27.

4. Wang WP, Lehtoma K, Varban ML, Krishnan I, Chiu IM. Cloning of the gene coding for human class 1 heparin-binding growth factor and its expression in fetal tissues. Mol Cell Biol 1989;9:2387-2395.

5. Chiu IM, Liu Y, Payson RA. Isolation of yeast artificial chromosomes containing the entire transcriptional unit of the human FGF1 gene: a 720-kb contig spanning human chromosome 5q31.3-->q32. Cancer Genet Cytogenet 1998;106:1-10.

6. Madiai F, Hackshaw KV, Chiu IM. Cloning and characterization of the mouse Fgf1 gene. Gene 1996;179:231-236.

7. Madiai F, Hackshaw KV, Chiu IM. Characterization of the entire transcription unit of the mouse fibroblast growth factor 1 (FGF-1) gene. Tissue-specific expression of the FGF-1.A mRNA. J Biol Chem 1999;274:11937-11944.

8. Sarabipour S, Hristova K. Mechanism of FGF receptor dimerization and activation. Nat Commun 2016;7:10262.

9. Suh JM, Jonker JW, Ahmadian M, Goetz R, Lackey D, Osborn O, Huang Z, et al. Endocrinization of FGF1 produces a neomorphic and potent insulin sensitizer. Nature 2014;513:436-439.

10. Pellegrini L, Burke DF, von Delft F, Mulloy B, Blundell TL. Crystal structure of fibroblast growth factor receptor ectodomain bound to ligand and heparin. Nature 2000;407:1029-1034.

11. Raju R, Palapetta SM, Sandhya VK, Sahu A, Alipoor A, Balakrishnan L, Advani J, et al. A Network Map of FGF-1/FGFR Signaling System. J Signal Transduct 2014;2014:962962.

12. Goetz R, Mohammadi M. Exploring mechanisms of FGF signalling through the lens of structural biology. Nat Rev Mol Cell Biol 2013;14:166-180. 
13. Lopez JJ, Edelman ER, Stamler A, Hibberd MG, Prasad P, Thomas KA, DiSalvo $\mathrm{J}$, et al. Angiogenic potential of perivascularly delivered aFGF in a porcine model of chronic myocardial ischemia. Am J Physiol 1998;274:H930-936.

14. Schumacher B, Pecher P, von Specht BU, Stegmann T. Induction of neoangiogenesis in ischemic myocardium by human growth factors: first clinical results of a new treatment of coronary heart disease. Circulation 1998;97:645-650.

15. Palmen M, Daemen MJ, De Windt LJ, Willems J, Dassen WR, Heeneman S, Zimmermann R, et al. Fibroblast growth factor-1 improves cardiac functional recovery and enhances cell survival after ischemia and reperfusion: a fibroblast growth factor receptor, protein kinase $\mathrm{C}$, and tyrosine kinase-dependent mechanism. J Am Coll Cardiol 2004;44:1113-1123.

16. Maquet V, Martin D, Scholtes F, Franzen R, Schoenen J, Moonen G, Jer me R. Poly(D,L-lactide) foams modified by poly(ethylene oxide)-block-poly(D,L-lactide) copolymers and a-FGF: in vitro and in vivo evaluation for spinal cord regeneration. Biomaterials 2001;22:1137-1146.

17. Cheng $\mathrm{H}$, Cao $\mathrm{Y}$, Olson L. Spinal cord repair in adult paraplegic rats: partial restoration of hind limb function. Science 1996;273:510-513.

18. Huang MC, Chen KC, Chuang TY, Chang WC, Lee LS, Huang WC, Cheng $\mathrm{H}$. Cervical root repair in adult rats after transection: recovery of forelimb motor function. Exp Neurol 2003;180:101-109.

19. Tan Y, Wang KY, Wang N, Li G, Liu D. Ectopic expression of human acidic fibroblast growth factor 1 in the medicinal plant, Salvia miltiorrhiza, accelerates the healing of burn wounds. BMC Biotechnol 2014;14:74.

20. Jonker JW, Suh JM, Atkins AR, Ahmadian M, Li P, Whyte J, He M, et al. A PPARgamma-FGF1 axis is required for adaptive adipose remodelling and metabolic homeostasis. Nature 2012;485:391-394.

21. Liu JJ, Foo JP, Liu S, Lim SC. The role of fibroblast growth factor 21 in diabetes and its complications: A review from clinical perspective. Diabetes Res Clin Pract 2015;108:382-389.

22. Forbes JM, Cooper ME. Mechanisms of diabetic complications. Physiol Rev 2013;93:137-188.

23. Alam U, Asghar O, Azmi S, Malik RA. General aspects of diabetes mellitus. Handb Clin Neurol 2014;126:211-222.

24. Scarlett JM, Rojas JM, Matsen ME, Kaiyala KJ, Stefanovski D, Bergman RN, Nguyen HT, et al. Central injection of fibroblast growth factor 1 induces sustained remission of diabetic hyperglycemia in rodents. Nat Med 2016;22:800-806.

25. Huang Z, Lu M, Zhu G, Gao H, Xie L, Zhang X, Ye C, et al. Acceleration of diabetic-wound healing with PEGylated rhaFGF in healing-impaired streptozocin diabetic rats. Wound Repair Regen 2011;19:633-644. 
26. Liang G, Song L, Chen Z, Qian Y, Xie J, Zhao L, Lin Q, et al. Fibroblast growth factor 1 ameliorates diabetic nephropathy by an anti-inflammatory mechanism. Kidney Int 2017.

27. Perry RJ, Lee S, Ma L, Zhang D, Schlessinger J, Shulman GI. FGF1 and FGF19 reverse diabetes by suppression of the hypothalamic-pituitary-adrenal axis. Nat Commun 2015;6:6980.

28. Alberti KG, Zimmet P. Global burden of disease--where does diabetes mellitus fit in? Nat Rev Endocrinol 2013;9:258-260.

29. Ahlqvist E, van Zuydam NR, Groop LC, McCarthy MI. The genetics of diabetic complications. Nat Rev Nephrol 2015;11:277-287.

30. Rice JB, Desai U, Cummings AK, Birnbaum HG, Skornicki M, Parsons NB. Burden of diabetic foot ulcers for medicare and private insurers. Diabetes Care 2014;37:651-658.

31. Jeffcoate WJ, Harding KG. Diabetic foot ulcers. Lancet 2003;361:1545-1551.

32. Amin N, Doupis J. Diabetic foot disease: From the evaluation of the "foot at risk" to the novel diabetic ulcer treatment modalities. World J Diabetes 2016;7:153-164.

33. Naves CC. The Diabetic Foot: A Historical Overview and Gaps in Current Treatment. Adv Wound Care (New Rochelle) 2016;5:191-197.

34. Blakytny R, Jude E. The molecular biology of chronic wounds and delayed healing in diabetes. Diabet Med 2006;23:594-608.

35. Hilton JR, Williams DT, Beuker B, Miller DR, Harding KG. Wound dressings in diabetic foot disease. Clin Infect Dis 2004;39 Suppl 2:S100-103.

36. Edmonds M, Foster A. The use of antibiotics in the diabetic foot. Am J Surg 2004;187:25s-28s.

37. Thomas KA, Rios-Candelore M, Gimenez-Gallego G, DiSalvo J, Bennett C, Rodkey J, Fitzpatrick S. Pure brain-derived acidic fibroblast growth factor is a potent angiogenic vascular endothelial cell mitogen with sequence homology to interleukin 1. Proc Natl Acad Sci U S A 1985;82:6409-6413.

38. Mellin TN, Cashen DE, Ronan JJ, Murphy BS, DiSalvo J, Thomas KA. Acidic Fibroblast Growth Factor Accelerates Dermal Wound Healing in Diabetic Mice. Journal of Investigative Dermatology 1995;104:850-855.

39. Matuszewska B, Keogan M, Fisher DM, Soper KA, Hoe CM, Huber AC, Bondi $\mathrm{JV}$. Acidic fibroblast growth factor: evaluation of topical formulations in a diabetic mouse wound healing model. Pharm Res 1994;11:65-71.

40. Blaber SI, Diaz J, Blaber M. Accelerated healing in NONcNZO10/LtJ type 2 diabetic mice by FGF-1. Wound Repair Regen 2015;23:538-549. 
41. Xie L, Zhang M, Dong B, Guan M, Lu M, Huang Z, Gao H, et al. Improved refractory wound healing with administration of acidic fibroblast growth factor in diabetic rats. Diabetes Res Clin Pract 2011;93:396-403.

42. Wang W, Lin S, Xiao Y, Huang Y, Tan Y, Cai L, Li X. Acceleration of diabetic wound healing with chitosan-crosslinked collagen sponge containing recombinant human acidic fibroblast growth factor in healing-impaired STZ diabetic rats. Life Sci 2008;82:190-204.

43. Severson DL. Diabetic cardiomyopathy: recent evidence from mouse models of type 1 and type 2 diabetes. Can J Physiol Pharmacol 2004;82:813-823.

44. Papa G, Degano C, lurato MP, Licciardello C, Maiorana R, Finocchiaro C. Macrovascular complication phenotypes in type 2 diabetic patients. Cardiovasc Diabetol 2013;12:20.

45. Grundy SM. Pre-diabetes, metabolic syndrome, and cardiovascular risk. J Am Coll Cardiol 2012;59:635-643.

46. Gilca GE, Stefanescu G, Badulescu O, Tanase DM, Bararu I, Ciocoiu M. Diabetic Cardiomyopathy: Current Approach and Potential Diagnostic and Therapeutic Targets. J Diabetes Res 2017;2017:1310265.

47. Waltenberger J. Modulation of growth factor action: implications for the treatment of cardiovascular diseases. Circulation 1997;96:4083-4094.

48. Casscells W, Speir E, Sasse J, Klagsbrun M, Allen P, Lee M, Calvo B, et al. Isolation, characterization, and localization of heparin-binding growth factors in the heart. J Clin Invest 1990;85:433-441.

49. Speir E, Tanner V, Gonzalez AM, Farris J, Baird A, Casscells W. Acidic and basic fibroblast growth factors in adult rat heart myocytes. Localization, regulation in culture, and effects on DNA synthesis. Circ Res 1992;71:251-259.

50. Wu X, Su Z, Li X, Zheng Q, Huang Y, Yuan H. High-level expression and purification of a nonmitogenic form of human acidic fibroblast growth factor in Escherichia coli. Protein Expr Purif 2005;42:7-11.

51. Zhang C, Zhang L, Chen S, Feng B, Lu X, Bai Y, Liang G, et al. The prevention of diabetic cardiomyopathy by non-mitogenic acidic fibroblast growth factor is probably mediated by the suppression of oxidative stress and damage. PLoS One 2013;8:e82287.

52. Zhao YZ, Zhang M, Wong HL, Tian XQ, Zheng L, Yu XC, Tian FR, et al. Prevent diabetic cardiomyopathy in diabetic rats by combined therapy of aFGF-loaded nanoparticles and ultrasound-targeted microbubble destruction technique. J Control Release 2016;223:11-21.

53. Zhang M, Yu WZ, Shen XT, Xiang Q, Xu J, Yang JJ, Chen PP, et al. Advanced Interfere Treatment of Diabetic Cardiomyopathy Rats by aFGF-Loaded Heparin-Modified Microbubbles and UTMD Technique. Cardiovasc Drugs Ther 2016;30:247-261. 
54. Gheith O, Farouk N, Nampoory N, Halim MA, Al-Otaibi T. Diabetic kidney disease: world wide difference of prevalence and risk factors. J Nephropharmacol 2016;5:49-56.

55. Gross JL, de Azevedo MJ, Silveiro SP, Canani LH, Caramori ML, Zelmanovitz T. Diabetic nephropathy: diagnosis, prevention, and treatment. Diabetes Care 2005;28:164-176.

56. Kanwar YS, Sun L, Xie P, Liu FY, Chen S. A glimpse of various pathogenetic mechanisms of diabetic nephropathy. Annu Rev Pathol 2011;6:395-423.

57. Maric-Bilkan C. Obesity and diabetic kidney disease. Med Clin North Am 2013;97:59-74.

58. Rabkin R. Diabetic nephropathy. Clin Cornerstone 2003;5:1-11.

59. Floege J, Kriz W, Schulze M, Susani M, Kerjaschki D, Mooney A, Couser WG, et al. Basic fibroblast growth factor augments podocyte injury and induces glomerulosclerosis in rats with experimental membranous nephropathy. J Clin Invest 1995;96:2809-2819.

60. Guan X, Nie L, He T, Yang K, Xiao T, Wang S, Huang Y, et al. Klotho suppresses renal tubulo-interstitial fibrosis by controlling basic fibroblast growth factor-2 signalling. J Pathol 2014;234:560-572.

61. Baelde HJ, Eikmans M, Doran PP, Lappin DW, de Heer E, Bruijn JA. Gene expression profiling in glomeruli from human kidneys with diabetic nephropathy. Am J Kidney Dis 2004;43:636-650.

62. Rossini M, Cheunsuchon B, Donnert E, Ma LJ, Thomas JW, Neilson EG, Fogo AB. Immunolocalization of fibroblast growth factor-1 (FGF-1), its receptor (FGFR-1), and fibroblast-specific protein-1 (FSP-1) in inflammatory renal disease. Kidney Int 2005;68:2621-2628.

63. Tomaszewski M, Eales J, Denniff M, Myers S, Chew GS, Nelson CP, Christofidou P, et al. Renal Mechanisms of Association between Fibroblast Growth Factor 1 and Blood Pressure. J Am Soc Nephrol 2015;26:3151-3160.

64. Ahn JM, Paik YH, Kim SH, Lee JH, Cho JY, Sohn W, Gwak GY, et al. Relationship of liver stiffness and controlled attenuation parameter measured by transient elastography with diabetes mellitus in patients with chronic liver disease. $\mathrm{J}$ Korean Med Sci 2014;29:1113-1119.

65. Kantartzis K, Machann J, Schick F, Fritsche A, Haring HU, Stefan N. The impact of liver fat vs visceral fat in determining categories of prediabetes. Diabetologia 2010;53:882-889.

66. Byrne CD, Olufadi R, Bruce KD, Cagampang FR, Ahmed MH. Metabolic disturbances in non-alcoholic fatty liver disease. Clin Sci (Lond) 2009;116:539-564. 
67. Cusi K. Role of obesity and lipotoxicity in the development of nonalcoholic steatohepatitis: pathophysiology and clinical implications. Gastroenterology 2012;142:711-725 e716.

68. Barros BSV, Santos DC, Pizarro MH, del Melo LGN, Gomes MB. Type 1 Diabetes and Non-Alcoholic Fatty Liver Disease: When Should We Be Concerned? A Nationwide Study in Brazil. Nutrients 2017;9.

69. Marchesini G, Bugianesi E, Forlani G, Cerrelli F, Lenzi M, Manini R, Natale S, et al. Nonalcoholic fatty liver, steatohepatitis, and the metabolic syndrome. Hepatology 2003;37:917-923.

70. Byrne CD, Targher G. NAFLD: a multisystem disease. J Hepatol 2015;62:S4764.

71. Samuel VT, Liu ZX, Qu X, Elder BD, Bilz S, Befroy D, Romanelli AJ, et al. Mechanism of hepatic insulin resistance in non-alcoholic fatty liver disease. J Biol Chem 2004;279:32345-32353.

72. Nies VJ, Sancar G, Liu W, van Zutphen T, Struik D, Yu RT, Atkins AR, et al. Fibroblast Growth Factor Signaling in Metabolic Regulation. Front Endocrinol (Lausanne) 2015;6:193.

73. Ye D, Wang Y, Li H, Jia W, Man K, Lo CM, Wang Y, et al. Fibroblast growth factor 21 protects against acetaminophen-induced hepatotoxicity by potentiating peroxisome proliferator-activated receptor coactivator protein-1alpha-mediated antioxidant capacity in mice. Hepatology 2014;60:977-989.

74. Gong Q, Hu Z, Zhang F, Cui A, Chen X, Jiang H, Gao J, et al. Fibroblast growth factor 21 improves hepatic insulin sensitivity by inhibiting mammalian target of rapamycin complex 1 in mice. Hepatology 2016;64:425-438.

75. Liu W, Struik D, Nies VJ, Jurdzinski A, Harkema L, de Bruin A, Verkade HJ, et al. Effective treatment of steatosis and steatohepatitis by fibroblast growth factor 1 in mouse models of nonalcoholic fatty liver disease. Proc Natl Acad Sci U S A 2016;113:22882293.

76. Khuu LA, Tayyari F, Sivak JM, Flanagan JG, Singer S, Brent MH, Huang D, et al. Aqueous humour concentrations of TGF-beta, PLGF and FGF-1 and total retinal blood flow in patients with early non-proliferative diabetic retinopathy. Acta Ophthalmol 2017;95:e206-e211.

77. Skibba M, Zhang C, Jiang X, Xin Y, Cai L. Preventive effect of non-mitogenic acidic fibroblast growth factor on diabetes-induced testicular cell death. Reprod Toxicol 2014;49:136-144.

78. Zakrzewska M, Marcinkowska E, Wiedlocha A. FGF-1: from biology through engineering to potential medical applications. Crit Rev Clin Lab Sci 2008;45:91-135.

79. Kim TH, Eltohamy M, Kim M, Perez RA, Kim JH, Yun YR, Jang JH, et al. 
Therapeutic foam scaffolds incorporating biopolymer-shelled mesoporous nanospheres with growth factors. Acta Biomater 2014;10:2612-2621.

80. Jiang B, Akar B, Waller TM, Larson JC, Appel AA, Brey EM. Design of a composite biomaterial system for tissue engineering applications. Acta Biomater 2014;10:1177-1186.

81. Okunieff P, Fenton BM, Zhang L, Kern FG, Wu T, Greg JR, Ding I. Fibroblast growth factors (FGFS) increase breast tumor growth rate, metastases, blood flow, and oxygenation without significant change in vascular density. Adv Exp Med Biol 2003;530:593-601.

82. Henriksson ML, Edin S, Dahlin AM, Oldenborg PA, Oberg A, Van Guelpen B, Rutegard J, et al. Colorectal cancer cells activate adjacent fibroblasts resulting in FGF1/FGFR3 signaling and increased invasion. Am J Pathol 2011;178:1387-1394.

83. Shi H, Fu C, Wang W, Li Y, Du S, Cao R, Chen J, et al. The FGF-1-specific single-chain antibody scFv1C9 effectively inhibits breast cancer tumour growth and metastasis. J Cell Mol Med 2014;18:2061-2070.

84. Chen W, Yu M, Wang Y, Peng Y, Li X, Lam DM, Chen X, et al. Non-mitogenic human acidic fibroblast growth factor reduces retinal degeneration induced by sodium iodate. J Ocul Pharmacol Ther 2009;25:315-320.

85. Huang Z, Tan Y, Gu J, Liu Y, Song L, Niu J, Zhao L, et al. Uncoupling the Mitogenic and Metabolic Functions of FGF1 by Tuning FGF1-FGF Receptor Dimer Stability. Cell Rep 2017;20:1717-1728.

86. Moore JB. Non-alcoholic fatty liver disease: the hepatic consequence of obesity and the metabolic syndrome. Proc Nutr Soc 2010;69:211-220.

87. Yang Y, Li W, Liu Y, Sun Y, Li Y, Yao Q, Li J, et al. Alpha-lipoic acid improves high-fat diet-induced hepatic steatosis by modulating the transcription factors SREBP-1, FoxO1 and Nrf2 via the SIRT1/LKB1/AMPK pathway. J Nutr Biochem 2014;25:12071217.

88. Gurzov EN, Tran M, Fernandez-Rojo MA, Merry TL, Zhang X, Xu Y, Fukushima A, et al. Hepatic oxidative stress promotes insulin-STAT-5 signaling and obesity by inactivating protein tyrosine phosphatase N2. Cell Metab 2014;20:85-102.

89. Rolo AP, Teodoro JS, Palmeira CM. Role of oxidative stress in the pathogenesis of nonalcoholic steatohepatitis. Free Radic Biol Med 2012;52:59-69.

90. Houstis N, Rosen ED, Lander ES. Reactive oxygen species have a causal role in multiple forms of insulin resistance. Nature 2006;440:944-948.

91. Furukawa S, Fujita T, Shimabukuro M, Iwaki M, Yamada Y, Nakajima Y, Nakayama $\mathrm{O}$, et al. Increased oxidative stress in obesity and its impact on metabolic syndrome. J Clin Invest 2004;114:1752-1761. 
92. Sumida $\mathrm{Y}$, Niki E, Naito $\mathrm{Y}$, Yoshikawa T. Involvement of free radicals and oxidative stress in NAFLD/NASH. Free Radic Res 2013;47:869-880.

93. Than NN, Newsome PN. Non-alcoholic fatty liver disease: when to intervene and with what. Clin Med (Lond) 2015;15:186-190.

94. Herman $\mathrm{WH}$. The global agenda for the prevention of type 2 diabetes. Nutr Rev 2017;75:13-18.

95. Yasuda K, Miyake K, Horikawa Y, Hara K, Osawa H, Furuta H, Hirota Y, et al. Variants in KCNQ1 are associated with susceptibility to type 2 diabetes mellitus. Nat Genet 2008;40:1092-1097.

96. Unoki H, Takahashi A, Kawaguchi T, Hara K, Horikoshi M, Andersen G, Ng DP, et al. SNPs in KCNQ1 are associated with susceptibility to type 2 diabetes in East Asian and European populations. Nat Genet 2008;40:1098-1102.

97. Arslanian SA. Type 2 diabetes mellitus in children: pathophysiology and risk factors. J Pediatr Endocrinol Metab 2000;13 Suppl 6:1385-1394.

98. Eppens MC, Craig ME, Cusumano J, Hing S, Chan AK, Howard NJ, Silink M, et al. Prevalence of diabetes complications in adolescents with type 2 compared with type 1 diabetes. Diabetes Care 2006;29:1300-1306.

99. Hillier TA, Pedula KL. Complications in young adults with early-onset type 2 diabetes: losing the relative protection of youth. Diabetes Care 2003;26:2999-3005.

100. Hurwitz Eller N, Netterstrom B. The intima media thickness and coronary risk factors. Int Angiol 2001;20:118-125.

101. Reinehr T, Kiess W, Kapellen T, Wiegand S, Holl RW, Apv, Group DPVWS, et al. Children with diabetes mellitus type 2 in Europe: an underserved population. Arch Dis Child 2010;95:954.

102. Shah AS, Dolan LM, Kimball TR, Gao Z, Khoury PR, Daniels SR, Urbina EM. Influence of duration of diabetes, glycemic control, and traditional cardiovascular risk factors on early atherosclerotic vascular changes in adolescents and young adults with type 2 diabetes mellitus. J Clin Endocrinol Metab 2009;94:3740-3745.

103. Stratton IM, Adler AI, Neil HA, Matthews DR, Manley SE, Cull CA, Hadden D, et al. Association of glycaemia with macrovascular and microvascular complications of type 2 diabetes (UKPDS 35): prospective observational study. BMJ 2000;321:405-412.

104. Bhatt HB, Smith RJ. Fatty liver disease in diabetes mellitus. Hepatobiliary Surg Nutr 2015;4:101-108.

105. Liu Z, Hartman YE, Warram JM, Knowles JA, Sweeny L, Zhou T, Rosenthal EL. Fibroblast growth factor receptor mediates fibroblast-dependent growth in EMMPRINdepleted head and neck cancer tumor cells. Mol Cancer Res 2011;9:1008-1017. 
106. Mohammadi M, Olsen SK, Ibrahimi OA. Structural basis for fibroblast growth factor receptor activation. Cytokine Growth Factor Rev 2005;16:107-137.

107. Yeh BK, Igarashi M, Eliseenkova AV, Plotnikov AN, Sher I, Ron D, Aaronson SA, et al. Structural basis by which alternative splicing confers specificity in fibroblast growth factor receptors. Proc Natl Acad Sci U S A 2003;100:2266-2271.

108. Olsen SK, Li JY, Bromleigh C, Eliseenkova AV, Ibrahimi OA, Lao Z, Zhang F, et al. Structural basis by which alternative splicing modulates the organizer activity of FGF8 in the brain. Genes Dev 2006;20:185-198.

109. Kurosu H, Choi M, Ogawa Y, Dickson AS, Goetz R, Eliseenkova AV, Mohammadi $\mathrm{M}$, et al. Tissue-specific expression of betaKlotho and fibroblast growth factor (FGF) receptor isoforms determines metabolic activity of FGF19 and FGF21. J Biol Chem 2007;282:26687-26695.

110. Ogawa Y, Kurosu H, Yamamoto M, Nandi A, Rosenblatt KP, Goetz R, Eliseenkova AV, et al. BetaKlotho is required for metabolic activity of fibroblast growth factor 21. Proc Natl Acad Sci U S A 2007;104:7432-7437.

111. Urakawa I, Yamazaki Y, Shimada T, lijima K, Hasegawa H, Okawa K, Fujita T, et al. Klotho converts canonical FGF receptor into a specific receptor for FGF23. Nature 2006;444:770-774.

112. Goetz R, Beenken A, Ibrahimi OA, Kalinina J, Olsen SK, Eliseenkova AV, Xu C, et al. Molecular insights into the klotho-dependent, endocrine mode of action of fibroblast growth factor 19 subfamily members. Mol Cell Biol 2007;27:3417-3428.

113. Mohammadi M, Dikic I, Sorokin A, Burgess WH, Jaye M, Schlessinger J. Identification of six novel autophosphorylation sites on fibroblast growth factor receptor 1 and elucidation of their importance in receptor activation and signal transduction. Mol Cell Biol 1996;16:977-989.

114. Gasser E, Moutos CP, Downes M, Evans RM. FGF1 - a new weapon to control type 2 diabetes mellitus. Nat Rev Endocrinol 2017.

115. Brandes RP, Janiszewski M. Direct detection of reactive oxygen species ex vivo. Kidney Int 2005;67:1662-1664.

116. Khoubnasabjafari M, Ansarin K, Jouyban A. Reliability of malondialdehyde as a biomarker of oxidative stress in psychological disorders. Bioimpacts 2015;5:123-127.

117. Sid B, Glorieux C, Valenzuela M, Rommelaere G, Najimi M, Dejeans N, Renard $P$, et al. AICAR induces Nrf2 activation by an AMPK-independent mechanism in hepatocarcinoma cells. Biochem Pharmacol 2014;91:168-180.

118. Gu J, Cheng Y, Wu H, Kong L, Wang S, Xu Z, Zhang Z, et al. Metallothionein Is Downstream of Nrf2 and Partially Mediates Sulforaphane Prevention of Diabetic Cardiomyopathy. Diabetes 2017;66:529-542. 
119. Muller YL, Bogardus C, Pedersen O, Baier L. A Gly482Ser missense mutation in the peroxisome proliferator-activated receptor gamma coactivator-1 is associated with altered lipid oxidation and early insulin secretion in Pima Indians. Diabetes 2003;52:895898.

120. Ponziani FR, Pecere S, Gasbarrini A, Ojetti V. Physiology and pathophysiology of liver lipid metabolism. Expert Rev Gastroenterol Hepatol 2015;9:1055-1067.

121. Rui L. Energy metabolism in the liver. Compr Physiol 2014;4:177-197.

122. Day EA, Ford RJ, Steinberg GR. AMPK as a Therapeutic Target for Treating Metabolic Diseases. Trends Endocrinol Metab 2017;28:545-560.

123. Schieber M, Chandel NS. ROS function in redox signaling and oxidative stress. Curr Biol 2014;24:R453-462.

124. Pham-Huy LA, He H, Pham-Huy C. Free radicals, antioxidants in disease and health. Int J Biomed Sci 2008;4:89-96.

125. Giacco F, Brownlee M. Oxidative stress and diabetic complications. Circ Res 2010;107:1058-1070.

126. Baynes JW, Thorpe SR. Role of oxidative stress in diabetic complications: a new perspective on an old paradigm. Diabetes 1999;48:1-9.

127. Maritim AC, Sanders RA, Watkins JB, 3rd. Diabetes, oxidative stress, and antioxidants: a review. J Biochem Mol Toxicol 2003;17:24-38.

128. Dandekar A, Mendez R, Zhang K. Cross talk between ER stress, oxidative stress, and inflammation in health and disease. Methods Mol Biol 2015;1292:205-214.

129. Matough FA, Budin SB, Hamid ZA, Alwahaibi N, Mohamed J. The role of oxidative stress and antioxidants in diabetic complications. Sultan Qaboos Univ Med J 2012;12:5-18.

130. Li S, Tan HY, Wang N, Zhang ZJ, Lao L, Wong CW, Feng Y. The Role of Oxidative Stress and Antioxidants in Liver Diseases. Int J Mol Sci 2015;16:26087-26124.

131. Silva-Gomes S, Santos AG, Caldas C, Silva CM, Neves JV, Lopes J, Carneiro F, et al. Transcription factor NRF2 protects mice against dietary iron-induced liver injury by preventing hepatocytic cell death. J Hepatol 2014;60:354-361.

132. Theodore M, Kawai Y, Yang J, Kleshchenko Y, Reddy SP, Villalta F, Arinze IJ. Multiple nuclear localization signals function in the nuclear import of the transcription factor Nrf2. J Biol Chem 2008;283:8984-8994.

133. Tamaki N, Cristina Orihuela-Campos R, Inagaki Y, Fukui M, Nagata T, Ito HO. Resveratrol improves oxidative stress and prevents the progression of periodontitis via the activation of the Sirt1/AMPK and the Nrf2/antioxidant defense pathways in a rat periodontitis model. Free Radic Biol Med 2014;75:222-229. 
134. Chen J, Zhang Z, Cai L. Diabetic cardiomyopathy and its prevention by nrf2: current status. Diabetes Metab J 2014;38:337-345.

135. Dai X, Yan X, Zeng J, Chen J, Wang Y, Chen J, Li Y, et al. Elevating CXCR7 Improves Angiogenic Function of EPCs via Akt/GSK-3beta/Fyn-Mediated Nrf2 Activation in Diabetic Limb Ischemia. Circ Res 2017;120:e7-e23.

136. Wu H, Kong L, Cheng Y, Zhang Z, Wang Y, Luo M, Tan Y, et al. Metallothionein plays a prominent role in the prevention of diabetic nephropathy by sulforaphane via upregulation of Nrf2. Free Radic Biol Med 2015;89:431-442.

137. Xue P, Hou Y, Chen Y, Yang B, Fu J, Zheng H, Yarborough K, et al. Adipose deficiency of Nrf2 in ob/ob mice results in severe metabolic syndrome. Diabetes 2013;62:845-854.

138. Xu J, Kulkarni SR, Donepudi AC, More VR, Slitt AL. Enhanced Nrf2 activity worsens insulin resistance, impairs lipid accumulation in adipose tissue, and increases hepatic steatosis in leptin-deficient mice. Diabetes 2012;61:3208-3218.

139. Tanaka Y, Ikeda T, Yamamoto K, Ogawa H, Kamisako T. Dysregulated expression of fatty acid oxidation enzymes and iron-regulatory genes in livers of Nrf2null mice. J Gastroenterol Hepatol 2012;27:1711-1717.

140. Tang W, Jiang YF, Ponnusamy M, Diallo M. Role of Nrf2 in chronic liver disease. World J Gastroenterol 2014;20:13079-13087.

141. Chartoumpekis DV, Palliyaguru DL, Wakabayashi N, Fazzari M, Khoo NK, Schopfer FJ, Sipula I, et al. Nrf2 deletion from adipocytes, but not hepatocytes, potentiates systemic metabolic dysfunction after long-term high-fat diet-induced obesity in mice. Am J Physiol Endocrinol Metab 2018.

142. Sekiya M, Hiraishi A, Touyama M, Sakamoto K. Oxidative stress induced lipid accumulation via SREBP1c activation in HepG2 cells. Biochem Biophys Res Commun 2008;375:602-607.

143. Oliveira CP, da Costa Gayotto LC, Tatai C, Della Bina BI, Janiszewski M, Lima $\mathrm{ES}$, Abdalla DS, et al. Oxidative stress in the pathogenesis of nonalcoholic fatty liver disease, in rats fed with a choline-deficient diet. J Cell Mol Med 2002;6:399-406.

144. Sykiotis GP, Habeos IG, Samuelson AV, Bohmann D. The role of the antioxidant and longevity-promoting Nrf2 pathway in metabolic regulation. Curr Opin Clin Nutr Metab Care 2011;14:41-48.

145. Ly LD, Xu S, Choi SK, Ha CM, Thoudam T, Cha SK, Wiederkehr A, et al. Oxidative stress and calcium dysregulation by palmitate in type 2 diabetes. Exp Mol Med 2017;49:e291.

146. Zhang Y, Chen ML, Zhou Y, Yi L, Gao YX, Ran L, Chen SH, et al. Resveratrol improves hepatic steatosis by inducing autophagy through the CAMP signaling pathway. Mol Nutr Food Res 2015;59:1443-1457. 
147. Parhofer KG. The Treatment of Disorders of Lipid Metabolism. Dtsch Arztebl Int 2016;113:261-268.

148. Jaiswal M, Schinske A, Pop-Busui R. Lipids and lipid management in diabetes. Best Pract Res Clin Endocrinol Metab 2014;28:325-338.

149. Hashimoto E, Taniai M, Tokushige K. Characteristics and diagnosis of NAFLD/NASH. J Gastroenterol Hepatol 2013;28 Suppl 4:64-70.

150. Postic C, Girard J. Contribution of de novo fatty acid synthesis to hepatic steatosis and insulin resistance: lessons from genetically engineered mice. J Clin Invest 2008;118:829-838.

151. Utzschneider KM, Kahn SE. Review: The role of insulin resistance in nonalcoholic fatty liver disease. J Clin Endocrinol Metab 2006;91:4753-4761.

152. Cai D, Yuan M, Frantz DF, Melendez PA, Hansen L, Lee J, Shoelson SE. Local and systemic insulin resistance resulting from hepatic activation of IKK-beta and NFkappaB. Nat Med 2005;11:183-190.

153. Goldberg RB. Lipid disorders in diabetes. Diabetes Care 1981;4:561-572.

154. Hardie DG, Ross FA, Hawley SA. AMPK: a nutrient and energy sensor that maintains energy homeostasis. Nat Rev Mol Cell Biol 2012;13:251-262.

155. Li Y, Xu S, Mihaylova MM, Zheng B, Hou X, Jiang B, Park O, et al. AMPK phosphorylates and inhibits SREBP activity to attenuate hepatic steatosis and atherosclerosis in diet-induced insulin-resistant mice. Cell Metab 2011;13:376-388.

156. Bujak AL, Crane JD, Lally JS, Ford RJ, Kang SJ, Rebalka IA, Green AE, et al. AMPK activation of muscle autophagy prevents fasting-induced hypoglycemia and myopathy during aging. Cell Metab 2015;21:883-890.

157. Viollet B, Andreelli F, Jorgensen SB, Perrin C, Geloen A, Flamez D, Mu J, et al. The AMP-activated protein kinase alpha2 catalytic subunit controls whole-body insulin sensitivity. J Clin Invest 2003;111:91-98.

158. Seo E, Park EJ, Joe Y, Kang S, Kim MS, Hong SH, Park MK, et al. Overexpression of AMPKalpha1 Ameliorates Fatty Liver in Hyperlipidemic Diabetic Rats. Korean J Physiol Pharmacol 2009;13:449-454.

159. Zhang HA, Yang XY, Xiao YF. AMPKalpha1 overexpression alleviates the hepatocyte model of nonalcoholic fatty liver disease via inactivating p38MAPK pathway. Biochem Biophys Res Commun 2016;474:364-370.

160. Foretz M, Ancellin N, Andreelli F, Saintillan Y, Grondin P, Kahn A, Thorens B, et al. Short-term overexpression of a constitutively active form of AMP-activated protein kinase in the liver leads to mild hypoglycemia and fatty liver. Diabetes 2005;54:13311339. 
161. Woods A, Williams JR, Muckett PJ, Mayer FV, Liljevald M, Bohlooly YM, Carling D. Liver-Specific Activation of AMPK Prevents Steatosis on a High-Fructose Diet. Cell Rep 2017;18:3043-3051.

162. Egan DF, Shackelford DB, Mihaylova MM, Gelino S, Kohnz RA, Mair W, Vasquez DS, et al. Phosphorylation of ULK1 (hATG1) by AMP-activated protein kinase connects energy sensing to mitophagy. Science 2011;331:456-461.

163. Dugan LL, You YH, Ali SS, Diamond-Stanic M, Miyamoto S, DeCleves AE, Andreyev A, et al. AMPK dysregulation promotes diabetes-related reduction of superoxide and mitochondrial function. J Clin Invest 2013;123:4888-4899.

164. Kim J, Kundu M, Viollet B, Guan KL. AMPK and mTOR regulate autophagy through direct phosphorylation of Ulk1. Nat Cell Biol 2011;13:132-141.

165. Mo C, Wang L, Zhang J, Numazawa S, Tang H, Tang X, Han X, et al. The crosstalk between Nrf2 and AMPK signal pathways is important for the anti-inflammatory effect of berberine in LPS-stimulated macrophages and endotoxin-shocked mice. Antioxid Redox Signal 2014;20:574-588.

166. Liu Y, Zhao C, Xiao J, Liu L, Zhang M, Wang C, Wu G, et al. Fibroblast growth factor 21 deficiency exacerbates chronic alcohol-induced hepatic steatosis and injury. Sci Rep 2016;6:31026.

167. Ruderman NB, Carling D, Prentki M, Cacicedo JM. AMPK, insulin resistance, and the metabolic syndrome. J Clin Invest 2013;123:2764-2772.

168. Romero-Gomez M, Zelber-Sagi S, Trenell M. Treatment of NAFLD with diet, physical activity and exercise. J Hepatol 2017;67:829-846.

169. McPherson S, Hardy T, Henderson E, Burt AD, Day CP, Anstee QM. Evidence of NAFLD progression from steatosis to fibrosing-steatohepatitis using paired biopsies: implications for prognosis and clinical management. J Hepatol 2015;62:1148-1155.

170. Chen L, Magliano DJ, Zimmet PZ. The worldwide epidemiology of type 2 diabetes mellitus--present and future perspectives. Nat Rev Endocrinol 2012;8:228-236.

171. Bourdel-Marchasson I, Schweizer A, Dejager S. Incretin therapies in the management of elderly patients with type 2 diabetes mellitus. Hosp Pract (1995) 2011;39:7-21.

172. van Dieren S, Beulens JW, van der Schouw YT, Grobbee DE, Neal B. The global burden of diabetes and its complications: an emerging pandemic. Eur J Cardiovasc Prev Rehabil 2010;17 Suppl 1:S3-8.

173. Kirkman MS, Briscoe VJ, Clark N, Florez H, Haas LB, Halter JB, Huang ES, et al. Diabetes in older adults. Diabetes Care 2012;35:2650-2664.

174. Lakey WC, Barnard K, Batch BC, Chiswell K, Tasneem A, Green JB. Are current clinical trials in diabetes addressing important issues in diabetes care? Diabetologia 2013;56:1226-1235. 
175. Fonseca VA. Defining and characterizing the progression of type 2 diabetes. Diabetes Care 2009;32 Suppl 2:S151-156.

176. Schievink B, Kropelin T, Mulder S, Parving HH, Remuzzi G, Dwyer J, Vemer P, et al. Early renin-angiotensin system intervention is more beneficial than late intervention in delaying end-stage renal disease in patients with type 2 diabetes. Diabetes Obes Metab 2016;18:64-71.

177. Calzadilla Bertot L, Adams LA. The Natural Course of Non-Alcoholic Fatty Liver Disease. Int J Mol Sci 2016;17.

178. Pessayre D, Fromenty B. NASH: a mitochondrial disease. J Hepatol 2005;42:928-940.

179. Egnatchik RA, Leamy AK, Noguchi Y, Shiota M, Young JD. Palmitate-induced activation of mitochondrial metabolism promotes oxidative stress and apoptosis in H4IIEC3 rat hepatocytes. Metabolism 2014;63:283-295.

180. Zhou Y, Yu S, Cai C, Zhong L, Yu H, Shen W. LXRa participates in the mTOR/S6K1/SREBP-1c signaling pathway during sodium palmitate-induced lipogenesis in HepG2 cells. Nutr Metab (Lond) 2018;15:31.

181. Kim DI, Park MJ, Lim SK, Park JI, Yoon KC, Han HJ, Gustafsson JA, et al. PRMT3 regulates hepatic lipogenesis through direct interaction with LXRalpha. Diabetes 2015;64:60-71.

182. Sanders FW, Griffin JL. De novo lipogenesis in the liver in health and disease: more than just a shunting yard for glucose. Biol Rev Camb Philos Soc 2016;91:452-468.

183. Horton JD, Goldstein JL, Brown MS. SREBPs: activators of the complete program of cholesterol and fatty acid synthesis in the liver. J Clin Invest 2002;109:11251131.

184. Goldstein JL, Brown MS. From fatty streak to fatty liver: 33 years of joint publications in the JCl. J Clin Invest 2008;118:1220-1222.

185. Matsuzaka T, Shimano H, Yahagi N, Amemiya-Kudo M, Okazaki H, Tamura Y, lizuka $Y$, et al. Insulin-independent induction of sterol regulatory element-binding protein1c expression in the livers of streptozotocin-treated mice. Diabetes 2004;53:560-569.

186. Chau MD, Gao J, Yang Q, Wu Z, Gromada J. Fibroblast growth factor 21 regulates energy metabolism by activating the AMPK-SIRT1-PGC-1alpha pathway. Proc Natl Acad Sci U S A 2010;107:12553-12558.

187. Zimmermann K, Baldinger J, Mayerhofer B, Atanasov AG, Dirsch VM, Heiss EH. Activated AMPK boosts the Nrf2/HO-1 signaling axis--A role for the unfolded protein response. Free Radic Biol Med 2015;88:417-426.

188. Lim CT, Kola B, Korbonits M. AMPK as a mediator of hormonal signalling. J Mol Endocrinol 2010;44:87-97. 
189. Shackelford DB, Shaw RJ. The LKB1-AMPK pathway: metabolism and growth control in tumour suppression. Nat Rev Cancer 2009;9:563-575.

190. Hughes SE. Differential expression of the fibroblast growth factor receptor (FGFR) multigene family in normal human adult tissues. J Histochem Cytochem 1997;45:1005-1019.

191. Steiling H, Wustefeld T, Bugnon P, Brauchle M, Fassler R, Teupser D, Thiery J, et al. Fibroblast growth factor receptor signalling is crucial for liver homeostasis and regeneration. Oncogene 2003;22:4380-4388.

192. Bohm F, Speicher T, Hellerbrand C, Dickson C, Partanen JM, Ornitz DM, Werner S. FGF receptors 1 and 2 control chemically induced injury and compound detoxification in regenerating livers of mice. Gastroenterology 2010;139:1385-1396.

193. Sandhu DS, Baichoo E, Roberts LR. Fibroblast growth factor signaling in liver carcinogenesis. Hepatology 2014;59:1166-1173.

194. Qiu WH, Zhou BS, Chu PG, Chen WG, Chung C, Shih J, Hwu P, et al. Overexpression of fibroblast growth factor receptor 3 in human hepatocellular carcinoma. World J Gastroenterol 2005;11:5266-5272.

195. Owen BM, Mangelsdorf DJ, Kliewer SA. Tissue-specific actions of the metabolic hormones FGF15/19 and FGF21. Trends Endocrinol Metab 2015;26:22-29.

196. Salminen A, Kauppinen A, Kaarniranta K. FGF21 activates AMPK signaling: impact on metabolic regulation and the aging process. J Mol Med (Berl) 2017;95:123131. 


\section{LIST OF ABBREVIATIONS}

FGF1: Fibroblast Growth Factor 1

T2D: Type 2 Diabetes

NAFLD: Nonalcoholic Fatty Liver Disease

Nrf2: Nuclear Factor Erythroid 2-Related Factor 2

ROS: Reactive Oxygen Species

Pal: Palmitate

DHE: Dihydroethidium

MDA: Malondialdehyde

HO-1: Heme Oxygenase 1 (HO1)

NQO1: NAD(P)H Quinone Oxidase 1

CAT: Catalase

ALT: Alanine Aminotransferase

AST: Aspartate Aminotransferase

TG: Triglyceride

AMPK: AMP-activated protein kinase

ACC: Acetyl-CoA Carboxylase

SREBP-1: Sterol Regulatory Element-Binding Protein-1

FAS: Fatty Acid Synthase

SCD-1: Stearoyl-CoA desaturase-1

CPT-1 $\alpha$ : Carnitine Palmitoyltransferase I $\alpha$

PPARa: Peroxisome Proliferator-Activated Receptor $\alpha$

PGC-1 $\alpha$ : Peroxisome Proliferator-Activated Receptor- $\gamma$ Coactivator $\alpha$ 
CURRICULUM VITAE

Qian Lin

570 S Preston Street, Baxter-1 Building, Suite 311

Louisville, KY 40202

502-852-2631

Q0LIN002@LOUISVILLE.EDU

\section{EDUCATION}

08/2015-08/2018

Ph.D. Candidate in Pharmacology and Toxicology, University

of Louisville, Louisville, Kentucky, United states

M.S. in Pharmacology, Wenzhou Medical University, Wenzhou,

09/2013-06/2016

Zhejiang, China

B.S. in Pharmacy, Wenzhou Medical University, Wenzhou,

06/2009-09/2013

$$
\text { Zhejiang, China }
$$

\section{HONORS AND AWARDS}

2016 Graduate Students Poster Award (Third Place), presented by the Ohio Valley

Society of Toxicology Annual Meeting (OVSOT), October 28th, 2016. Eli Lilly

Campus. Awardee: Qian Lin. Mentor: Yi Tan. 
2017 Renal Toxicology Award (2nd Place), presented by the Mechanisms Specialty Section, the Society of Toxicology (SOT) 56th Annual Meeting and ToxExpo. Baltimore, Maryland, March 12-16, 2017. Awardee: Qian Lin. Mentor: Yi Tan. 2017 Graduate Student Travel Award, presented by the Society of Toxicology (SOT) 56th Annual Meeting and ToxExpo. Baltimore, Maryland, March 12-16, 2017. Awardee: Qian Lin. Mentor: Yi Tan.

2017 Outstanding Young Investigator Award (First Prize), Recognition of outstanding research and scientific presentation at the Fourth ACRE-APS symposium, July 09, 2017 in Portland, Oregon. Awardee: Qian Lin. Mentor: Yi Tan.

2018 Student Presentation Award, presented by the 9th Scientific Symposium, Chinese-American Diabetes Association. June 20-22, 2018, Hyatt Place Orlando/Lake Buena Vista, Orlando, FL. Awardee: Qian Lin. Mentor: Yi Tan.

2018 Ronald G.Thurman Student Travel Award, presented by the Mechanisms Specialty Section at the Society of Toxicology (SOT) 57 th Annual Meeting and ToxExpo. San Antonio, Texas, March 11-15, 2018. Awardee: Qian Lin. Mentor: Yi Tan.

\section{PROFESSIONAL EXPERIENCE}

2015 - Present Membership of Society of Toxicology of USA

2017 Chairperson in "Neurotoxicology-Dopaminergic Systems and

Toxicants" Section, SOT 56th Annual Meeting and ToxExpo. Baltimore, Maryland, March 15, 2017.

2018 Manuscript review for the journal Drug Design, Development and Therapy.

2018 Chairperson in "New Models and Biomarkers for Liver Damage" Section, SOT 57th Annual Meeting and ToxExpo. San Antonio, Texas, March 12, 2018. 
2018 The 2nd Place Award in the Science Fair of Louisville by Chaochen Tan and Joey Chen (Two students from the Dupont Manual High School), March 2018. (Two students were directly trained and instructed by Qian Lin under the supervisor of Dr. Yi Tan)

\section{PUBLICATIONS (List in chronological order and number)}

\section{PEER-REVIEWED ORIGINAL AND REVIEW ARTICLES}

(\#, equal contribution; * , corresponding authors)

1. Zhao $\mathrm{YZ}^{\#}$, Tian $X Q^{\#}$, Zhang $M^{\#}$, Cai L, Ru A, Shen $X T$, Jiang $X$, Jin $R$, Zheng $L$, Hawkins K, Charkrabarti S, Li XK, Lin Q, Yu WZ, Ge S, Lu CT*, Wong HL*.

Functional and pathological improvements of the hearts in diabetes model by the combined therapy of bFGF-loaded nanoparticles with ultrasound-targeted microbubble destruction. J Control Release. 2014; 186:22-31.

2. Lu CT*, Jin RR*, Jiang YN, Lin $Q$, Yu WZ, Mao KL, Tian FR, Zhao YP*, Zhao $Y Z^{*}$. Gelatin nanoparticle-mediated intranasal delivery of substance P protects against 6-hydroxydopamine-induced apoptosis: an in vitro and in vivo study. Drug Des Devel Ther. 2015; 9:1955-62.

3. Zhao $Y Z^{\#}$, Jin RR\#, Yang W, Xiang Q, Yu WZ, Lin Q, Tian FR, Mao KL, Lv CZ, Wáng YX, Lu CT*. Using Gelatin Nanoparticle Mediated Intranasal Delivery of Neuropeptide Substance P to Enhance Neuro-Recovery in Hemiparkinsonian Rats. PLoS One. 2016; 19;11(2): e0148848.

4. $X u Z^{\#}$, Sun $\mathrm{J}^{\#}$, Tong $\mathrm{Q}^{\#}$, Lin $\mathbf{Q}$, Qian $\mathrm{L}$, Park $\mathrm{Y}^{*}$, Zheng $\mathrm{Y}^{*}$. The Role of ERK $1 / 2$ in the Development of Diabetic Cardiomyopathy. Int J Mol Sci. 2016; 17(12). Review.

5. Zhao $\mathrm{YZ}^{\#}$, Jiang $\mathrm{X}^{\#}$, Xiao J\#, Lin $\mathbf{Q}, \mathrm{Yu} W Z$, Tian $F R$, Mao $\mathrm{KL}$, Yang $W$, Wong $\mathrm{HL}^{*}$, Lu CT* ${ }^{*}$ Using NGF heparin-poloxamer thermosensitive hydrogels to enhance the nerve regeneration for spinal cord injury. Acta Biomater. 2016; 29:71-80. 
6. Zhao $\mathrm{YZ}^{\#}$, Lin $\mathrm{M}^{\#}$, Lin $\mathbf{Q}$, Yang $\mathrm{W}, \mathrm{Yu} \mathrm{XC}$, Tian FR, Mao KL, Yang JJ, Lu CT, Wong HL. Intranasal delivery of bFGF with nanoliposomes enhances in vivo neuroprotection and neural injury recovery in a rodent stroke model. $\boldsymbol{J}$ Control Release. 2016; 224:165-175.

7. Lin $\mathbf{Q}^{\#}$, Mao KL, Tian FR, Yang JJ, Chen PP, Xu J, Fan ZL, Zhao YP, Li WF, Zheng $\mathrm{L}$, Zhao $\mathrm{YZ} \mathrm{Z}^{*}$, Lu CT*. Brain tumor-targeted delivery and therapy by focused ultrasound introduced doxorubicin-loaded cationic liposomes. Cancer Chemother Pharmacol. 2016; 77(2): 269-280.

8. Zhao $Y Z^{\#}$, Lin $Q^{\#}$, Wong $H^{\#}$, Shen $X T$, Yang $W, X u H L$, Mao KL, Tian FR, Yang JJ, Xu J, Xiao J, Lu CT*. Glioma-targeted therapy using Cilengitide nanoparticles combined with UTMD enhanced delivery. J Control Release. 2016; 224:112-125.

9. Wang Q\#, He Y, Zhao Y, Xie H, Lin Q, He Z, Wang X, Li J, Zhang H, Wang C, Gong F, Li X, Xu H, Ye Q, Xiao J*. A Thermosensitive Heparin-Poloxamer Hydrogel Bridges aFGF to Treat Spinal Cord Injury. ACS Appl Mater Interfaces. 2017; 9(8):6725-6745.

10. Zhao $Y Z^{\#}$, Jiang $X^{\#}$, Lin $Q^{\#}, X u H L$, Huang $Y D$, Lu CT, Cai J*. Thermosensitive heparin-poloxamer hydrogels enhance the effects of GDNF on neuronal circuit remodeling and neuroprotection after spinal cord injury. J Biomed Mater Res A. 2017; 105(10):2816-2829.

11. Lin $\mathbf{Q}^{\#}$, Wong $\mathrm{HL}^{\#}$, Tian $F R^{\#}$, Huang YD, Xu J, Yang JJ, Chen PP, Fan ZL, Lu CT, Zhao YZ*. Enhanced neuroprotection with decellularized brain extracellular matrix containing bFGF after intracerebral transplantation in Parkinson's disease rat model. Int J Pharm. 2017; 517(1-2): 383-394.

12. Yan $X^{\#}$, Wu L, Lin Q, Dai X, Hu H, Wang K, Zhang C, Shao M, Cai L, Tan $Y^{*}$. Alcohol Inhibition of the Enzymatic Activity of Glyceraldehyde 3-Phosphate 
Dehydrogenase Impairs Cardiac Glucose Utilization, Contributing to Alcoholic Cardiomyopathy. Toxicol Sci. 2017; 159(2):392-401.

13. Huang $Z^{\#}$, Tan $Y^{\#}$, Gu J\#, Liu Y, Song L, Niu J, Zhao L, Srinivasan L, Lin Q, Deng J, Li Y, Conklin DJ, Neubert TA, Cai L, Li X*, Mohammadi $\mathrm{M}^{*}$. Uncoupling the Mitogenic and Metabolic Functions of FGF1 by Tuning FGF1-FGF Receptor Dimer Stability. Cell Rep. 2017, 20(7):1717-1728.

14. Liang $\mathrm{G}^{\#}$, Song $\mathrm{L}^{\#}$, Chen $Z^{\#}$, Qian $Y$, Xie J, Zhao L, Lin Q, Zhu G, Tan Y, Li X, Mohammadi M, Huang Z*. Fibroblast growth factor 1 ameliorates diabetic nephropathy by an anti-inflammatory mechanism. Kidney Int. 2018,93(1):95-109.

15. Dai X", Zeng J\#, Yan X, Lin Q, Wang K, Chen J, Shen F, Gu X, Wang Y, Chen J, Pan K, Cai L, Wintergerst KA, Tan $Y^{*}$. Sitagliptin-mediated preservation of endothelial progenitor cell function via augmenting autophagy enhances ischaemic angiogenesis in diabetes. J Cell Mol Med. 2018; 22(1):89-100.

16. Gu J", Yan X", Dai X, Wang Y, Lin Q, Xiao J, Zhou S, Zhang J, Wang K, Zeng J, Xin Y, Barati MT, Zhang C, Bai Y, Li Y, Epstein PN, Wintergerst KA, Li X, Tan Y*, Cai L. Metallothionein Preserves Akt2 Activity and Cardiac Function via Inhibiting TRB3 in Diabetic Hearts. Diabetes. 2018;67(3):507-517.

\section{ORAL PRESENTATIONS (List in chronological order and number)}

\section{National/International/Regional Meetings}

2017 Fibroblast Growth Factor 1 Prevents Diabetic Nephropathy Through an AntiJNK/NF-kB Signal pathway. The 8th Scientific Symposium of the ChineseAmerican Diabetes Association (CADA), June 8-9, 2017 in San Diego, California.

2017 Fibroblast Growth Factor 1 Prevents Diabetic Nephropathy Through an AntiJNK/NF-kB Signal pathway. American Diabetes Association 77th Scientific Sessions (ADA), June 9 - 13, 2017, San Diego, California. 
2017 Fibroblast Growth Factor 1 Prevents Diabetic Nephropathy Through an AntiJNK/NF-KB Signal pathway. The Fourth ACRE-APS symposium, July 09, 2017 in Portland, Oregon.

2018 A novel fibroblast growth factor 1 variant reverses nonalcoholic fatty liver disease in type 2 diabetes. Pediatric Research Institute-WIP, Department of Pediatrics, University of Louisville. March 31, 2018, Louisville, KY

2018 A novel fibroblast growth factor 1 variant reverses nonalcoholic fatty liver disease in type 2 diabetes. 9th Scientific Symposium, Chinese-American Diabetes Association, June 20-22, 2018, Orlando, FL

\section{ABSTRACTS AND POSTER PRESENTATIONS}

\section{National/International/Regional Meetings}

2015

1. Qian Lin, Furong Tian, Kaili Mao, Yingzheng Zhao, Yi Tan. Long-term neuroprotection of decellularized brain extracellular matrix containing bFGF by intracerebral transplantation in a rat Parkinson's disease model.

Research!Louisville 2015, October 27-30, 2015, University of Louisville, KY, USA. 2016

1. Qian Lin, Lu Cai, Yi Tan. Fibroblast Growth Factor 1 Ameliorates Diabetic Nephropathy Through an Anti-inflammatory Mechanism. Research!Louisville 2016. October 11-14, 2016, University of Louisville, KY, USA.

2. Qian Lin, Furong Tian, Kaili Mao, Yingzheng Zhao, Yi Tan. Long-term neuroprotection of decellularized brain extracellular matrix containing bFGF by intracerebral transplantation in a rat Parkinson's disease model. The $55^{\text {th }}$ Annual Meeting of the Society of Toxicology, March 13-17, 2016, New Orleans, Louisiana. 
1. Qian Lin, Lu Cai, Yi Tan. Fibroblast Growth Factor 1 Prevents Diabetic Nephropathy Through an Anti-JNK/NF-KB Signal pathway. American Diabetes Association $77^{\text {th }}$ Scientific Sessions, June 9 - 13, 2017, San Diego, California.

2. Qian Lin, Lu Cai, Yi Tan. Fibroblast Growth Factor 1 Ameliorates Diabetic Nephropathy Through an Anti-inflammatory Mechanism. EXPERIMENTAL BIOLOGY 2017, April 22 26, 2017, Chicago, IL.

3. Qian Lin, Zhifeng Huang, Lintao Song, Yuanyuan Qian, Lu Cai, Moosa Mohammadi, Yi Tan. Fibroblast Growth Factor 1 Ameliorates Diabetic Nephropathy Through an Anti-inflammatory Mechanism. March 12-16, 2017, Baltimore, Maryland.

4. Qian Lin, Paul N. Epstein, Lu Cai, Yi Tan. A novel fibroblast growth factor 1 variant reverses nonalcoholic fatty liver disease in type 2 diabetes. Research!Louisville 2017, September 11 - 15, 2017, Louisville, KY.

5. Qian Lin, Paul N. Epstein, Lu Cai, Yi Tan. A novel fibroblast growth factor 1 variant reverses nonalcoholic fatty liver disease in type 2 diabetes. Ohio Valley Society of Toxicology Annual Meeting. December 1, 2017, West Lafayette, IN.

2018

1. Qian Lin, Paul N. Epstein, Lu Cai, Yi Tan. A novel fibroblast growth factor 1 variant reverses nonalcoholic fatty liver disease in type 2 diabetes. Society of Toxicology (SOT) 57th Annual Meeting, Mar 11 - 15, 2018, San Antonio, Texas.

2. Qian Lin, Paul N. Epstein, Lu Cai1, Yi Tan. A novel fibroblast growth factor 1 variant reverses nonalcoholic fatty liver disease in type 2 diabetes. The American Diabetes Association 78th Scientific Sessions, June 22-26, 2018 in Orlando, Florida. 